FIREPLUME Model for Plume Dispersion from Fires: Application to Uranium Hexafluoride Cylinder Fires

DISTRIBUTION OF THIS DOCUMENT IS UNLIMITED,

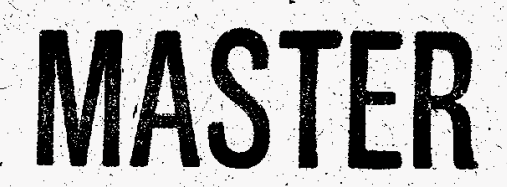

Environmental Assessment Division Argonne National Laboratory

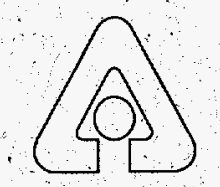

Operated by The University of Chicago, under Contract W-31-109-Eng-38, for the

United States Department of Energy 


\section{Argonne National Laboratory}

Argonne National Laboratory, with facilities in the states of Illinois and Idaho, is owned by the United States Government, and operated by the University of Chicago under the provisions of a contract with the Department of Energy.

This technical memo is a product of Argonne's Environmental Assessment Division (EAD). For information on the division's scientific and engineering activities, contact:

Director, Environmental Asssessment Division

Argonne National Laboratory

Árgonne, Illinóis 60439-4815

Telephone (630) 252-3107

Presented in this technical memo are preliminary, results of ongoing work or - work that is more limited in scope and depth than that described in formal reports issued by the EAD.

Publishing support services were provided by Argonne's Information and Publishing Division (for more information, see IPD's home page: http://www.ipd.anl.gov/).

\section{Disclaimer}

This report was prepared as an account of work sponsored by an agency of the United States Government: Neither the United States Government nor any agency thereof, nor any of their employees, makes any warranty; express or implied, or assumes any legal liability or responsibility for the accuracy, completeness, or usefulness of any information, apparatus, product, or process disclosed, or represents that its use would not infringe privately owned rights. Reference herein to any specific commercial product, process, or service by trade name, trademark, manufacturer, or otherwise, does not necessarily constitute or imply its endorsement, recommendation, or favoring by the United States Government or any agency thereof. The views and opinions of authors expressed herein do not necessarily state or reflect those of the United States Govemment or any agency thereof. 


\section{FIREPLUME Model for Plume Dispersion from Fires: Application to Uranium Hexafluoride Cylinder Fires}

by D.F. Brown, ${ }^{\star}$ W.E. Dunn, ${ }^{\star}$ A.J. Policastro, and D. Maloney

Environmental Assessment Division,

Argonne National Laboratory, 9700 South Cass Avenue, Argonne, Illinois 60439

June 1997

Work sponsored by United States Department of Energy, Office of Facilities, Office of Nuclear Energy, Science and Technology

*Brown and Dunn are affiliated with the Department of Mechanical Engineering, University of Illinois, Champaign-Urbana. 
6y

This report is printed on recycled paper. 


\section{DISCLAMIER}

Portions of this document may be illegible in electronic image products. Images are produced from the best available original document. 



\section{CONTENTS}

NOTATION $\ldots \ldots \ldots \ldots \ldots \ldots \ldots \ldots \ldots \ldots \ldots \ldots \ldots \ldots \ldots \ldots \ldots \ldots \ldots$ viii

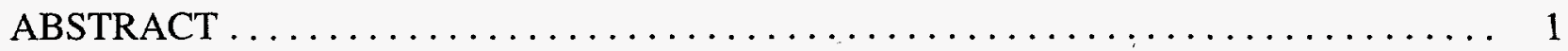

1 INTRODUCTION $\ldots \ldots \ldots \ldots \ldots \ldots \ldots \ldots \ldots \ldots \ldots \ldots \ldots \ldots \ldots \ldots \ldots$

1.1 The FIREPLUME Model $\ldots \ldots \ldots \ldots \ldots \ldots \ldots \ldots \ldots \ldots \ldots \ldots \ldots$

1.2 Characterization of Depleted $\mathrm{UF}_{6}$ Fire Releases $\ldots \ldots \ldots \ldots \ldots \ldots \ldots \ldots \ldots$

2 DESCRIPTION OF FIREPLUME $\ldots \ldots \ldots \ldots \ldots \ldots \ldots \ldots \ldots \ldots \ldots \ldots \ldots$

2.1 The Monte Carlo Lagrangian Dispersion Model $\ldots \ldots \ldots \ldots \ldots \ldots \ldots$

2.1.1 The Langevin Equation and Its Application $\ldots \ldots \ldots \ldots \ldots \ldots \ldots \ldots$

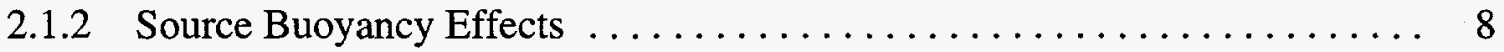

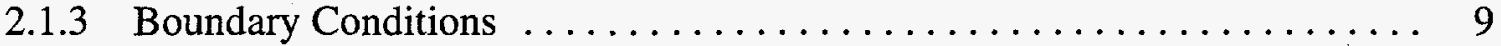

2.2 Determination of Ground-Level Concentrations $\ldots \ldots \ldots \ldots \ldots \ldots \ldots \ldots$

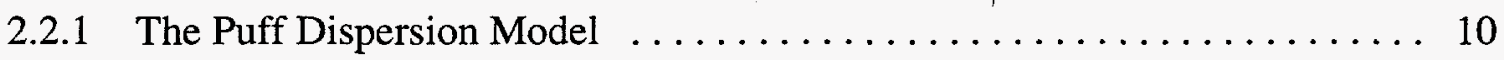

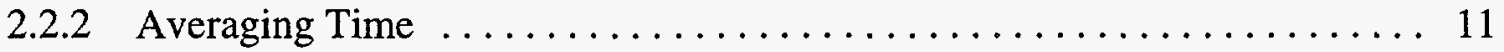

2.2.3 Treatment of the Smoldering or Cool-Down Release Phase . . . . . . . . 11

3 APPLICATION OF FIREPLUME TO RELEASES OF DEPLETED URANIUM HEXAFLUORIDE $\ldots \ldots \ldots \ldots \ldots \ldots \ldots \ldots \ldots \ldots \ldots \ldots \ldots$

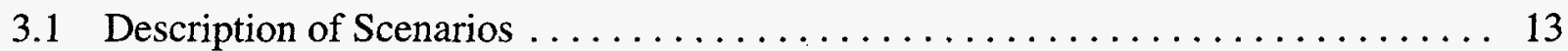

3.1 .1 Overview . . . . . . . . . . . . . . . . . . . . . . . . 13

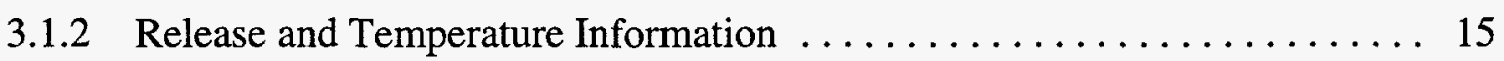

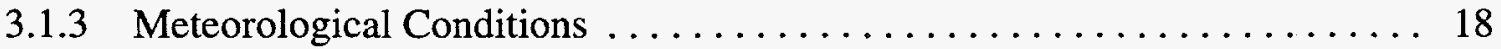

3.2 Treatment of Release Phases . . . . . . . . . . . . . . . . . . . 18

3.2.1 The Hydraulic Rupture Release . . . . . . . . . . . . . . . . . . . . 19

3.2.2 Release into the Fire . . . . . . . . . . . . . . . . . . . . 22

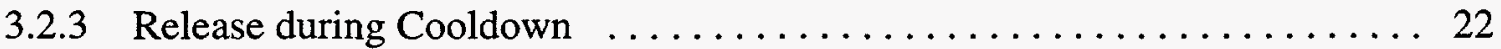

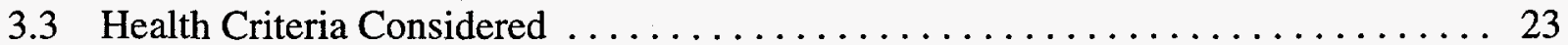

3.4 Results and Discussion $\ldots \ldots \ldots \ldots \ldots \ldots \ldots \ldots \ldots \ldots \ldots \ldots \ldots \ldots$

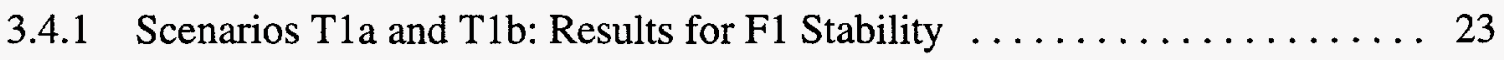

3.4 .2 Scenarios Tla and T1b: Results for D4 Stability .............. 27

3.4.3 Summary Statistics for Remaining Release Scenarios . . . . . . . . . . . 28

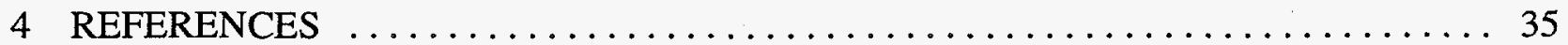




\section{CONTENTS (Cont.)}

APPENDIX A: Calculation of Lagrangian Particle Trajectorie

in the Atmospheric Boundary Layer.

A-1

APPENDIX B: Plume and Thermal Rise Relationships Used in FIREPLUME ........ B-1

APPENDIX C: Results for all Other FIREPLUME Scenarios $\ldots \ldots \ldots \ldots \ldots \ldots$ C-1

APPENDIX D: Analysis of Initial Uranium Hexafluoride Release

to Initialize FIREPLUME $\ldots \ldots \ldots \ldots \ldots \ldots \ldots \ldots \ldots \ldots \ldots \ldots \ldots \ldots \ldots \ldots \ldots$

\section{TABLES}

1 Five Accident Scenarios Evaluated in the Current Study ................. 14

2 Summary of 6FIRE and SUBLIME Results, as Presented by Williams and

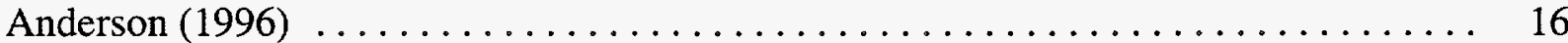

3 Temperature and Release History for $48 \mathrm{G}$ and $48 \mathrm{Y}$ Depleted $\mathrm{UF}_{6}$ Cylinders Exposed to a $1,475^{\circ} \mathrm{F}$ Regulatory Fire for 30 Minutes, as Presented

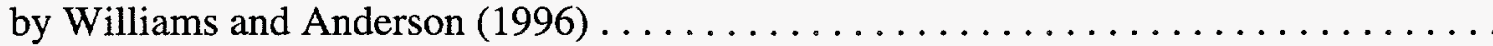

4 Summary of Meteorological Conditions Used in the FIREPLUME Runs $\ldots \ldots \ldots \ldots \quad 18$

5 Limiting Toxicological Values for $\mathrm{HF}$ and $\mathrm{UO}_{2} \mathrm{~F}_{2} \ldots \ldots \ldots \ldots \ldots \ldots \ldots \ldots \ldots \ldots$

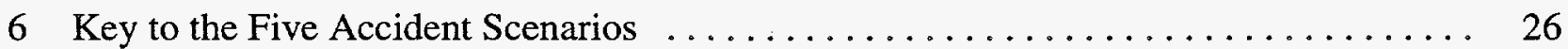

7 Downwind Centerline Concentrations for HF for Scenario T1

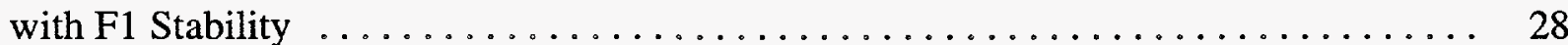

8 Downwind Centerline Concentrations for $\mathrm{UO}_{2} \mathrm{~F}_{2}$ for Scenario $\mathrm{T} 1$

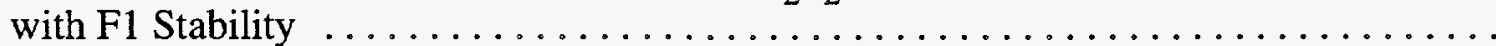

9 Downwind Centerline Concentrations for HF for Scenario T1

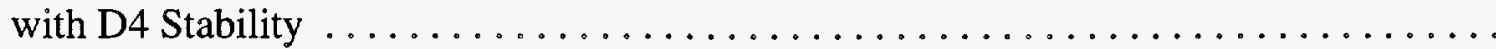

10 Downwind Centerline Concentrations for $\mathrm{UO}_{2} \mathrm{~F}_{2}$ for Scenario $\mathrm{T} 1$ with D4 Stability 


\section{TABLES (Cont.)}

11 Distance to the Maximally Exposed Individual and Concentration at That Distance for the Five Accident Scenarios

with D and F Stability

12 Total Area and the Maximum Distance for Which Concentration Exceeds

Potential-Irreversible-Adverse-Effects Criterion for the Five Accident

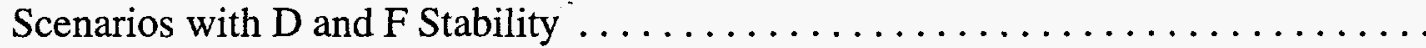

13 Total Area and the Maximum Distance for Which Concentration Exceeds

Potential-Adverse-Effects Criterion for the Five Accident Scenarios

with D and F Stability

C.1 Downwind Centerline Concentrations for HF for Scenario T2

with D4 Stability

C.2 Downwind Centerline Concentrations for $\mathrm{UO}_{2} \mathrm{~F}_{2}$ for Scenario T2

with D4 Stability

C.3 Downwind Centerline Concentrations for HF for Scenario T2

with F1 Stability

C.4 Downwind Centerline Concentrations for $\mathrm{UO}_{2} \mathrm{~F}_{2}$ for Scenario T2

with F1 Stability

C.5 Downwind Centerline Concentrations for HF for Scenario T3

with D4 Stability

C.6 Downwind Centerline Concentrations for $\mathrm{UO}_{2} \mathrm{~F}_{2}$ for Scenario T3

with D4 Stability

C.7 Downwind Centerline Concentrations for HF for Scenario T3

with F1 Stability

C.8 Downwind Centerline Concentrations for $\mathrm{UO}_{2} \mathrm{~F}_{2}$ for Scenario T3

with F1 Stability

C.9 Downwind Centerline Concentrations for HF for Scenario T4 with D4 Stability

C.10 Downwind Centerline Concentrations for $\mathrm{UO}_{2} \mathrm{~F}_{2}$ for Scenario T4

with D4 Stability 


\section{TABLES (Cont.)}

C.11 Downwind Centerline Concentrations for HF for Scenario T4 with F1 Stability

C.12 Downwind Centerline Concentrations for $\mathrm{UO}_{2} \mathrm{~F}_{2}$ for Scenario T4 with F1 Stability

C.13 Downwind Centerline Concentrations for HF for Scenario T5 with D4 Stability

C.14 Downwind Centerline Concentrations for $\mathrm{UO}_{2} \mathrm{~F}_{2}$ for Scenario T5 with D4 Stability

C.15 Downwind Centerline Concentrations for HF for Scenario T5 with F1 Stability

C.16 Downwind Centerline Concentrations for $\mathrm{UO}_{2} \mathrm{~F}_{2}$ for Scenario T5 with F1 Stability

\section{FIGURES}

1 Dispersion of the Three Phases of the Release Scenario for Class F Stability Conditions . . . . . . . . . . . . . . . . . . . . . . .

2 Predicted Potential-Adverse-Effects Impacted Areas for $\mathrm{HF}$ and $\mathrm{UO}_{2} \mathrm{~F}_{2}$ for the Three-48G-Cylinder Release for F1 Meteorological Conditions . .

3 Dispersion of the Three Phases of the Release Scenario for Class D Stability Conditions

A.1 Standard Deviation of the Vertical Velocity Fluctuations as Given by Equation A.18, Shown in Comparison with Data from Water Tank Studies and ABL Studies

A.2 Comparison of the Interpolation Formula with Both Numerical and Actual Vertical Velocity Standard Deviation Data from Near-Neutral Boundary Layers

A.3 Standard Deviation of Vertical Velocity Fluctuations as Given by Equation A.20, Shown in Comparison with Data from Minnesota, Cabauw, and Oklahoma 


\section{FIGURES (Cont.)}

A.4 Third-Order Vertical Velocity Moments as Given by Equation A.24, Shown in Comparison with Data from Water Tank Studies and ABL Studies

A.5 Horizontal Velocity Variances as Given by Equation A.36, Shown in Comparison with Data from Minnesota, Cabauw, and Oklahoma

A.6 Vertical Velocity Fluctuation Skewness within the Canopy as Provided by Equation A.45 


\section{NOTATION}

The following is a list of the acronyms, initialisms, and abbreviations (including units of measure) used in this document. Acronyms used only in tables are defined in the respective tables.

\section{ACRONYMS, INITIALISMS, AND ABBREVIATIONS}

ERPG Emergency Response Planning Guideline

MCLDM Monte Carlo Lagrangian Dispersion Model

MEI maximally exposed individual

PEIS programmatic environmental impact statement

STP standard temperature and pressure

\section{CHEMICALS}

HF hydrogen fluoride

$\mathrm{UF}_{6} \quad$ uranium hexafluoride

$\mathrm{UO}_{2} \mathrm{~F}_{2}$ uranyl fluoride

\section{UNITS OF MEASURE}

$\begin{array}{ll}\mathrm{cm} & \text { centimeter(s) } \\ { }^{\circ} \mathrm{F} & \text { degree(s) Fahrenheit } \\ \mathrm{K} & \text { (degree[s]) Kelvin } \\ \mathrm{kg} & \text { kilogram(s) } \\ \mathrm{kJ} & \text { kilojoule(s) } \\ \mathrm{km} & \text { kilometer(s) } \\ \mathrm{km}^{2} & \text { square kilometer(s) } \\ \mathrm{lb}^{\mathrm{b}} & \text { pound(s) } \\ \mathrm{m} & \text { meter(s) } \\ \mathrm{m}^{2} & \text { square meter(s) } \\ \mathrm{m}^{3} & \text { cubic meter(s) } \\ \mathrm{mg} & \text { milligram(s) } \\ \mathrm{min} & \text { minute(s) } \\ \mathrm{mol} & \text { mole(s) } \\ \mathrm{s} & \text { second(s) } \\ \mu \mathrm{m} & \text { micrometer(s) }\end{array}$




\title{
FIREPLUME MODEL FOR PLUME DISPERSION \\ FROM FIRES: APPLICATION TO URANIUM \\ HEXAFLUORIDE CYLINDER FIRES
}

\author{
by
}

D.F. Brown, W.E. Dunn, A.J. Policastro, and D. Maloney

\begin{abstract}
This report provides basic documentation of the FIREPLUME model and discusses its application to the prediction of health impacts resulting from releases of uranium hexafluoride $\left(\mathrm{UF}_{6}\right)$ in fires. The model application outlined in this report was conducted for the Draft Programmatic Environmental Impact Statement for Alternative Strategies for the Long-Term Management and Use of Depleted UF 6 . The FIREPLUME model is an advanced stochastic model for atmospheric plume dispersion that predicts the downwind consequences of a release of toxic materials from an explosion or a fire. The model is based on the nonbuoyant atmospheric dispersion model MCLDM (Monte Carlo Lagrangian Dispersion Model), which has been shown to be consistent with available laboratory and field data. The inclusion of buoyancy and the addition of a postprocessor to evaluate time-varying concentrations lead to the current model. No data currently exist to test the model for the $\mathrm{UF}_{6}$ fire cases analyzed in this study; however, the algorithms for predictions of plume buoyancy have been evaluated previously and performed well. The FIREPLUME model, as applied to fire-related $\mathrm{UF}_{6}$ cylinder releases, accounts for three phases of release and dispersion. The first phase of release involves the hydraulic rupture of the cylinder due to heating of the uranium hexafluoride in the fire. The second phase involves the emission of material into the burning fire, and the third phase involves the emission of material after the fire has died during the cool-down period. The model predicts the downwind concentration of the material as a function of time at any point downwind at or above the ground. Application of suitable health criteria leads to the prediction of impacts on the basis of human health end points; these end points are based on potential adverse effects and irreversible adverse effects. All together, five fire-related release scenarios are examined in this report. For each scenario, downwind concentrations of the $\mathrm{UF}_{6}$ reaction products, uranyl fluoride and hydrogen fluoride, are provided for two meteorological conditions: (1) D stability with a 4-m/s wind speed, and (2) F stability with a $1-\mathrm{m} / \mathrm{s}$ wind speed. Also provided are the concentrations for the maximally exposed individual, the exposed area, and the greatest downwind distances for which respective health criteria are exceeded.
\end{abstract}




\section{INTRODUCTION}

This report provides basic documentation of the FIREPLUME model for plume dispersion from fires and its application to uranium hexafluoride $\left(\mathrm{UF}_{6}\right)$ fires. The model has been used in preparation of the Draft Programmatic Environmental Impact Statement (PEIS) for evaluating alternative strategies for long-term management and use of depleted UF 6 . That PEIS is hereafter referred to as the Depleted $\mathrm{UF}_{6}$ PEIS.

\subsection{THE FIREPLUME MODEL}

The FIREPLUME model is an extension of the Monte Carlo Lagrangian Dispersion Model (MCLDM) developed over the past 10 years. That model was originally developed to predict dispersion from military smoke (fog oil and hexachloroethane) from generators and smoke pots near the ground and was later extended to treat all passive releases. The evolution of the current model began with a study of dispersion in convective conditions (Liljegren 1989). The Monte Carlo model developed for that application compared very well with available field and laboratory data for such conditions. A particularly valuable feature of the model was its ability to match the rising centerline phenomenon that has been observed with plumes from surface releases under convective conditions (e.g., water tank data by Willis and Deardorff [1974]). Brown (1997) extended the model to treat dispersion in stable and near-neutral conditions and refined the Monte Carlo modeling in the surface layer to better estimate ground-level concentrations. In the current effort, (1) buoyancy was added to the MCLDM model, and (2) a postprocessor was added to evaluate time-varying concentrations. Although the current effort, as discussed in this report, has been specifically for the prediction of the consequences of $\mathrm{UF}_{6}$ fire plume scenarios, the model is equally applicable to the prediction of fire

plume consequences other than those from $\mathrm{UF}_{6}$ accidents. (FIREPLUME does not explicitly handle the $\mathrm{UF}_{6}$ chemistry. The important chemical and physical transformations are taken into account in setting up FIREPLUME, as discussed in Section 3.2.) Specific details concerning the modeling methodology are provided in Section 2 and in Appendixes A and B.

\subsection{CHARACTERIZATION OF DEPLETED UF ${ }_{6}$ FIRE RELEASES}

Off-site and on-site transportation accidents and in-facility accidents involving $\mathrm{UF}_{6}$ may

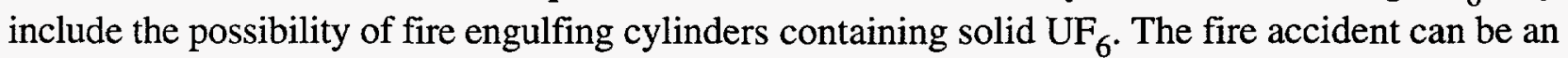
important case for off-site impacts, leading to potentially significant ground-level concentrations and deposition of fire products. Although such accidents have only recently been examined, the impacts of a variety of accident scenarios coupled with specific meteorological conditions are important to characterize. 
The fundamental physical processes involved in the fire and its plume dispersion are simple to summarize, although a detailed analysis of each step can be quite complex. A typical scenario is the following. One or more cylinders containing solid $\mathrm{UF}_{6}$ are involved in an accident in which the diesel fuel from a transport vehicle spills and ignites, engulfing the cylinder(s). During the fire, the heat transferred to the cylinder sublimates a portion of the solid inside. This sublimation causes pressure to build inside of the cylinder to a level that leads to hydraulic rupture of the cylinder. This rupture releases to the atmosphere a puff of hot $\mathrm{UF}_{6}$ vapor, which quickly reacts with atmospheric water vapor to produce a mixture of uranyl fluoride $\left(\mathrm{UO}_{2} \mathrm{~F}_{2}\right)$ and hydrogen fluoride (HF). The continuing fire then sends additional $\mathrm{UF}_{6}$ upward with the fire plume; this $\mathrm{UF}_{6}$ also reacts quickly to form $\mathrm{UO}_{2} \mathrm{~F}_{2}$ and HF. Finally, as the fire subsides, the cool-down or smoldering phase of the release continues for 30 minutes or more. During this cool-down period, the temperature of the emitted plume decreases rapidly (reducing emitted buoyancy) until the emission ceases. All firerelated scenarios outlined in the Depleted $\mathrm{UF}_{6}$ PEIS and studied in this report are variations of this basic case.

In the application of FIREPLUME to the Depleted $\mathrm{UF}_{6}$ PEIS fire scenarios, the assumption is made that the $\mathrm{UF}_{6}$ released into the fire is quickly converted to $\mathrm{UO}_{2} \mathrm{~F}_{2}(1-\mu \mathrm{m}$ particles) and $\mathrm{HF}$ (vapor) and that those two substances act as tracers in the dispersion of the fire plume. In this procedure, the important chemical and physical transformations are taken into account in establishing the initial conditions for FIREPLUME. For the scenarios examined in this report, this approximation is reasonable. Uranyl fluoride can deposit on the ground at very low deposition rates during the accident. The deposition rate of HF is negligible because of its gaseous state. (Hydrogen fluoride can potentially be taken up by vegetation; however, this possibility was not accounted for in the current study.)

Application of the FIREPLUME model requires the user to identify the health or ecological end points needed for the analysis of human health or environmental impacts. In the Depleted $\mathrm{UF}_{6}$ PEIS, two health end points are considered: (1) potential adverse effects, and (2) potential irreversible adverse effects. The potential-adverse-effects level for uranium compounds is represented by an intake of $10 \mathrm{mg}$ (McGuire 1991); for HF, the potential-adverse-effects level is represented by the Emergency Response Planning Guideline 1 (ERPG-1) one-hour value (AIHA 1996). The potential-irreversible-adverse effects level for uranium compounds is represented by an intake of $30 \mathrm{mg}$ (U.S. Nuclear Regulatory Commission guidance, 10 CFR Part 76); for HF, the potential-irreversible-adverse-effects level is represented by the ERPG-2 one-hour value. To extrapolate the health criteria for averaging times under an hour, chemical-specific exponential functions relating toxicity to exposure time are used (i.e., probit equations; see Section 2.2.2). Details on the extrapolation of the uranium compound and HF health criteria for averaging times less than an hour are given in the Depleted $\mathrm{UF}_{6}$ PEIS, Appendix C.

For any downwind location, the FIREPLUME model predicts a rolling (in time) average concentration. Comparing that value with the concentration value for the corresponding health end 
point being considered determines if that point lies inside of the impact area. Because of the transient nature of the $\mathrm{UF}_{6}$ releases, the maximum average concentration varies widely with averaging time. Therefore, FIREPLUME determines a worst-case averaging time by considering several averaging times at each downwind location and comparing these concentrations with the health criteria extrapolated to the same averaging time. 


\section{DESCRIPTION OF FIREPLUME}

The FIREPLUME model predicts the ground-level concentration field resulting from releases of hazardous materials from (1) instantaneously discharged thermals, (2) fires, or (3) passive releases. Releases during smoldering or cool-down phases of fires are also considered. The FIREPLUME model consists of two primary components. The first component is a Monte Carlo dispersion model, denoted as MCLDM (Monte Carlo Lagrangian Dispersion Model), that estimates dispersion of both buoyant and nonbuoyant releases in the atmospheric boundary layer. For computational efficiency, MCLDM is constrained to two-dimensional dispersion $(x, z)$ because lateral dispersion is well characterized with simple Gaussian models. The strength of MCLDM is in treating the vertical dispersion part of the problem, because simple Gaussian relationships do not adequately represent vertical concentration distributions in the atmospheric boundary layer. Furthermore, the Monte Carlo approach allows for convenient inclusion of the effects of plume rise (however, negatively buoyant plumes are not currently treated in MCLDM or FIREPLUME). The second component of FIREPLUME is a puff dispersion model that acts as a postprocessor to MCLDM. The puff dispersion model uses MCLDM-generated estimates of vertical dispersion, together with standard Gaussian relationships for horizontal dispersion, to estimate the ground-level concentration for a time-dependent release rate and a specified averaging time. For a time-varying release, the postprocessor is necessary because MCLDM provides only steady-state results.

In this chapter, we first briefly discuss MCLDM and then describe the puff dispersion model. Additional details of MCLDM are provided in Appendixes A and B. Appendix A discusses the calculation of Lagrangian particle trajectories in the atmospheric boundary layer, and Appendix B outlines the plume and thermal rise relationships used in FIREPLUME. Further details on MCLDM are provided by Brown (1997).

\subsection{THE MONTE CARLO LAGRANGIAN DISPERSION MODEL}

\subsubsection{The Langevin Equation and Its Application}

In MCLDM, the Lagrangian trajectories of a large number of particles are simulated to develop the mean concentration field directly from the probability density function of the particle positions. The particle trajectories are calculated by using atmospheric boundary layer statistics as well as initial source buoyancy. To calculate particle trajectories, MCLDM employs the Langevin equation, which provides the best physical description of particle behavior in a turbulent flow field. Application of the Langevin equation to model turbulent motion takes advantage of the fact that the time scales governing variations in acceleration are much smaller than the time scales governing 
variations in velocity. Indeed, for the atmospheric boundary layer, this assumption proves to be very good, as illustrated in the photographic evidence of van Dop et al. (1985).

For one-dimensional particle motion, the Langevin equation reads

$$
\frac{\mathrm{d} u}{\mathrm{~d} t}=-\frac{u}{T_{L}}+\eta(t)
$$

where

$$
\begin{aligned}
u & =\text { a fluctuating velocity component }(\text { i.e., } \bar{u}=0 \text { ), } \\
T_{L} & =\text { the Lagrangian time scale, and } \\
\eta(t) & =\text { a white-noise random process. }
\end{aligned}
$$

For homogeneous turbulence, integration of this stochastic differential equation provides the following Markov-chain relationship for the particle velocity:

$$
u(t+\Delta t)=\left(1-\frac{\Delta t}{T_{L}}\right) u(t)+\mu
$$

where

$$
\bar{\mu}=0
$$

and

$$
\overline{\mu^{2}}=\frac{2 \Delta t \sigma_{u}^{2}}{T_{L}}
$$

Here, $\mu$ is a random forcing function that is Gaussian for homogeneous turbulence. Reid (1979) and Ley (1982) have illustrated the applicability of the Langevin equation for modeling dispersion in the homogeneous neutral surface layer and have shown that predicted vertical distributions of particles (i.e., vertical concentration profiles) are in close agreement with experimental data.

The application of the Langevin approach to model dispersion in vertically inhomogeneous turbulence (such as that seen in the convective boundary layer) is more complicated. Early investigators (Legg and Rapauch 1982; Ley and Thomson 1983; Wilson et al. 1983) noted that the addition of a mean vertical velocity was necessary to prevent particles from clustering in regions of 
low vertical velocity variance or low Lagrangian time scale. Thomson $(1984,1987)$ further argued that additional moments of the random forcing function needed to be modified to prevent unphysical particle behavior. By requiring the steady-state density function of the particle distribution to approach the density function of the air as specified by the Eulerian velocity moments, Thomson (1984) derived a general expression for relating the moments of $\mu$ to the Eulerian velocity field. Thomson's expressions include a mean vertical velocity, corrections to $\overline{\mu^{2}}$, and expressions for higher order moments of $\mu$. De Baas et al. (1986) and Liljegren (1989) employed the approach of Thomson to study dispersion in the convective boundary layer using Eulerian velocity moment data from both atmospheric and water tank studies. Predictions of concentrations from these studies agreed very well with water tank concentration data reported by Deardorff and Willis (1985) and with atmospheric concentration data from several field experiments.

The MCLDM model extends the convective boundary layer models advanced by De Baas et al. (1986) and by Liljegren (1989) in two primary directions. First, MCLDM treats dispersion in near-neutral and stable conditions by incorporating statistics for these boundary layers as determined from several numerical and observational studies. Second, MCLDM provides a more careful treatment of the lower boundary by correctly representing all turbulent statistics through the surface layer and incorporating a realistic canopy layer utilizing turbulence statistics from several laboratory and field studies, as summarized by Kaimal and Finnigan (1994). This more realistic lower boundary has allowed for more accurate estimates of near-ground concentrations, especially from near-ground sources. Further discussion of MCLDM for the treatment of nonbuoyant releases is contained in Appendix A.

\subsubsection{Source Buoyancy Effects}

In the development of the FIREPLUME model, the effects of buoyancy have been included in MCLDM by adding a mean vertical velocity to the particles, as determined from standard plume rise relationships. The downwind distance over which buoyancy effects are included is determined by using associated limiting rise relationships. Additionally, the variances in particle velocity are also increased in a stochastic manner to account for the buoyant plume entrainment. Two sets of rise equations are incorporated in MCLDM: one for fires and another for instantaneous thermals. Fires are modeled by using standard plume relationships, whereas the instantaneous thermals are modeled by using relationships for buoyant thermals (Morton et al. 1956). As discussed by Weil (1982), buoyant thermal relationships are not as well developed as those for continuous plumes because of the limited laboratory and field data from which entrainment relationships can be refined. The plume and buoyant thermal rise relationships are further discussed in Appendix B. 


\subsubsection{Boundary Conditions}

We shall now discuss the boundary conditions invoked in MCLDM and their effect on the results of the simulation. At the ground, a reflection boundary condition is used for all cases; however, because of the fact that both the Lagrangian time scale and the vertical velocity variance approach zero as $z$ approaches zero (see Appendix A), the lower boundary is statistically unattainable, and reflection rarely occurs. A reflection boundary condition is also employed at the upper boundary for all conditions for nonbuoyant releases. For buoyant releases, the upper boundary condition is dependent on the meteorological conditions. The convective boundary layer is usually capped by a rather strong inversion. Thus, we use a reflection boundary condition for all particles at all times at the inversion. For our application, this assumption is reasonable because the initial buoyancy required to penetrate inversions typical of those capping the convective boundary layer is substantially larger than the initial buoyancy typical of the depleted $\mathrm{UF}_{6}$ release scenarios we consider (see Weil [1988] for a discussion of elevated inversion penetration).

Our treatment of the upper boundary condition for the stable boundary layer is more complicated, but understanding it is very important in terms of interpreting the results of the model. In short, particles under the effect of ambient turbulence are reflected at the boundary layer height, whereas particles experiencing buoyant rise are allowed to exit the boundary layer. This treatment means that particles that pass completely through the boundary layer under the effects of buoyant rise do not return to the boundary layer and thus do not contribute to ground-level impacts. This formulation is a direct consequence of the turbulence structure of the stable boundary layer, as discussed in Appendix A. Although this assumption may seem at first to be unrealistic, the basic premise involved here is strongly supported by observations of both turbulence and dispersion in the stable boundary layer. Observations of turbulence show that the turbulence energy (in particular the vertical velocity variance $\sigma_{w}$ ) falls to near zero at the boundary layer height $h$ (Nieuwstadt 1984). Thus material that rises above $h$ because of buoyancy effects or is released above $h$ (e.g., from a stack) does not diffuse back down into the boundary layer. This interpretation of events is clearly inferred from elevated releases, which often show undetectable concentrations at ground level until the boundary layer becomes convective in the morning (Csanady 1973; Hanna and Paine 1989).

\subsection{DETERMINATION OF GROUND-LEVEL CONCENTRATIONS}

The MCLDM model treats only stationary, or steady-state, problems. This fact means that MCLDM cannot model concentrations from instantaneous or time-varying releases. For this reason, we use a puff dispersion model to postprocess the "steady-state" MCLDM results so that problems with time-varying release rates and problems where several release phases exist (e.g., a fire with a cool-down period) can be treated. The puff dispersion model and its application are outlined in the following subsections. 


\subsubsection{The Puff Dispersion Model}

For each depleted $\mathrm{UF}_{6}$ release scenario modeled in this study (i.e., a given source configuration and set of meteorological conditions), up to three classes of MCLDM simulations are used, corresponding to (1) a baseline case with no buoyancy, (2) a fire plume case, and (3) a buoyant thermal case. The ground-level, nondimensionalized crosswind-integrated concentrations for these cases are then used directly to model the vertical dispersion of the puffs within the puff dispersion model. In this framework, the estimates of ground-level vertical dispersion that MCLDM provides are applied like the $\sigma_{z}$ curves in traditional Gaussian plume models (Turner 1969); however, the MCLDM estimates of " $\sigma_{z}$ " intrinsically correct the deficiencies in standard Gaussian $\sigma_{z}$ relationships and incorporate source buoyancy effects. Note that the $\sigma_{z}$ implied here is not the true $\sigma_{z}$ determined from the vertical concentration distribution but is rather a fitting parameter that, when inserted into the puff dispersion model, will provide the correct ground-level crosswind-integrated concentration.

The puff dispersion model is constructed in a standard manner. The release is broken up into a series of two-dimensional Gaussian puffs [i.e., $(x, y, z=0)$ ] that are released in a certain time interval (a 30-s release interval is currently used for all simulations discussed here). Each puff is advected downwind while growing in lateral and streamwise directions. The concentration at a particular point at a particular time $C(x, y, t)$ is provided by summing the contributions from all of the puffs, such that

$$
C(x, y, t)=\sum_{i=1}^{N} \frac{M_{i}}{(2 \pi)^{3 / 2} \sigma_{x i} \sigma_{y i} \sigma_{z i}} \exp \left[-\left(\frac{y-y_{o}}{\sqrt{2} \sigma_{y i}}\right)^{2}\right] \exp \left[-\left(\frac{x-U\left(t-t_{i}\right)}{\sqrt{2} \sigma_{x i}}\right)^{2}\right]
$$

where

$$
\begin{aligned}
N & =\text { the number of puffs; } \\
M_{i}, \sigma_{x i}, \sigma_{y i}, \sigma_{z i}, \text { and } t_{i} & =\begin{array}{l}
\text { the mass, plume spread parameters, and release times } \\
\text { for each puff } i \text {; and }
\end{array} \\
U & =\text { the average wind speed. }
\end{aligned}
$$

The $\sigma_{z}$ values in Equation 3 come directly from the MCLDM simulations. The $\sigma_{z}$ relationship for each puff corresponds to whether the puff is from (1) a thermal, (2) a fire, or (3) a smoldering fire. This latter category will be explained shortly. In the puff model, we assume that transverse diffusion and streamwise diffusion of the puffs are equal (i.e., $\sigma_{x}=\sigma_{y}$ ). The parameters for horizontal plume spread are estimated by using the relationships by Draxler (1976) for stable conditions and by Weil (1988, Equation 4.61) for unstable conditions. Enhancement of $\sigma_{y}$ due to buoyancy effects is neglected. For the scenarios considered in this study, this approximation is adequate. 


\subsubsection{Averaging Time}

To relate the concentration to a toxicological end point, the puff model integrates over time the concentration expression in Equation 3 to provide an average concentration over a given time interval. In the averaging process, the puff model uses a "rolling average," returning the maximum average concentration over the time interval in question.

The puff dispersion model either (1) can use a preset averaging time (e.g., a one-hour averaging time such as would correspond to a one-hour ERPG health criterion) or (2) can search various averaging times and corresponding health criteria to determine the worst case. The second method is employed in this study. Here, we define a probit exponent that relates the health criteria to the averaging time, such that

$$
\frac{C_{l i m}\left(T_{1}\right)}{C_{l i m}\left(T_{2}\right)}=\left(\frac{T_{2}}{T_{1}}\right)^{b},
$$

where $b$ is the probit exponent. The probit exponent typically varies between about 0.3 and 0.67 for corrosive toxic gases such as HF (Wilson 1991). An exponent of 1 indicates a linear relationship of toxicity with exposure time. For the chemicals of interest in this study, the probit exponent assumed was 0.5 for $\mathrm{HF}$ and 1.0 for $\mathrm{UO}_{2} \mathrm{~F}_{2}$. (See Appendix $\mathrm{C}$ of the Depleted $\mathrm{UF}_{6}$ PEIS for details on these assumptions.) For $\mathrm{HF}$ averaging times less than five minutes, the health criterion was fixed at the five-minute value. Health criteria values for $\mathrm{HF}$ and $\mathrm{UO}_{2} \mathrm{~F}_{2}$ are further discussed in Section 3.3.

\subsubsection{Treatment of the Smoldering or Cool-Down Release Phase}

Within the framework outlined, the modeling of passive releases, as well as releases in thermals and fires, is straightforward in that the MCLDM $\sigma_{z}$ values are directly used in Equation 3. However, for releases that continue after a fire dies, the problem becomes more difficult because the buoyancy gradually decreases as the burned material cools. The treatment of this phase of the problem is especially important because ground-level concentrations within a few kilometers of the source can be dominated by this low-buoyancy phase of the release. Unfortunately, using the MCLDM model for the intermediate-buoyancy cases is not practical because each MCLDM model run consumes from one to five hours on a Sun- 5 workstation. In principle, 10 or more such runs would be necessary to adequately characterize the plume behavior through the cool-down period.

To model the smoldering phase of the release in an economical manner, we have developed an interpolation scheme using the MCLDM results from two runs: one with a fire plume and another with zero buoyancy. For these intermediate-buoyancy cases, our scheme uses simpler empirical models to scale the MCLDM results between the fire plume and the zero-buoyancy case. Although 
the concentration estimates of the simple empirical models estimates, their use in our interpolation scheme provides $r$ scheme has been tested against estimates directly from the ] provides concentration estimates within $20 \%$ of actual MCLD effort; we are currently working toward a more physically phase of the release because of its importance in near-sol treatment of the cool-down phase of the release is outlined $i$

The buoyancy of the plume in the cool-down temperature. For depleted $\mathrm{UF}_{6}$ release scenarios considerec is provided by Williams and Anderson (1996) (see Section 3 Froude number is assumed to be constant. Therefore, the ? source vertical velocity, and $U_{r}$ is the reference wind speed

$$
K^{2} \sim \frac{T_{r}(t)}{T_{f}}
$$

By using the time-dependent value of $K$, the groun interpolating between the results of the baseline (nonbuoyan scheme for interpolation is constructed by using estimat simple, empirical buoyant plume models. By using empiric. by the models by Weil (1988) for unstable conditions conditions, the ground-level, crosswind-integrated concer determined by using the interpolation equation, e not as precise as our MCLDM onable results. This interpolation LDM model for several cases and ins. This approach is a preliminary ct description of the smoldering round-level concentrations. Our following paragraphs.

1 is estimated from the release is study, this release temperature Juring the cool-down period, the y ratio, $K=U_{r} / w_{o}$ (where $w_{o}$ is $\mathrm{l}$ at $10 \mathrm{~m}]$ ), varies as concentrations are estimated by he fire plume MCLDM runs. The ound-level concentrations from ntration estimates as determined Venkatram (1988) for stable for arbitrary $K$ [i.e., $C(x, K)]$ is

$$
C(x, K)=C_{b}(x)+\left[C_{f}(x)-C_{b}(x)\right] \frac{\tilde{C}(x, K)-\tilde{C}(x, K=0)}{\tilde{C}\left(x, K_{\text {fire }}\right)-\tilde{C}(x, K=0)},
$$

where

$C_{b}=$ the baseline MCLDM case,

$C_{f}=$ the fire plume MCLDM case, and

$\tilde{C}=$ the concentration estimated with the simpler empirical method. 


\section{APPLICATION OF FIREPLUME TO RELEASES OF DEPLETED URANIUM HEXAFLUORIDE}

This chapter details the application of the FIREPLUME model in predicting the consequences of accidents involving depleted $\mathrm{UF}_{6}$. First, the release scenarios are described in Section 3.1, including (1) a basic overview of the release scenarios, (2) a review of the temperature and release rate information, and (3) a discussion of the meteorological conditions analyzed. Next, the treatment of the three release phases (i.e., the initial hydraulic rupture, the release in the fire, and the smoldering or cool-down phase) in setting up the model runs is outlined in Section 3.2. Then health criteria are reviewed in Section 3.3; and finally in Section 3.4, the results of FIREPLUME are presented and discussed for one scenario. Also provided are result summaries for the four other scenarios. More detailed results are presented in Appendix C.

\subsection{DESCRIPTION OF SCENARIOS}

\subsubsection{Overview}

Table 1 lists the five accident scenarios evaluated in the current study. These scenarios consist of three primary scenarios with two subcases involving different types of depleted $\mathrm{UF}_{6}$ cylinders.

The first primary scenario involves a fuel fire engulfing three cylinders of depleted $\mathrm{UF}_{6}$ that are in storage. Here, one possible initiating event is a vehicle operator losing control of his vehicle and striking the storage area. In this accident, diesel fuel contained in the fuel tank of the vehicle spills and ignites, resulting in a 30-minute fuel fire. Considering the typical capacity of a vehicle fuel tank, three cylinders is a reasonable upper limit of the total number of cylinders that would be affected by such a fuel fire. As discussed further in Section 3.1.2, the fuel fire ultimately leads to the hydraulic rupture of the three cylinders. Upon rupture, each cylinder releases a large puff of $\mathrm{UF}_{6}$, which quickly mixes with air and becomes slightly buoyant. This instantaneous release of $\mathrm{UF}_{6}$ is followed by a continuous release of $\mathrm{UF}_{6}$ into the fire plume during the remaining period of the 30-minute fire. Because it is very unlikely that all three cylinders would rupture at the same moment, it was assumed that they rupture at 30-second intervals. Once the fire dies, the cylinders cool, releasing additional $\mathrm{UF}_{6}$. Although several types of depleted $\mathrm{UF}_{6}$ cylinders could be affected by this storage-yard scenario, only $48 \mathrm{G}$ and $48 \mathrm{Y}$ cylinders are considered in this analysis because, due to their projected release rates, their impacts should be bounding.

The second primary scenario considered in our analysis involves the crash landing of a small aircraft. Upon impact, one cylinder is assumed to rupture immediately, and a second cylinder 


\section{TABLE 1 Five Accident Scenarios Evaluated in the Current Study}

\begin{tabular}{|c|c|c|c|c|c|}
\hline \multirow[b]{2}{*}{ Accident Scenario } & \multirow[b]{2}{*}{ Accident Description } & \multicolumn{3}{|c|}{ Release (Source Term) } & \multirow[b]{2}{*}{$\begin{array}{r}\text { Release } \\
\text { Level } \\
\end{array}$} \\
\hline & & $\begin{array}{l}\text { Chemical } \\
\text { Form }\end{array}$ & $\begin{array}{l}\text { Amount } \\
\text { (lb) }\end{array}$ & $\begin{array}{l}\text { Duration } \\
\text { (min) }\end{array}$ & \\
\hline $\begin{array}{l}\text { Vehicle-induced fire; three } \\
\text { full } 48 \mathrm{G} \text { cylinders }\end{array}$ & $\begin{array}{l}\text { Three full } \mathrm{UF}_{6} \text { cylinders } \\
\text { hydraulically rupture during a fire } \\
\text { resulting from the ignition of fuel or } \\
\text { hydraulic fluid from the transport } \\
\text { vehicle, etc. }\end{array}$ & $\mathrm{UF}_{6}$ & $\begin{array}{r}0 \\
11,500 \\
8,930 \\
3,580\end{array}$ & $\begin{array}{l}0-12 \\
12 \\
12-30 \\
30-121\end{array}$ & Ground \\
\hline $\begin{array}{l}\text { Vehicle-induced fire; three } \\
\text { full } 48 \mathrm{Y} \text { cylinders }\end{array}$ & $\begin{array}{l}\text { Three full } \mathrm{UF}_{6} \text { cylinders } \\
\text { hydraulically rupture during a fire } \\
\text { resulting from the ignition of fuel or } \\
\text { hydraulic fluid from the transport } \\
\text { vehicle, etc. }\end{array}$ & $\mathrm{UF}_{6}$ & $\begin{array}{r}0 \\
18,000 \\
2,770 \\
8,010\end{array}$ & $\begin{array}{l}0-24 \\
24 \\
24-30 \\
30-236\end{array}$ & Ground \\
\hline \multirow[t]{2}{*}{$\begin{array}{l}\text { Small aircraft-induced fire; } \\
\text { two full } 48 \mathrm{G} \text { cylinders }\end{array}$} & $\begin{array}{l}\text { A full } \mathrm{UF}_{6} \text { cylinder hydraulically } \\
\text { ruptures during a fire resulting from } \\
\text { the ignition of aviation fuel. }\end{array}$ & $\mathrm{UF}_{6}$ & $\begin{array}{r}0 \\
3,840 \\
2,980 \\
1,190\end{array}$ & $\begin{array}{l}0-12 \\
12 \\
12-30 \\
30-121\end{array}$ & Ground \\
\hline & $\begin{array}{l}\text { Initial breach of one cylinder due to } \\
\text { impact with aircraft debris, followed } \\
\text { by sublimation due to fire. }\end{array}$ & $\mathrm{UF}_{6}$ & $\begin{array}{l}4,240 \\
1,190\end{array}$ & $\begin{array}{l}0-30 \\
30-121\end{array}$ & Ground \\
\hline \multirow[t]{2}{*}{$\begin{array}{l}\text { Small aircraft-induced fire; } \\
\text { two full } 48 \mathrm{Y} \text { cylinders }\end{array}$} & $\begin{array}{l}\text { A full } \mathrm{UF}_{6} \text { cylinder hydraulically } \\
\text { ruptures during a fire resulting from } \\
\text { the ignition of aviation fuel. }\end{array}$ & $\mathrm{UF}_{6}$ & $\begin{array}{r}0 \\
6,020 \\
920 \\
2,670\end{array}$ & $\begin{array}{l}0-24 \\
24 \\
24-30 \\
30-236\end{array}$ & Ground \\
\hline & $\begin{array}{l}\text { Initial breach of one cylinder due to } \\
\text { impact with aircraft debris, followed } \\
\text { by sublimation due to fire. }\end{array}$ & $\mathrm{UF}_{6}$ & $\begin{array}{l}3,210 \\
2,730\end{array}$ & $\begin{array}{l}0-30 \\
30-236\end{array}$ & Ground \\
\hline $\begin{array}{l}\text { Vehicle-induced fire; } \\
\text { two heel cylinders }\end{array}$ & $\begin{array}{l}\text { A vehicle crashes into the depleted } \\
\mathrm{UF}_{6} \text { heel cylinder storage pad, } \\
\text { damaging two cylinders. The fuel } \\
\text { from the vehicle ignites and releases } \\
\text { all of the depleted UF }\end{array}$ & $\mathrm{UF}_{6}$ & $\begin{array}{l}39 \\
10\end{array}$ & $\begin{array}{l}30 \\
30\end{array}$ & Ground \\
\hline
\end{tabular}


remains in the fire and ruptures later. The characteristics of the fuel fire (e.g., temperature, size, and duration) in this scenario are the same as in the previous scenario. Like the first primary scenario, this case has two subcases involving (1) two $48 \mathrm{G}$ cylinders and (2) two $48 \mathrm{Y}$ cylinders.

The third primary scenario, which has no subcases, involves heel cylinders exposed to the same fuel fire as in the vehicle and aircraft accidents. (Heel cylinders are relatively small cylinders containing small amounts of depleted $\mathrm{UF}_{6}$.) This third scenario does not include either a puff release (due to a hydraulic rupture) or a cool-down phase; the entire contents of the heel cylinders is released into the fire over its 30 -minute duration.

\subsubsection{Release and Temperature Information}

The release rate and temperature information for the releases of depleted $\mathrm{UF}_{6}$ considered in this study were generated by Williams and Anderson (1996) using the 6FIRE and SUBLIME models. In their analysis, Williams and Anderson (1996) modeled the release characteristics of 14-ton $48 \mathrm{G}$ and $48 \mathrm{Y}$ cylinders of depleted $\mathrm{UF}_{6}$ that were fully engulfed in a $1,475^{\circ} \mathrm{F}$ fire for 30 minutes. For both the $48 \mathrm{G}$ and $48 \mathrm{Y}$ cylinders, two release scenarios were considered. The first scenario, corresponding to the first primary scenario noted in Section 3.1.1, involves a cylinder that is initially undamaged but fully engulfed in a fire. In this scenario, the $48 \mathrm{G}$ and $48 \mathrm{Y}$ cylinders rupture after 12 and 24 minutes in the fire, respectively. In each case, the rupture of the cylinder is due to hoop stress failure caused by internal pressure buildup, resulting in an instantaneous hydraulic release. After rupture, the cylinders release $\mathrm{UF}_{6}$ vapor at a nearly constant rate for the remainder of the fire. After the 30-minute fire, the cool-down phase begins, where emissions are reduced until the temperature of the cylinder decreases to $133^{\circ} \mathrm{F}$. This cool-down phase of the release lasts for 91 and 206 minutes for the $48 \mathrm{G}$ and $48 \mathrm{Y}$ cylinders, respectively. (The cool-down phase of the $48 \mathrm{Y}$ cylinder is greater because of its larger heat capacity.)

The second release scenario considered by Williams and Anderson (1996) is similar to the first, except here one cylinder is assumed to be breached initially (i.e., no hydraulic rupture occurs). This release scenario corresponds to the cylinder in the aircraft scenario (primary scenario 2 , as noted in Section 3.1.1) that is breached upon impact. Here, the release rate is initially zero but quickly increases as the temperature of the cylinder increases. After the 30-minute fire, the cool-down characteristics for the second scenario are very similar to those of the first scenario.

A summary of 6FIRE and SUBLIME results for $48 \mathrm{G}$ and $48 \mathrm{Y}$ cylinders for the previous scenarios is provided in Table 2. Information on the release rate and temperature is provided in Table 3. 
TABLE 2 Summary of 6FIRE and SUBLIME Results, as Presented by Williams and Anderson (1996)

\begin{tabular}{|c|c|c|c|c|}
\hline 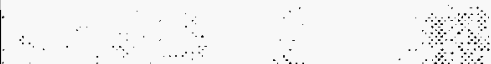 & \multicolumn{2}{|c|}{ \&. Therinal ruphre } & \multicolumn{2}{|c|}{ b. Initial breach } \\
\hline & 48G & $48 Y$ & $48 G$ & $48 Y$ \\
\hline \multicolumn{5}{|c|}{ GFIRE Resulss } \\
\hline Initial UF 6 mass, lb & 28000 & 28000 & 28000 & 28000 \\
\hline Time of rupture, min & 12.2 & 23.9 & $0^{+}$ & $0^{+}$ \\
\hline $\begin{array}{l}\text { Composition at } \\
\text { rupture, lb (\%) }\end{array}$ & $\begin{array}{l}24163 \\
(86.3)\end{array}$ & $\begin{array}{l}21984 \\
(78.5)\end{array}$ & & \\
\hline Liquid & $\begin{array}{c}3523 \\
(12.6)\end{array}$ & $\begin{array}{r}4744 \\
(16.9)\end{array}$ & & \\
\hline Vapor & $\begin{array}{c}314 \\
(1.1)\end{array}$ & $\begin{array}{l}1272 \\
(4.6)\end{array}$ & & \\
\hline $\begin{array}{l}\text { Cylinder pressure at rupture, } \\
\text { psia }\end{array}$ & 231.8 & 670.9 & & \\
\hline $\begin{array}{l}\text { Liquid temperature at rupture, } \\
{ }^{\circ} \mathrm{F}\end{array}$ & 260.0 & 284.9 & & \\
\hline $\begin{array}{l}\text { Vapor temperature at nupture, } \\
{ }^{\circ} \mathrm{F}\end{array}$ & 672.7 & 611.5 & & \\
\hline $\begin{array}{l}\text { Average shell temperature at } \\
\text { rupture, }{ }^{\circ} \mathrm{F}\end{array}$ & 1125 & 1085 & & \\
\hline Initial release, lb & 3837 & 6016 & $0^{+}$ & $0^{+}$ \\
\hline \multicolumn{5}{|c|}{ SUBLIME Resulss } \\
\hline $\begin{array}{l}\text { Time from rupture to end } \\
\text { of fire, } \min \end{array}$ & 17.8 & 6.1 & 30 & 30 \\
\hline $\begin{array}{l}\text { Vapor sublimated during } \\
\text { remainder of fire, lb }\end{array}$ & 2975 & 924 & 4240 & 3213 \\
\hline $\begin{array}{l}\text { Vapor temperature at end } \\
\text { of fire, }{ }^{\circ} \mathrm{F}\end{array}$ & 912 & 882 & 912 & 905 \\
\hline $\begin{array}{l}\text { Vapor sublimated after fire, } \\
\text { lb }\end{array}$ & 1192 & 2670 & 1192 & 2733 \\
\hline $\begin{array}{l}\text { Duration of post-fire release, } \\
\text { min }\end{array}$ & 91.4 & 205.7 & 91.4 & 206.1 \\
\hline $\begin{array}{l}\text { Total UF, released, Ib } \\
(\% \text { nitial UF) }\end{array}$ & $\begin{array}{l}8004 \\
(28.6)\end{array}$ & $\begin{array}{r}9610 \\
(34.3)\end{array}$ & $(19432)$ & $\frac{5946}{(21.2)}$ \\
\hline
\end{tabular}

+ A cylinder will always contain some $\mathrm{UF}_{6}$ vapor, some of which may be released when a cylinder is breached. This quantity of material, practically speaking, would be insignificant relative to uncertainties in the overall modeling of a cylinder that is breached coincident with the initiation of a fire. 
TABLE 3 Temperature and Release History for 48G and 48Y Depleted UF 6 Cylinders Exposed to a $1,475^{\circ} \mathrm{F}$ Regulatory Fire for 30 Minutes, as Presented by Williams and Anderson (1996)

\section{a. Thermal rupture}

\begin{tabular}{|c|c|c|c|c|}
\hline \multirow{2}{*}{ मे। } & \multicolumn{2}{|c|}{$48 \mathrm{G}$} & \multicolumn{2}{|c|}{$48 x$} \\
\hline & $\mathbf{T}_{\bullet} \cdot \mathbf{P}$ & $\mathrm{m}_{-}, \mathrm{b}$ & $T \% \mathrm{P}$ & $\mathbf{m}_{a \operatorname{lo}} \mathbf{b}$ \\
\hline \multirow{3}{*}{$\begin{array}{l}\text { "Initial" } \\
\text { conditions }\end{array}$} & \multicolumn{2}{|c|}{$t=12.2$} & \multicolumn{2}{|c|}{$1=23.9$} \\
\hline & \multicolumn{2}{|c|}{$X=0.757$} & \multicolumn{2}{|c|}{$X=0.923$} \\
\hline & 133.8 & 3837 & 133.8 & 6016 \\
\hline t, $\min$ & \multicolumn{4}{|c|}{ Transient conditions, $\mathrm{X}=1$} \\
\hline 15 & 893 & 4267 & \multirow{2}{*}{\multicolumn{2}{|c|}{ ४ै। }} \\
\hline 20 & 910 & 5105 & & \\
\hline 25 & 911 & 5957 & 837 & 6170 \\
\hline 30 & 912 & 6812 & 882 & 6940 \\
\hline 35 & 562 & 7292 & 685 & 7543 \\
\hline 40 & 429 & 7505 & 575 & 7917 \\
\hline 50 & 302 & 7727 & 447 & 8386 \\
\hline 60 & 239 & 7843 & 372 & 8683 \\
\hline 75 & 188 & 7935 & 301 & 8975 \\
\hline 90 & 160 & 7979 & 255 & 9167 \\
\hline 105 & 144 & 7999 & 224 & 9301 \\
\hline 120 & 134 & 8004 & 201 & 9396 \\
\hline 150 & \multirow{2}{*}{\multicolumn{2}{|c|}{ ४ }} & 170 & 9516 \\
\hline 180 & & & 152 & 9578 \\
\hline \multirow{2}{*}{$\begin{array}{c}\text { "Final" } \\
\text { conditions }\end{array}$} & \multicolumn{2}{|c|}{$t=121.4$} & \multicolumn{2}{|c|}{$1=235.7$} \\
\hline & 133.8 & 8004 & 133.8 & 9610 \\
\hline
\end{tabular}

b. Initial breach

\begin{tabular}{|c|c|c|c|c|}
\hline \multirow{2}{*}{ मै। } & \multicolumn{2}{|c|}{$48 \mathrm{G}$} & \multicolumn{2}{|c|}{$48 Y$} \\
\hline & T.PP & $m, a b$ & $T \cdot P$ & $m_{-1} \mathrm{lb}$ \\
\hline t, $\min$ & \multicolumn{4}{|c|}{ Transient conditions, $X=1$} \\
\hline $\mathbf{0}$ & 133.8 & $\mathbf{0}$ & 133.8 & $\mathbf{0}$ \\
\hline 5 & 691 & 191 & 407 & 62 \\
\hline 10 & 882 & 851 & 644 & 330 \\
\hline 15 & 909 & 1680 & 792 & 850 \\
\hline 20 & 911 & 2531 & 863 & 1558 \\
\hline 25 & 912 & 3385 & 893 & 2365 \\
\hline 30 & 912 & 4239 & 905 & 3213 \\
\hline 35 & 562 & 4720 & 696 & 3844 \\
\hline 40 & 429 & 4933 & 581 & 4229 \\
\hline 50 & 302 & 5155 & 451 & 4708 \\
\hline 60 & 239 & 5270 & 374 & 5010 \\
\hline 75 & 188 & 5363 & 302 & 5305 \\
\hline 90 & 160 & 5407 & 256 & 5499 \\
\hline 105 & 144 & 5426 & 225 & 5633 \\
\hline 120 & 134 & 5432 & 201 & 5730 \\
\hline 150 & & & 171 & 5851 \\
\hline 180 & & & 152 & 5913 \\
\hline "Final" & $t=$ & 21.4 & $1=$ & 16.1 \\
\hline conditions & 133.8 & 5432 & 133.8 & 5946 \\
\hline
\end{tabular}

$T=$ temperature, ${ }^{\bullet P} \quad m_{\mathrm{om}}=$ cumulative mass of $\mathrm{UF}_{\mathbf{6}}$ released, $\mathrm{lb} \quad \mathrm{l} \quad \mathrm{t}=$ time, $\min \quad X=$ vapor mass fraction 


\subsubsection{Meteorological Conditions}

For each scenario outlined in Section 3.1.1, FIREPLUME was run for two different meteorological conditions corresponding to a class-F-stability $1-\mathrm{m} / \mathrm{s}$ case and a class-D-stability 4-m/s case. Because FIREPLUME characterizes meteorological conditions in terms of boundary layer parameters (friction velocity $u_{*}$, Monin-Obukhov length $L$, and inversion or boundary layer height $z_{i}$ or $h$ ), rather than stability classes, conversion of the standard stability-class inputs to boundary layer parameters was necessary. To these ends, we chose boundary layer parameters to be consistent with the given stability classes and a roughness length of $10 \mathrm{~cm}$. For the class-Fstability $1-\mathrm{m} / \mathrm{s}$ case, a friction velocity $\left(u_{*}\right)$ of $0.02 \mathrm{~m} / \mathrm{s}$ and a Monin-Obukhov length $(L)$ of $5 \mathrm{~m}$ were used in the modeling. These parameters are typical of clear nighttime conditions with a $1-\mathrm{m} / \mathrm{s}$ wind speed in an area with roughness length of $10 \mathrm{~cm}$. The boundary layer height $(h)$ of $15 \mathrm{~m}$ was estimated from $u_{*}$ and $L$ by using the diagnostic relationship of Zilitinkevich (Nieuwstadt 1984; Brown 1997). Estimation of representative boundary layer parameters for the class D stability case is more difficult than for the class $F$ stability case because the class D stability case spans both unstable and stable meteorological conditions. For this study, we chose a weakly unstable class D stability case for analysis. Here, we used a friction velocity of $0.32 \mathrm{~m} / \mathrm{s}$, a Monin-Obukhov length $(L)$ of $-150 \mathrm{~m}$, and an inversion height of $500 \mathrm{~m}$. The applicable meteorological parameters are summarized in Table 4.

\subsection{TREATMENT OF RELEASE PHASES}

This section discusses the treatment of the three release phases (i.e., hydraulic rupture, release into a fire, and release during cooldown) in initializing FIREPLUME for the scenarios outlined in Section 3.1.1. The temperature and general release information used to model each release phase is that outlined in Section 3.1.2. In this study, releases from multiple cylinders are assumed to proceed independently; for instance, in the vehicle accident scenario, where three cylinders are involved, the release information is determined for a single cylinder. Then the dispersion results for the three-cylinder release are obtained by superimposing three single-cylinder releases.

TABLE 4 Summary of Meteorological Conditions Used in the FIREPLUME Runs

\begin{tabular}{ccccc}
\hline Case & $\begin{array}{c}\text { Wind } \\
\text { Speed }(\mathrm{m} / \mathrm{s})\end{array}$ & $\begin{array}{c}\text { Friction } \\
\text { Velocity }(\mathrm{m} / \mathrm{s})\end{array}$ & $\begin{array}{c}\text { Monin-Obukhov } \\
\text { Length }(\mathrm{m})\end{array}$ & $\begin{array}{c}\text { Mixing } \\
\text { Height }(\mathrm{m})\end{array}$ \\
\hline Class F stability & 1 & 0.02 & 5 & 15 \\
Class D stability & 4 & 0.32 & -150 & 500 \\
\hline
\end{tabular}


Our treatment of the initial hydraulic rupture is reviewed in Section 3.2.1. Because FIREPLUME does not explicitly account for the chemical transformations of $\mathrm{UF}_{6}$ and associated physical effects, an independent analysis of the $\mathrm{UF}_{6}$ chemistry and physics is made to determine the initial size and buoyancy of the $\mathrm{UF}_{6}$-air mixture released in the hydraulic rupture. This information is then used to initialize FIREPLUME. In this analysis, all $\mathrm{UF}_{6}$ is assumed to transform into $\mathrm{HF}$ and $\mathrm{UO}_{2} \mathrm{~F}_{2}$ within the first several seconds following the release. This transformation creates a HF-air mixture containing small $\mathrm{UO}_{2} \mathrm{~F}_{2}$ particles. Our analysis demonstrates that this mixture is positively buoyant. As a result, FIREPLUME is fully applicable to calculate the subsequent dispersion. [Note that FIREPLUME may not be applicable for other release scenarios, especially those that do not involve fires or hydraulic ruptures. Scenarios of $\mathrm{UF}_{6}$ release for which FIREPLUME may not be applicable include liquid or vapor releases that (1) lead to dense gas plumes or (2) may take considerable time to undergo chemical transformation.]

The characterizations of the fire and cool-down release phases are reviewed in Sections 3.2.2 and 3.2.3. As demonstrated in these sections, the physical effects of $\mathrm{UF}_{6}$ are not important for these release phases. As a result, the $\mathrm{UF}_{6}$ products $\left(\mathrm{HF}\right.$ and $\left.\mathrm{UO}_{2} \mathrm{~F}_{2}\right)$ are assumed to be entrained into the fire or cool-down plume without altering plume buoyancy.

\subsubsection{The Hydraulic Rupture Release}

As outlined in Section 3.1.2, the $48 \mathrm{G}$ and $48 \mathrm{Y}$ cylinders rupture after 12 and 24 minutes in the fuel fire, respectively. For the vehicle accident scenario, where three cylinders are involved, we assume that the cylinders rupture at 30-s intervals. As discussed previously, the products of each ruptured cylinder are assumed to react and travel independently.

Upon rupture of the cylinder, $\mathrm{UF}_{6}$ is released as solid, liquid, and vapor. Because of the large instantaneous drop in pressure, the liquid immediately flashes to vapor and solid $\mathrm{UF}_{6}$. The solid $\mathrm{UF}_{6}$ generated in this flashing process quickly sublimes to vapor. This vapor forms a cloud or puff of a $\mathrm{UF}_{6}$-air mixture that quickly reacts with water vapor to form $\mathrm{HF}$ and $\mathrm{UO}_{2} \mathrm{~F}_{2}$ and then moves downwind. The key issues in determining the downwind concentrations from this puff revolve around the buoyancy of this initial mixture. Three principal factors influence the initial buoyancy:

- Uranium hexafluoride is a very dense gas because of its high molecular weight $\left(\sim 14 \mathrm{~kg} / \mathrm{m}^{3}\right.$ at standard temperature and pressure [STP]). This density imparts strong negative buoyancy, which, without the addition of heat, would lead to a dense, ground-hugging plume. 
- Heat is released into the initial puff because of the reaction of $\mathrm{UF}_{6}$ with water vapor, namely,

$$
\mathrm{UF}_{6}+2 \mathrm{H}_{2} \mathrm{O} \rightarrow \mathrm{UO}_{2} \mathrm{~F}_{2}+4 \mathrm{HF}+101.5 \mathrm{~kJ} / \mathrm{mol} \mathrm{UF}_{6}
$$

In this reaction, $2 \mathrm{~mol}$ of water vapor are required for every $1 \mathrm{~mol}$ of $\mathrm{UF}_{6}$. This water vapor is provided through the entrainment of combustion gases and atmospheric air into the plume. Although combustion gases do provide some water vapor for the hydrolysis reaction, their contributions are small compared with the amount of water vapor entrained from ambient air because the fuel fire provides water vapor at only about $1 \mathrm{~kg} / \mathrm{s}$.

- The hydraulic rupture of the cylinder will lead to the initial entrainment of some hot combustion gas. Additional fuel combustion products may also be entrained into the plume in the first few seconds following the release. This entrainment will increase the temperature of the plume and lead to an increase in the buoyancy of the initial puff.

Because the physical effects of $\mathrm{UF}_{6}$ are clearly important to this release phase, we have incorporated the key chemical and physical effects in developing the initial conditions for the dispersion calculation. The FIREPLUME model does not consider the transformation of $\mathrm{UF}_{6}$ as the plume evolves (such as is done in the HGSYSTEMS/UF ${ }_{6}$ model); however, because of the nature of this release, we are able to apply FIREPLUME because we believe that the hydrolysis reaction converting $\mathrm{UF}_{6}$ to $\mathrm{HF}$ and $\mathrm{UO}_{2} \mathrm{~F}_{2}$ occurs fairly soon (within several seconds) after the hydraulic rupture of the cylinder. This general conclusion is supported by the results of HGSYSTEMS/UF 6 as presented by Lombardi (1996). The initial hydraulic rupture in the fire environment leads to a large amount of initial entrainment. In such an explosive release, the entrainment greatly exceeds that observed in jet releases. The entrainment of $50-75 \mathrm{~m}^{3}$ of air to each cubic meter of UF 6 gas within the first few seconds after release is certainly a realistic assumption. Entrainment amounts of this order can be inferred from fireball diameters observed in the first few seconds after hydraulic ruptures of propane and liquefied natural gas tanks (AICHE 1994). Initial entrainment amounts in this range allow the hydrolysis reaction to approach completion very quickly. For all calculations discussed here, we assume that $75 \mathrm{~m}^{3}$ of air is entrained for every cubic meter of $\mathrm{UF}_{6}$ that is initially released. This assumption is thought to be somewhat conservative because in the range of entrainment amounts, downwind concentrations generally increase with increasing initial entrainment (however, very low entrainment amounts lead to dense-gas effects and elevated concentrations close to the source).

For the reasons set forth, we initialize FIREPLUME with a puff containing the by-products of the initial $\mathrm{UF}_{6}$ released in the hydraulic rupture, together with air mixed at an initial volume ratio 
of 75:1. The temperature and buoyancy of this puff are determined by conducting a mass and enthalpy balance on the mixture. This analysis was accomplished by using a detailed set of equations that was solved by using the Engineering Equation Solver. The equation set and solutions for the 48G cylinder are provided in Appendix D. This analysis provides results very similar to those from the "mxuf6" code used by Lombardi (1996) to model similar release scenarios for depleted UF 6 . In calculating the mixture buoyancy, the enthalpy changes due to (1) the entrainment of combustion gases, (2) the hydrolysis reaction, and (3) the sublimation of solid $\mathrm{UF}_{6}$ to vapor $\mathrm{UF}_{6}$ are included in our calculation. Specific assumptions employed in this calculation for the $48 \mathrm{G}$ cylinder are listed below. A similar set of assumptions is applicable for the $48 \mathrm{Y}$ cylinder.

- A total of $1,744 \mathrm{~kg}(3,837 \mathrm{lb})$ of $\mathrm{UF}_{6}$ is initially released in the explosion. Of this amount, $143 \mathrm{~kg}$ is vapor at $628 \mathrm{~K}\left(672^{\circ} \mathrm{F}\right)$, and the remaining $1,601 \mathrm{~kg}$ is liquid. The liquid flashes to form a solid-vapor mixture at $330 \mathrm{~K}\left(133^{\circ} \mathrm{F}\right)$. After flashing, $75.5 \%$ of the total initial release is vapor, with the remaining amount being solid.

- In the initial explosion and in the following several seconds after release, $400 \mathrm{~m}^{3}$ of combustion air at $1,075 \mathrm{~K}\left(1,475^{\circ} \mathrm{F}\right)$ and about $10,300 \mathrm{~m}^{3}$ of ambient air at $300 \mathrm{~K}\left(80^{\circ} \mathrm{F}\right)$ are entrained into the plume. This amount of combustion air entrained is approximately equivalent to the volume of combustion gases produced every $4 \mathrm{~s}$ for the fuel fire outlined in Section 3.1.1.

- The hydrolysis reaction provides $101.5 \mathrm{~kJ} / \mathrm{mol}$ of $\mathrm{UF}_{6}$ released. This reaction is assumed to be completed in the first several seconds after release. This reaction provides $502,886 \mathrm{~kJ}$ of energy to the thermal.

- The $24.5 \%$ of the initial release that is in solid form sublimes to vapor, consuming $47.6 \mathrm{~kJ} / \mathrm{mol}$ of solid $\mathrm{UF}_{6}(57,780 \mathrm{~kJ}$ total$)$.

- By using the analysis outlined in Appendix D, the above assumptions lead to an initial puff of cylindrical shape with a radius of about $16 \mathrm{~m}$ and a height of about $16 \mathrm{~m}$. (The geometry of the puff is chosen to be consistent with that of buoyant thermals; see Scorer [1978].) From our energy balance and the thermodynamic relationships, the temperature and density of this $\mathrm{HF}$-air- $\mathrm{UO}_{2} \mathrm{~F}_{2}$ particle mixture are $344 \mathrm{~K}\left(170^{\circ} \mathrm{F}\right)$ and $1.138 \mathrm{~kg} / \mathrm{m}^{3}$. (For comparison, ambient air density is $1.174 \mathrm{~kg} / \mathrm{m}^{3}$.) This puff is used to initialize FIREPLUME. 


\subsubsection{Release into the Fire}

After the hydraulic rupture, $\mathrm{UF}_{6}$ continues to sublimate into vapor. This vapor, which quickly transforms to $\mathrm{HF}$ and $\mathrm{UO}_{2} \mathrm{~F}_{2}$, is entrained into the fire plume. The fire is modeled as a buoyant plume by using the plume rise relationships provided in Appendix B. For all fuel fires considered in our analysis, the fire parameters are

- $\quad$ Fire diameter $=5 \mathrm{~m}$,

- $\quad$ Fire temperature $=1,075 \mathrm{~K}\left(1,475^{\circ} \mathrm{F}\right)$, and

- Froude number $=0.8$.

On the basis of the definition of the Froude number, the above parameters provide that the vertical velocity directly above the fire is about $5 \mathrm{~m} / \mathrm{s}$. Our analysis has shown that the negative buoyancy of the $\mathrm{UO}_{2} \mathrm{~F}_{2}$ is negligible compared with the positive buoyancy of the combustion gases. The fire produces about $100 \mathrm{~m}^{3}$ of combustion gases every second. This air is a temperature of about $1,200 \mathrm{~K}$, leading to an initial buoyancy $(\Delta \rho / \rho)$ of about 0.75 . The release rate of $U_{6}$ into the fire is about $1.7 \mathrm{~kg} / \mathrm{s}$. The buoyancy of the resulting $\mathrm{UO}_{2} \mathrm{~F}_{2}$-combustion gas mixture is about 0.74 , about $1 \%$ less than the buoyancy of the fire plume alone.

\subsubsection{Release during Cooldown}

After the fire is extinguished, the release of $\mathrm{UF}_{6}$ continues as the cylinders cool. This so-called "cool-down" phase of the release continues for 91 and 205 minutes for the $48 G$ and $48 Y$ cylinders, respectively. Recall from Section 2.2.3 that the cool-down phase is treated by using an interpolation scheme that is based on MCLDM results from an initial fire run and a neutrally buoyant run. The fire parameters used in the initial fire run, which are somewhat different from those used for the actual fire release, are as follows:

- $\quad$ Fire diameter $=3 \mathrm{~m}$,

- Fire temperature $=800 \mathrm{~K}$, and

- $\quad$ Froude number $=0.8$.

The initial temperature is selected on the basis of the data provided by Williams and Anderson (1996), as outlined in Section 3.1.2. The fire diameter is chosen to be consistent with the cylinder dimensions. Clearly, the cylinder, ground, and any other material involved in the fire will be cooling after the fire subsides; however, because of its size and weight, we assume that the heat 
capacitance of the cylinder dominates the postfire buoyancy and, therefore, adjust the fire diameter accordingly.

During the cool-down phase, the temperatures and $\mathrm{UF}_{6}$ release rates used in the puff dispersion model in FIREPLUME (i.e., Equations 3, 5, and 6) are taken from the analysis of Williams and Anderson (1996), as discussed in Section 3.1.2.

\subsection{HEALTH CRITERIA CONSIDERED}

The health criteria considered for this study are provided in Table 5. Toxicological values are provided for averaging times between 1 and 60 minutes. These toxicological values are used with corresponding time-averaged concentrations predicted from FIREPLUME. As discussed in Section 2.2.2, the worst-case combination of averaging time and health criteria is used at each downwind distance considered. Note that the health criteria for $\mathrm{UO}_{2} \mathrm{~F}_{2}$ are based on dosage; that is, the health criteria are linear with respect to averaging time.

\subsection{RESULTS AND DISCUSSION}

This section discusses results of FIREPLUME as applied to the five accident scenarios outlined in Section 3.1.1. First, detailed concentration and exposure results are provided for the truck accident scenario where three $48 \mathrm{G}$ cylinders are exposed to a fuel fire and hydraulically rupture. The results for the F and D stability cases are presented in Sections 3.4.1 and 3.4.2, respectively. Then, in Section 3.4.3, summary statistics for the other release scenarios are presented. Detailed data on concentration and exposure for the remaining four scenarios are provided in Appendix C.

In the following discussions, the five accident scenarios are denoted as $\mathrm{T} 1$ to $\mathrm{T} 5$, as noted in Table 6. Where applicable, the tags " $\mathrm{a}$ " and " $\mathrm{b}$ " are used to denote results for $\mathrm{UO}_{2} \mathrm{~F}_{2}$ and $\mathrm{HF}$, respectively.

\subsubsection{Scenarios T1a and T1b: Results for F1 Stability}

Figure 1 pictorially illustrates the dispersion of the three phases of the release scenario for class $\mathrm{F}$ stability conditions with $1-\mathrm{m} / \mathrm{s}$ wind speed $(\mathrm{F} 1)$. Here the initial puff originating from the hydraulic rupture is slightly buoyant and rises only about $10 \mathrm{~m}$. The fire plume, on the other hand, rises considerably above the boundary layer and, therefore, does not lead to ground-level impacts. During the smoldering or cool-down phase, buoyancy decreases, leading to progressively lower plume rise and eventually ground-level impacts. The overall impact of the cool-down phase is small, however, because the release rate decreases substantially as the cylinders cool. 
TABLE 5 Limiting Toxicological Values for $\mathrm{HF}$ and $\mathrm{UO}_{2} \mathrm{~F}_{2}{ }^{a}$

\begin{tabular}{|c|c|c|c|c|}
\hline \multirow[b]{2}{*}{$\begin{array}{l}\text { Averaging } \\
\text { Time (min) }\end{array}$} & \multicolumn{2}{|c|}{$\mathrm{HF}$} & \multicolumn{2}{|c|}{$\mathrm{UO}_{2} \mathrm{~F}_{2}$} \\
\hline & $\begin{array}{c}\text { Potential } \\
\text { Irreversible Adverse } \\
\text { Effects }\left(\mathrm{mg} / \mathrm{m}^{3}\right)\end{array}$ & $\begin{array}{c}\text { Potential } \\
\text { Adverse Effects } \\
\left(\mathrm{mg} / \mathrm{m}^{3}\right)\end{array}$ & $\begin{array}{c}\text { Potential } \\
\text { Irreversible Adverse } \\
\text { Effects }\left(\mathrm{mg} / \mathrm{m}^{3}\right)\end{array}$ & $\begin{array}{c}\text { Potential } \\
\text { Adverse Effects } \\
\left(\mathrm{mg} / \mathrm{m}^{3}\right)\end{array}$ \\
\hline 1 & 57 & 5.7 & 1,600 & 520 \\
\hline 2 & 57 & 5.7 & 780 & 260 \\
\hline 3 & 57 & 5.7 & 520 & 170 \\
\hline 4 & 57 & 5.7 & 390 & 130 \\
\hline 5 & 57 & 5.7 & 310 & 100 \\
\hline 6 & 52 & 5.2 & 260 & 86 \\
\hline 7 & 48 & 4.8 & 220 & 74 \\
\hline 8 & 45 & 4.5 & 190 & 65 \\
\hline 9 & 42 & 4.2 & 170 & 58 \\
\hline 10 & 40 & 4.0 & 160 & 52 \\
\hline 11 & 38 & 3.8 & 140 & 47 \\
\hline 12 & 37 & 3.7 & 130 & 43 \\
\hline 13 & 35 & 3.5 & 120 & 40 \\
\hline 14 & 34 & 3.4 & 110 & 37 \\
\hline 15 & 33 & 3.3 & 100 & 35 \\
\hline 16 & 32 & 3.2 & 97 & 32 \\
\hline 17 & 31 & 3.1 & 91 & 30 \\
\hline 18 & 30 & 3.0 & 86 & 29 \\
\hline 19 & 29 & 2.9 & 82 & 27 \\
\hline 20 & 28 & 2.8 & 78 & 26 \\
\hline 21 & 28 & 2.8 & 74 & 25 \\
\hline 22 & 27 & 2.7 & 71 & 24 \\
\hline 23 & 26 & 2.6 & 68 & 23 \\
\hline 24 & 26 & 2.6 & 65 & 22 \\
\hline 25 & 25 & 2.5 & 62 & 21 \\
\hline 26 & 25 & 2.5 & 60 & 20 \\
\hline 27 & 24 & 2.4 & 58 & 19 \\
\hline 28 & 24 & 2.4 & 55 & 18 \\
\hline 29 & 24 & 2.4 & 54 & 18 \\
\hline 30 & 23 & 2.3 & 52 & 17 \\
\hline 31 & 23 & 2.3 & 50 & 17 \\
\hline 32 & 22 & 2.2 & 49 & 16 \\
\hline 33 & 22 & 2.2 & 47 & 16 \\
\hline 34 & 22 & 2.2 & 46 & 15 \\
\hline
\end{tabular}


TABLE 5 (Cont.)

\begin{tabular}{|c|c|c|c|c|}
\hline \multirow[b]{2}{*}{$\begin{array}{l}\text { Averaging } \\
\text { Time (min) }\end{array}$} & \multicolumn{2}{|c|}{$\mathrm{HF}$} & \multicolumn{2}{|c|}{$\mathrm{UO}_{2} \mathrm{~F}_{2}$} \\
\hline & $\begin{array}{c}\text { Potential } \\
\text { Irreversible Adverse } \\
\text { Effects }\left(\mathrm{mg} / \mathrm{m}^{3}\right)\end{array}$ & $\begin{array}{l}\text { Potential } \\
\text { Adverse Effects } \\
\left(\mathrm{mg} / \mathrm{m}^{3}\right)\end{array}$ & $\begin{array}{c}\text { Potential } \\
\text { Irreversible Adverse } \\
\text { Effects }\left(\mathrm{mg} / \mathrm{m}^{3}\right)\end{array}$ & $\begin{array}{c}\text { Potential } \\
\text { Adverse Effects } \\
\left(\mathrm{mg} / \mathrm{m}^{3}\right)\end{array}$ \\
\hline 35 & 21 & 2.1 & 44 & 15 \\
\hline 36 & 21 & 2.1 & 43 & 14 \\
\hline 37 & 21 & 2.1 & 42 & 14 \\
\hline 38 & 21 & 2.1 & 41 & 14 \\
\hline 39 & 20 & 2.0 & 40 & 13 \\
\hline 40 & 20 & 2.0 & 39 & 13 \\
\hline 41 & 20 & 2.0 & 38 & 13 \\
\hline 42 & 20 & 2.0 & 37 & 12 \\
\hline 43 & 19 & 1.9 & 36 & 12 \\
\hline 44 & 19 & 1.9 & 35 & 12 \\
\hline 45 & 19 & 1.9 & 35 & 12 \\
\hline 46 & 19 & 1.9 & 34 & 11 \\
\hline 47 & 18 & 1.9 & 33 & 11 \\
\hline 48 & 18 & 1.8 & 32 & 11 \\
\hline 49 & 18 & 1.8 & 32 & 11 \\
\hline 50 & 18 & 1.8 & 31 & 10 \\
\hline 51 & 18 & 1.8 & 30 & 10 \\
\hline 52 & 18 & 1.8 & 30 & 10 \\
\hline 53 & 17 & 1.7 & 29 & 10 \\
\hline 54 & 17 & 1.7 & 29 & 10 \\
\hline 55 & 17 & 1.7 & 28 & 9.4 \\
\hline 56 & 17 & 1.7 & 28 & 9.2 \\
\hline 57 & 17 & 1.7 & 27 & 9.1 \\
\hline 58 & 17 & 1.7 & 27 & 8.9 \\
\hline 59 & 17 & 1.7 & 26 & 8.8 \\
\hline 60 & 16 & 1.6 & 26 & 8.6 \\
\hline
\end{tabular}

a One-hour HF values are based on ERPG values (AIHA 1996); $\mathrm{UO}_{2} \mathrm{~F}_{2}$ values are based on intake levels of $30 \mathrm{mg}$ (potential irreversible adverse effects) and $10 \mathrm{mg}$ (potential adverse effects). Details are provided in the Depleted UF 6 PEIS, Appendix C. 
TABLE 6 Key $t$ he Five Accident Scenarios

\begin{tabular}{|c|c|c|}
\hline Case & & Accident Scenario \\
\hline T1a & Vehicle & uced fire; three full $48 \mathrm{G}$ cylinders; $\mathrm{UO}_{2} \mathrm{~F}_{2}$ \\
\hline $\mathrm{T} 1 \mathrm{~b}$ & Vehicle & nduced fire; three full $48 \mathrm{G}$ cylinders; $\mathrm{HF}$ \\
\hline $\mathrm{T} 2 \mathrm{a}$ & Vehicle- & -induced fire; three full $48 \mathrm{Y}$ cylinders; $\mathrm{UO}_{2} \mathrm{~F}_{2}$ \\
\hline $\mathrm{T} 2 \mathrm{~b}$ & Vehicle- & -induced fire; three full $48 \mathrm{Y}$ cylinders; $\mathrm{HF}$ \\
\hline $\mathrm{T} 3 \mathrm{a}$ & Small ai & rcraft-induced fire; two full $48 \mathrm{G}$ cylinders; $\mathrm{UO}_{2} \mathrm{~F}_{2}$ \\
\hline $\mathrm{T} 3 \mathrm{~b}$ & Small ai & rcraft-induced fire; two full $48 \mathrm{G}$ cylinders; HF \\
\hline $\mathrm{T} 4 \mathrm{a}$ & Small ai & rcraft-induced fire; two full $48 \mathrm{Y}$ cylinders; $\mathrm{UO}_{2} \mathrm{~F}_{2}$ \\
\hline $\mathrm{T} 4 \mathrm{~b}$ & Small ai & rcraft-induced fire; two full $48 \mathrm{Y}$ cylinders; HF \\
\hline T5a & Vehicle- & -induced fire; two heel cylinders; $\mathrm{UO}_{2} \mathrm{~F}_{2}$ \\
\hline $\mathrm{T} 5 \mathrm{~b}$ & Vehicle- & -induced fire; two heel cylinders; HF \\
\hline
\end{tabular}

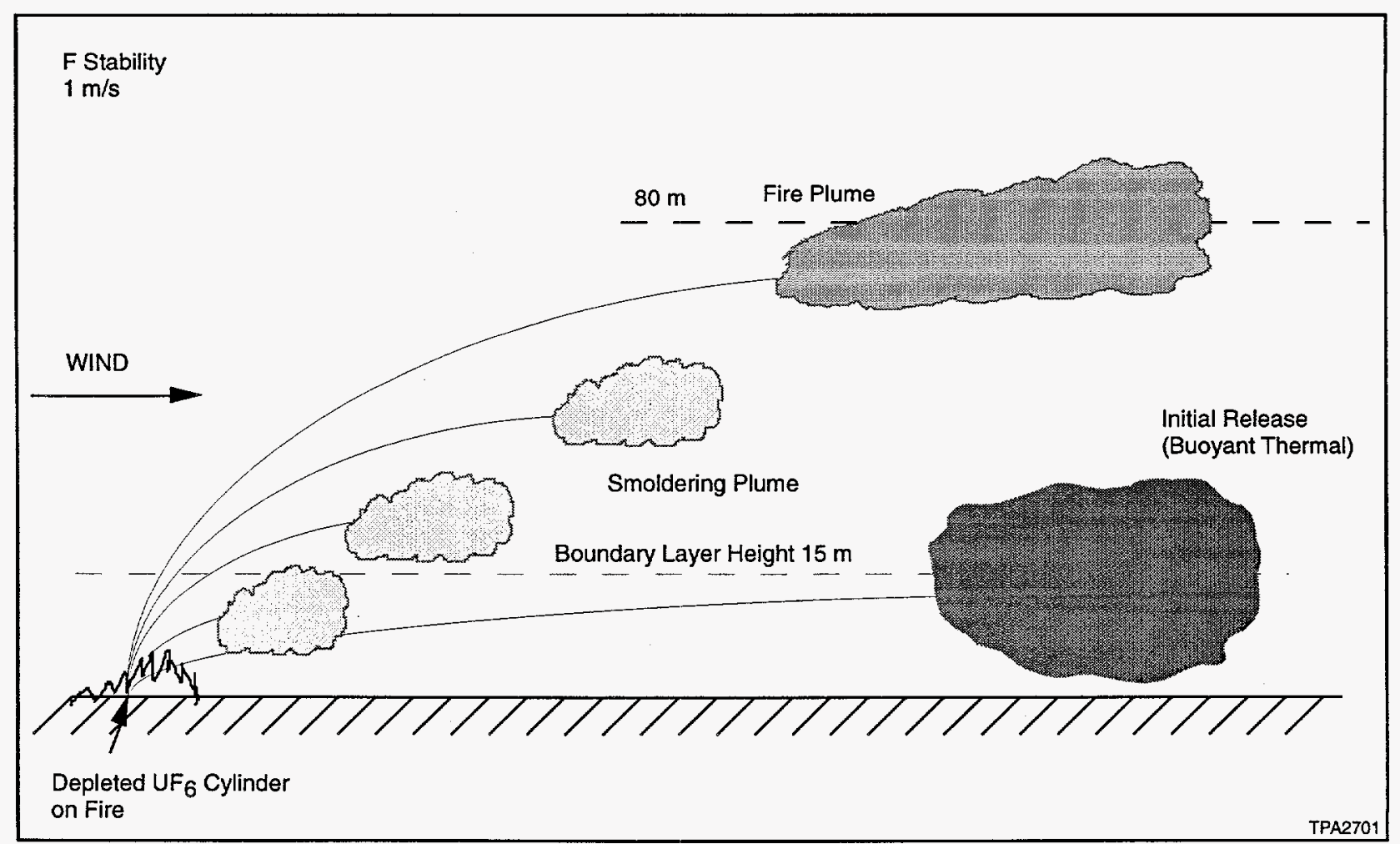

FIGURE 1 Dispersion of the Three Phases of the Release Scenario for Class F Stability Conditions 
Tables 7 and 8 present the downwind centerline concentrations from the three-48G-cylinder release for $\mathrm{HF}$ and $\mathrm{UO}_{2} \mathrm{~F}_{2}$, respectively. Concentrations are shown for averaging times that represent the worst-case ratio of concentration with respect to the health criteria. Because the health criteria for $\mathrm{UO}_{2} \mathrm{~F}_{2}$ are based on dosage (i.e., the health criteria are linear with respect to averaging time), a $3,600-\mathrm{s}(60-\mathrm{min})$ average concentration is the worst-case value for $\mathrm{UO}_{2} \mathrm{~F}_{2}$ over any time period of consideration between 0 and one hour at all downwind distances. A potential-irreversible-adverseeffects concentration of HF is predicted to extend out to less than $100 \mathrm{~m}$ downwind, with an impacted area of $2,600 \mathrm{~m}^{2}$; and a potential-adverse-effects concentration of $\mathrm{HF}$ is predicted to extend approximately $9,900 \mathrm{~m}$ downwind, with an impacted area of $10 \mathrm{~km}^{2}$. A potential-irreversibleadverse-effects concentration of $\mathrm{UO}_{2} \mathrm{~F}_{2}$ is predicted to extend out to less than $100 \mathrm{~m}$ downwind, with an impacted area of $1,500 \mathrm{~m}^{2}$; and a potential-adverse-effects concentration of $\mathrm{UO}_{2} \mathrm{~F}_{2}$ is predicted to extend approximately $7,400 \mathrm{~m}$ downwind, with an impacted area of $3.6 \mathrm{~km}^{2}$. Figure 2 depicts the predicted impacted areas (for both $\mathrm{HF}$ and $\mathrm{UO}_{2} \mathrm{~F}_{2}$ ) for the three-48G-cylinder release for $\mathrm{F} 1$ meteorological conditions, considering the potential-adverse-effects criterion.

\subsubsection{Scenarios T1a and T1b: Results for D4 Stability}

Figure 3 pictorially illustrates the dispersion of the three phases of the release scenario under class D stability conditions with $4-\mathrm{m} / \mathrm{s}$ wind speed (D4). Here, both the initial puff originating from the hydraulic rupture and the fire plume rise into the upper part of the boundary layer. The overall plume rise for this case is much greater than for class $F$ stability conditions because of the absence of thermal stratification. Because of the weak convective turbulence, the puff and fire plume subsequently diffuse back to ground level, leading to ground-level impacts at distances greater than about $2 \mathrm{~km}$. During the smoldering or cool-down phase, buoyancy decreases, leading to progressively lower plume rise and eventually ground-level impacts close to the source. These nearsource impacts, however, are relatively small.

Tables 9 and 10 present the downwind centerline concentrations for the three-48G-cylinder release for $\mathrm{HF}$ and $\mathrm{UO}_{2} \mathrm{~F}_{2}$, respectively. As before, concentrations are shown for averaging times that represent the worst-case situation with respect to the health criteria. Downwind impacts are minimal, considering the potential-irreversible-adverse-effects criteria for both $\mathrm{HF}$ and $\mathrm{UO}_{2} \mathrm{~F}_{2}$, with no exceedance beyond $100 \mathrm{~m}$ downwind. The impacted areas for the potential-irreversible-adverseeffects criteria for $\mathrm{HF}$ and $\mathrm{UO}_{2} \mathrm{~F}_{2}$ are $1,700 \mathrm{~m}^{2}$ and $810 \mathrm{~m}^{2}$, respectively. The downwind impacts considering the potential-adverse-effects criteria for $\mathrm{HF}$ include a small isolated region centered at around $2.5 \mathrm{~km}$ downwind. Downwind impacts are minimal, considering the potential-adverse-effects criteria for $\mathrm{UO}_{2} \mathrm{~F}_{2}$, with no exceedances beyond $100 \mathrm{~m}$ from the source. The impacted areas for the potential-adverse-effects criteria for $\mathrm{HF}$ and $\mathrm{UO}_{2} \mathrm{~F}_{2}$ are $190,000 \mathrm{~m}^{2}$ and $1,400 \mathrm{~m}^{2}$, respectively. 
TABLE 7 Downwind Centerline Concentrat ns for HF for Scenario T1 with F1 Stability ${ }^{\mathbf{a}}$

\begin{tabular}{|c|c|c|c|c|}
\hline $\begin{array}{l}\text { Downwind } \\
\text { Distance (m) }\end{array}$ & $\begin{array}{c}\text { Concentration } \\
\left(\mathrm{mg} / \mathrm{m}^{3}\right)\end{array}$ & $\begin{array}{c}\text { Averaging } \\
\text { Time (s) }\end{array}$ & $\begin{array}{l}\text { Exeeds Potential- } \\
\text { Irreversible-Adverse- } \\
\text { Effects Limit }\end{array}$ & $\begin{array}{c}\text { Exceeds Potential- } \\
\text { Adverse-Effects } \\
\text { Limit }\end{array}$ \\
\hline 100 & 0.026 & 3,600 & No & No \\
\hline 150 & 0.018 & 3,600 & No & No \\
\hline 250 & 0.011 & 3,600 & No & No \\
\hline 305 & 0.46 & 60 & No & No \\
\hline 350 & 1.8 & 60 & No & No \\
\hline 368 & 2.8 & 60 & No & No \\
\hline 450 & 6.8 & 60 & No & Yes \\
\hline 550 & 13 & 60 & No & Yes \\
\hline 650 & 16 & 60 & No & Yes \\
\hline 750 & 30 & 60 & No & Yes \\
\hline 805 & 33 & 60 & No & Yes \\
\hline 840 & 35 & 60 & No & Yes \\
\hline 850 & 36 & 60 & No & Yes \\
\hline 920 & 41 & 60 & No & Yes \\
\hline 1,210 & 28 & 60 & No & Yes \\
\hline 1,350 & 28 & 60 & No & Yes \\
\hline 1,450 & 26 & 60 & No & Yes \\
\hline 2,414 & 15 & 750 & No & Yes \\
\hline 4,023 & 8.5 & 1,200 & No & Yes \\
\hline 5,632 & 4.6 & 1,800 & No & Yes \\
\hline 7,241 & 3.2 & 2,100 & No & Yes \\
\hline 12,068 & 1.3 & 3,600 & No & No \\
\hline
\end{tabular}

a Class F stability with $1-\mathrm{m} / \mathrm{s}$ wind speed.

\subsubsection{Summary Statistics for Remaining Release Scenarios}

Tables 11 to 13 list summary statistics for all five release scenarios discussed in this report. Table 11 provides (1) the distance to the maximally exposed individual (MEI) and (2) the centerline concentration at that distance. For scenarios $\mathrm{T} 1$ to $\mathrm{T} 4$, the MEI is located $30 \mathrm{~m}$ from the release point, which is the minimum distance from the source for which FIREPLUME concentration predictions are believed reliable. For the T5 scenario, the MEI location is over $12 \mathrm{~km}$ downwind for the D stability meteorological conditions because all material is released into the fire plume, which takes a long time to disperse back down to ground level. For the T5 scenario with F stability, no ground-level impacts occur beyond $30 \mathrm{~m}$ because the fire plume rises considerably above the mixing 
TABLE 8 Downwind Centerline Concentrations for $\mathrm{UO}_{2} \mathrm{~F}_{2}$ for Scenario $\mathrm{T} 1$ with F1 Stability

\begin{tabular}{rcccc}
\hline $\begin{array}{c}\text { Downwind } \\
\text { Distance }(\mathrm{m})\end{array}$ & $\begin{array}{c}\text { Concentration } \\
\left(\mathrm{mg} / \mathrm{m}^{3}\right)\end{array}$ & $\begin{array}{c}\text { Averaging } \\
\text { Time }(\mathrm{s})\end{array}$ & $\begin{array}{c}\text { Exceeds Potential- } \\
\text { Irreversible-Adverse- } \\
\text { Effects Limit }\end{array}$ & $\begin{array}{c}\text { Exceeds Potential- } \\
\text { Adverse-Effects } \\
\text { Limit }\end{array}$ \\
\hline 100 & 0.10 & 3,600 & No & No \\
150 & 0.07 & $-3,600$ & No & No \\
250 & 0.04 & 3,600 & No & No \\
305 & 0.07 & 3,600 & No & No \\
350 & 0.20 & 3,600 & No & No \\
368 & 0.29 & 3,600 & No & No \\
450 & 0.78 & 3,600 & No & No \\
550 & 1.6 & 3,600 & No & No \\
650 & 2.6 & 3,600 & No & No \\
750 & 4.7 & 3,600 & No & No \\
805 & 6.0 & 3,600 & No & No \\
840 & 6.6 & 3,600 & No & No \\
850 & 6.4 & 3,600 & No & No \\
920 & 7.5 & 3,600 & No & No \\
1,210 & 7.9 & 3,600 & No & No \\
1,350 & 8.7 & 3,600 & No & Yes \\
1,450 & 9.2 & 3,600 & No & Yes \\
2,414 & 14 & 3,600 & No & Yes \\
4,023 & 13 & 3,600 & No & Yes \\
5,632 & 10 & 3,600 & No & Yes \\
7,241 & 8.8 & 3,600 & No & Yes \\
12,068 & 5.1 & 3,600 & No & No \\
\hline & & & &
\end{tabular}

a Class F stability with $1-\mathrm{m} / \mathrm{s}$ wind speed.

height. Note that the averaging times for the $\mathrm{HF}$ and $\mathrm{UO}_{2} \mathrm{~F}_{2}$ concentrations in Table 11 are $60 \mathrm{~s}$ and $3,600 \mathrm{~s}$, respectively, except for scenario $\mathrm{T} 5$, where the averaging time for $\mathrm{HF}$ concentrations is $1,800 \mathrm{~s}$.

Tables 12 and 13 provide (1) the overall area in which the health criteria are exceeded and (2) the maximum distance at which the health criteria are exceeded. Table 12 provides results for potential irreversible adverse effects, and Table 13 provides results for potential adverse effects. Note that the overall exposed areas and maximum distances for which the health criteria are exceeded are larger for the HF component of the releases for all cases considered here. The large differences between $\mathrm{HF}$ and $\mathrm{UO}_{2} \mathrm{~F}_{2}$ exposure areas and downwind distances result from the lower health criteria for HF, coupled with the use of a probit exponent of 0.5 for HF. 


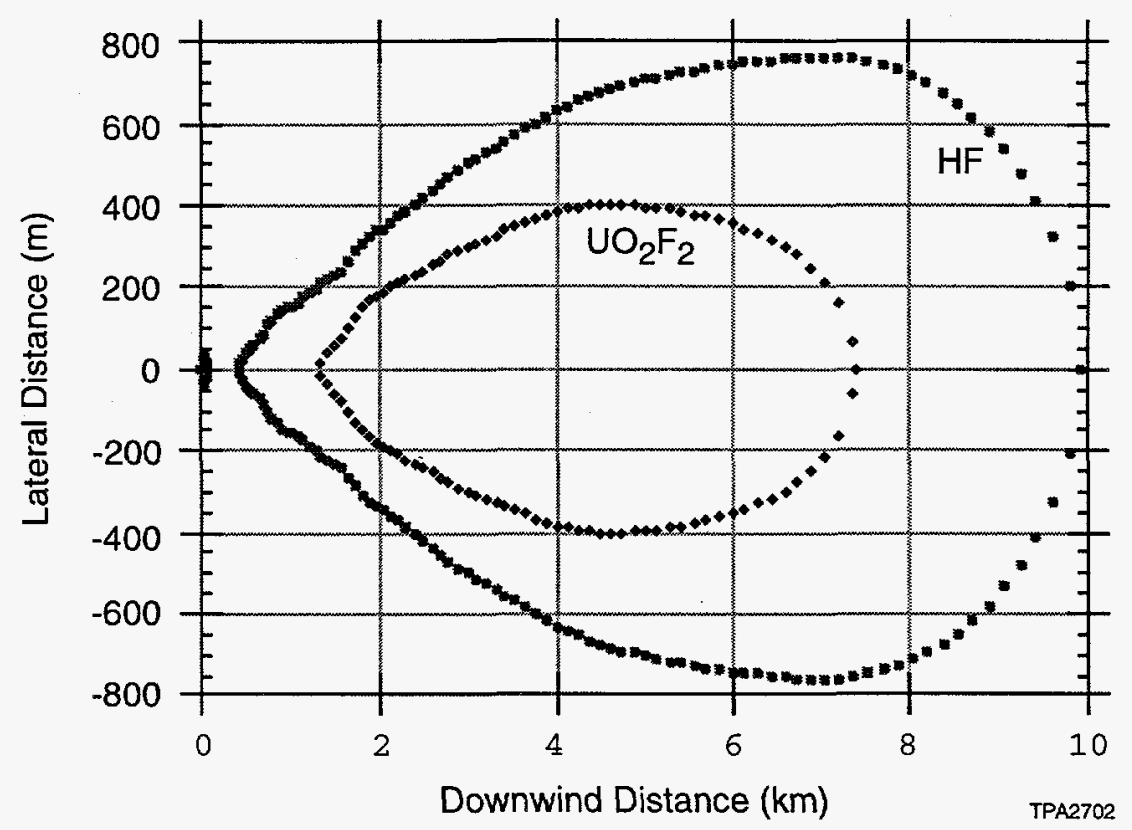

FIGURE 2 Predicted Potential-Adverse-Effects Impacted Areas for $\mathrm{HF}$ and $\mathrm{UO}_{2} \mathrm{~F}_{2}$ for the Three-48G-Cylinder Release for $\mathrm{F} 1$ Meteorological Conditions

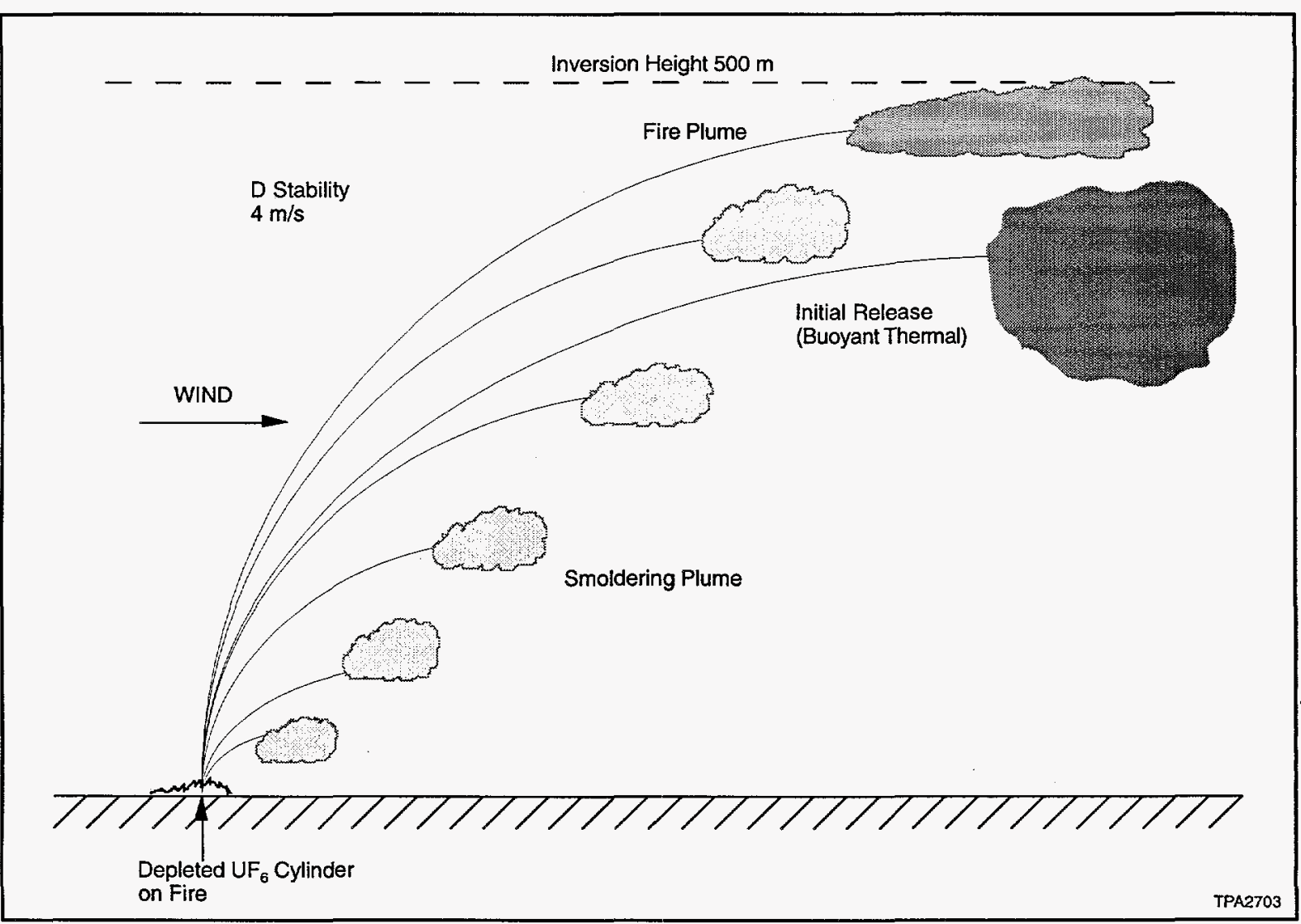

FIGURE 3 Dispersion of the Three Phases of the Release Scenario for Class D Stability Conditions 
TABLE 9 Downwind Centerline Concentrations for HF for Scenario T1 with D4 Stability ${ }^{\mathrm{a}}$

\begin{tabular}{ccccc}
\hline $\begin{array}{c}\text { Downwind } \\
\text { Distance }(\mathrm{m})\end{array}$ & $\begin{array}{c}\text { Concentration } \\
\left(\mathrm{mg} / \mathrm{m}^{3}\right)\end{array}$ & $\begin{array}{c}\text { Averaging } \\
\text { Time }(\mathrm{s})\end{array}$ & $\begin{array}{c}\text { Exceeds Potential- } \\
\text { Irreversible-Adverse- } \\
\text { Effects Limit }\end{array}$ & $\begin{array}{c}\text { Exceeds Potential- } \\
\text { Adverse-Effects } \\
\text { Limit }\end{array}$ \\
\hline 100 & 0.60 & 3,600 & No & No \\
150 & 0.49 & $-2,700$ & No & No \\
250 & 0.33 & 2,700 & No & No \\
305 & 0.28 & 2,700 & No & No \\
350 & 0.24 & 2,700 & No & No \\
368 & 0.23 & 2,700 & No & No \\
450 & 0.20 & 2,400 & No & No \\
550 & 0.16 & 2,400 & No & No \\
650 & 0.14 & 2,100 & No & No \\
750 & 0.13 & 2,100 & No & No \\
805 & 0.13 & 1,800 & No & No \\
840 & 0.13 & 1,800 & No & No \\
850 & 0.13 & 1,800 & No & No \\
920 & 0.61 & 60 & No & No \\
1,210 & 1.5 & 60 & No & No \\
1,350 & 3.3 & 60 & No & No \\
1,450 & 4.4 & 60 & No & No \\
2,414 & 6.0 & 60 & No & Yes \\
4,023 & 3.5 & 60 & No & No \\
5,632 & 1.6 & 60 & No & No \\
7,241 & 0.99 & 60 & No & No \\
12,068 & 0.26 & 1,500 & No & No \\
\hline & & & & \\
\hline
\end{tabular}

a Class D stability with $4-\mathrm{m} / \mathrm{s}$ wind speed.

For the five release scenarios discussed in this report, the maximum distance at which health effects criteria are exceeded is about $70 \mathrm{~m}$; however, for the potential-adverse-effects criteria, concentrations are exceeded up to almost $10 \mathrm{~km}$ for scenarios T1 and T2 with F stability. For $\mathrm{D}$ stability, the potential-adverse-effects criteria are not exceeded beyond $100 \mathrm{~m}$ except for scenarios $\mathrm{T} 1$ and $\mathrm{T} 2$, where the health criteria for HF are exceeded at distances in excess of $2,700 \mathrm{~m}$.

Detailed data on centerline concentration and exposure for scenarios $\mathrm{T} 2$ to $\mathrm{T} 5$ are provided in Appendix C. 
TABLE 10 Downwind Centerline Concentrations for $\mathrm{UO}_{2} \mathrm{~F}_{2}$ for Scenario $\mathrm{T} 1$ with D4 Stability

\begin{tabular}{ccccc}
\hline $\begin{array}{c}\text { Downwind } \\
\text { Distance }(\mathrm{m})\end{array}$ & $\begin{array}{c}\text { Concentration } \\
\left(\mathrm{mg} / \mathrm{m}^{3}\right)\end{array}$ & $\begin{array}{c}\text { Averaging } \\
\text { Time }(\mathrm{s})\end{array}$ & $\begin{array}{c}\text { Exceeds Potential- } \\
\text { Irreversible-Adverse- } \\
\text { Effects Limit }\end{array}$ & $\begin{array}{c}\text { Exceeds Potential- } \\
\text { Adverse-Effects } \\
\text { Limit }\end{array}$ \\
\hline 100 & 2.3 & 3,600 & No & No \\
150 & 1.6 & $-3,600$ & No & No \\
250 & 1.1 & 3,600 & No & No \\
305 & 0.91 & 3,600 & No & No \\
350 & 0.80 & 3,600 & No & No \\
368 & 0.76 & 3,600 & No & No \\
450 & 0.61 & 3,600 & No & No \\
550 & 0.48 & 3,600 & No & No \\
650 & 0.39 & 3,600 & No & No \\
750 & 0.35 & 3,600 & No & No \\
805 & 0.33 & 3,600 & No & No \\
840 & 0.32 & 3,600 & No & No \\
850 & 0.32 & 3,600 & No & No \\
920 & 0.32 & 3,600 & No & No \\
1,210 & 0.54 & 3,600 & No & No \\
1,350 & 0.77 & 3,600 & No & No \\
1,450 & 0.92 & 3,600 & No & No \\
2,414 & 1.3 & 3,600 & No & No \\
4,023 & 0.97 & 3,600 & No & No \\
5,632 & 0.68 & 3,600 & No & No \\
7,241 & 0.55 & 3,600 & No & No \\
12,068 & 0.48 & 3,600 & No & No \\
\hline & & & & \\
\hline
\end{tabular}

a Class D stability with $4-\mathrm{m} / \mathrm{s}$ wind speed. 
TABLE 11 Distance to the Maximally Exposed Individual (MED) and Concentration at That Distance for the Five Accident Scenarios with D and F Stability

\begin{tabular}{lrrrrr}
\hline & \multicolumn{2}{c}{ D Stability } & & \multicolumn{2}{c}{ F Stability } \\
\cline { 2 - 3 } \cline { 5 - 6 } & $\begin{array}{c}\text { MEI } \\
\text { Distance } \\
\text { Scenario }\end{array}$ & $\begin{array}{c}\text { Maximum } \\
\text { Concentration } \\
\left(\mathrm{mg} / \mathrm{m}^{3}\right)\end{array}$ & & $\begin{array}{c}\text { MEI } \\
\text { Distance } \\
(\mathrm{m})\end{array}$ & $\begin{array}{c}\text { Maximum } \\
\text { Concentration } \\
\left(\mathrm{mg} / \mathrm{m}^{3}\right)\end{array}$ \\
\hline T1a & 30 & 36 & & 30 & 130 \\
T1b & 30 & 520 & & 30 & 2,000 \\
T2a & 30 & 92 & & 30 & 180 \\
T2b & 30 & 1,400 & & 30 & 2,700 \\
T3a & 30 & 13 & & 30 & 43 \\
T3b & 30 & 180 & & 30 & 660 \\
T4a & 30 & 34 & & 30 & 60 \\
T4b & 30 & 490 & & 30 & 930 \\
T5a & 12,377 & $9.8 \times 10^{-4}$ & & $>20,000$ & 0 \\
T5b & 12,168 & $4.6 \times 10^{-4}$ & & $>20,000$ & 0 \\
\hline
\end{tabular}

TABLE 12 Total Area and the Maximum Distance for Which Concentration Exceeds Potential-Irreversible-Adverse-Effects Criterion for the Five Accident Scenarios with D and F Stability

\begin{tabular}{|c|c|c|c|c|}
\hline \multirow[b]{2}{*}{ Scenario } & \multicolumn{2}{|c|}{ D Stability } & \multicolumn{2}{|c|}{ F Stability } \\
\hline & $\begin{array}{c}\text { Total } \\
\text { Exposed } \\
\text { Area } \\
\left(\mathrm{m}^{2}\right)\end{array}$ & $\begin{array}{l}\text { Maximum } \\
\text { Distance } \\
(\mathrm{m})\end{array}$ & $\begin{array}{c}\text { Total } \\
\text { Exposed } \\
\text { Area } \\
\left(\mathrm{m}^{2}\right)\end{array}$ & $\begin{array}{c}\text { Maximum } \\
\text { Distance } \\
\text { (m) }\end{array}$ \\
\hline T1a & 810 & 35 & 1,500 & 43 \\
\hline $\mathrm{T} 1 \mathrm{~b}$ & 1,700 & 45 & 2,600 & 56 \\
\hline $\mathrm{T} 2 \mathrm{a}$ & 1,500 & 43 & 2,200 & 54 \\
\hline $\mathrm{T} 2 \mathrm{~b}$ & 2,700 & 55 & 3,800 & 69 \\
\hline T3a & 170 & 22 & 910 & 37 \\
\hline $\mathrm{T} 3 \mathrm{~b}$ & 1,100 & 41 & 2,000 & 51 \\
\hline $\mathrm{T} 4 \mathrm{a}$ & 780 & 35 & 1,300 & 42 \\
\hline $\mathrm{T} 4 \mathrm{~b}$ & 1,800 & 49 & 2,900 & 59 \\
\hline T5a & 0 & 0 & 0 & 0 \\
\hline $\mathrm{T} 5 \mathrm{~b}$ & 0 & 0 & 0 & 0 \\
\hline
\end{tabular}


TABLE 13 Total Area and the Maximum Distance for Which Concentration Exceeds Potential-Adverse-Effects Criterion for the Five Accident Scenarios with D and F Stability

\begin{tabular}{lrrrrr}
\hline & \multicolumn{2}{c}{ D Stability } & & \multicolumn{2}{c}{ F Stability } \\
\cline { 2 - 3 } \cline { 5 - 6 } & $\begin{array}{c}\text { Total } \\
\text { Exposed } \\
\text { Srea }\left(\mathrm{m}^{2}\right)\end{array}$ & $\begin{array}{c}\text { Maximum } \\
\text { Distance } \\
(\mathrm{m})\end{array}$ & & $\begin{array}{c}\text { Total } \\
\text { Exposed } \\
\text { Area }\left(\mathrm{m}^{2}\right)\end{array}$ & $\begin{array}{r}\text { Maximum } \\
\text { Distance } \\
(\mathrm{m})\end{array}$ \\
\hline T1a & 1,400 & 43 & & $3.6 \times 10^{6}$ & 7,400 \\
T1b & 190,000 & 2,800 & & $1.0 \times 10^{7}$ & 9,900 \\
T2a & 2,300 & 54 & & $2.1 \times 10^{6}$ & 6,100 \\
T2b & 33,000 & 2,900 & & $8.1 \times 10^{6}$ & 9,200 \\
T3a & 790 & 37 & & 1,500 & 43 \\
T3b & 2,000 & 54 & & $1.1 \times 10^{6}$ & 4,000 \\
T4a & 1,400 & 44 & & 2,200 & 54 \\
T4b & 2,900 & 62 & & 320,000 & 2,500 \\
T5a & 0 & 0 & & 0 & 0 \\
T5b & 0 & 0 & & 0 & 0 \\
\hline
\end{tabular}




\section{REFERENCES}

AICHE: See American Institute of Chemical Engineers.

AIHA: See American Industrial Hygiene Association.

American Industrial Hygiene Association, 1996, The AIHA 1996 Emergency Response Planning Guidelines and Workable Environmental Exposure Level Guides Handbook, Fairfax, Va.

American Institute of Chemical Engineers, 1994, Guidelines for Evaluating the Characteristics of Vapor Cloud Explosions, Flash Fires and BLEVE's, Center for Chemical Process Safety, New York, N.Y.

Bjorklund, J.R., et al., 1996, Open Burn/Open Detonation Dispersion Model (OBODM) User's Guide: Volume 2, Technical Description, DPG-TG-96-008b, U.S. Army Dugway Proving Ground, West Desert Test Center, Dugway, Utah.

Briggs, G.A., 1984, "Plume Rise and Buoyancy Effects," in Atmospheric Science and Power Production, D. Randerson (editor), DOE/TIC-27601, U.S. Department of Commerce, National Oceanic and Atmospheric Administration, Weather Service Nuclear Support Office, Las Vegas, Nev., pp. 327-366.

Brown, D.F., 1997, An Improved Methodology for Characterizing Atmospheric Boundary Layer Turbulence and Dispersion, Ph.D. thesis, University of Illinois, Urbana, Ill.

Csanady, G.T., 1973, Turbulent Diffusion in the Environment, D. Reidel Publishing Co., Boston, Mass.

Deardorff, J.W., and G.E. Willis, 1985, "Further Results from a Laboratory Model of the Convective Planetary Boundary Layer," Boundary-Layer Meteorology 32:205-236.

De Baas, A.F., et al., 1986, “An Application of the Langevin Equation for Inhomogeneous Conditions to Dispersion in a Convective Boundary Layer," Quarterly Journal of the Royal Meteorological Society 112:165-180.

Draxler, R.R., 1976, "Determination of Atmospheric Diffusion Parameters," Atmospheric Environment 10:99-105.

Hanna, S.R., and R.J. Paine, 1989, "Hybrid Plume Dispersion Model (HDPM) Development and Evaluation," Journal of Applied Meteorology 28:206-224. 
Horst, T.W., et al., 1979, Evaluation of Empirical Atmospheric Diffusion Data, PNL-2955, Batelle Pacific Northwest Laboratory, Richmond, Wash.

Kaimal, J.C., and J.J. Finnigan, 1994, Atmospheric Boundary Layer Flows, Oxford University Press, New York, N.Y.

Legg, B.J., and M.R. Raupach, 1982, "Markov-Chain Simulation of Particle Dispersion in Inhomogeneous Flows: The Mean Drift Velocity Induced by a Gradient in Eulerian Velocity Variance," Boundary-Layer Meteorology 24:3-13.

Ley, A.J., 1982, "A Random Walk Simulation of Two-Dimensional Turbulent Diffusion in the Neutral Surface Layer,” Atmospheric Environment 16:2799-2808.

Ley, A.J., and D.J. Thomson, 1983, "A Random Walk Model of Dispersion in the Diabatic Surface Layer," Quarterly Journal of the Royal Meteorological Society 109:847-880.

Liljegren, J.C., 1989, The Atterbury-87 Field Study of Smoke Dispersion and a New Stochastic Dispersion Model, Ph.D. thesis, Department of Mechanical Engineering, University of Illinois, Urbana, Ill.

Lombardi, D.A., 1996, Design and Analysis Calculation: Dispersion Analysis for Accidental UF 6 Releases for the K-25 Site, DAC-19045-CCA-84, Lockheed Martin Energy Systems, Oak Ridge, Tenn.

McGuire, S.A., 1991, Chemical Toxicity of Uranium Hexafluoride Compared to Acute Effects of Radiation, Final Report, NUREG-1391, U.S. Nuclear Regulatory Commission, Office of Nuclear Regulatory Research, Washington, D.C., Feb.

Morton, B.R., et al., 1956, "Turbulent Gravitational Convection from Maintained and Instantaneous Sources," Proceedings of the Royal Society of London A234:1-23.

Nieuwstadt, F.T.M., 1984, "The Turbulent Structure of the Stable, Nocturnal Boundary Layer," Journal of the Atmospheric Sciences 41:2202-2216.

Reid, J.D., 1979, "Markov Chain Simulations of Vertical Dispersion in the Neutral Surface Layer for Surface and Elevated Releases," Boundary-Layer Meteorology 16:3-22.

Scorer, R.S., 1978, Environmental Aerodynamics, Halsted Press, New York, N.Y.

Thomson, D.J., 1984, "Random Walk Modelling of Diffusion in Inhomogeneous Turbulence," Quarterly Journal of the Royal Meteorological Society 110:1107-1120. 
Thomson, D.J., 1987, "Criteria for the Selection of Stochastic Models of Particle Trajectories in Turbulent Flows," Journal of Fluid Mechanics 180:529-556.

Turner, D.B., 1969, Workbook of Atmospheric Dispersion Estimates, AP-26, U.S. Environmental Protection Agency, Office of Air Programs, Washington, D.C.

van Dop, H., et al., 1985, "Random Walk Models for Particle Displacements in Homogeneous Unsteady Turbulent Flows," Physical Fluids 28:1639-1653.

Venkatram, A., 1988, "Vertical Dispersion of Ground-Level Releases in the Surface Boundary Layer," Atmospheric Environment 26A:947-949.

Weil, J.C., 1982, "Source Buoyancy Effects in Boundary Layer Diffusion," in Workshop on the Parameterization of Mixed Layer Diffusion, R. Cionco (editor), New Mexico State University, Physical Sciences Laboratory, Las Cruces, N.M.

Weil, J.C., 1988, "Plume Rise," in Lectures on Air Pollution Modeling, A. Venkatram and J.C. Wyngaard (editors), American Meteorological Society, Boston, Mass., pp. 119-157.

Williams, W.R., and J.C. Anderson, 1996, UF ${ }_{6}$ Cylinder Accident Simulations ( $1475^{\circ} \mathrm{F}$ Regulatory Fire), DAC-EA-710660-A010 (draft), Lockheed Martin Energy Systems, Inc., Oak Ridge, Tenn.

Willis, G.E., and J.W. Deardorff, 1974, "A Laboratory Model of the Unstable Planetary Boundary Layer," Journal of the Atmospheric Sciences 31:1297-1307.

Wilson, D.J., 1991, "Accounting for Peak Concentrations in Atmospheric Dispersion for Worst Case Hazard Assessments," in Proceedings of the International Conference and Workshop on Modeling and Mitigating the Consequences of Accidental Releases of Hazardous Materials, May 20-24, 1991, New Orleans, Louisiana, American Institute of Chemical Engineers, New York, N.Y.

Wilson, J.D., et al, 1983, "Calculation of Particle Trajectories in the Presence of a Gradient in Turbulent Velocity Variance," Boundary-Layer Meteorology 27:163-169. 
APPENDIX A:

\section{CALCULATION OF LAGRANGIAN PARTICLE TRAJECTORIES IN THE ATMOSPHERIC BOUNDARY LAYER}


A-2 


\section{APPENDIX A:}

\section{CALCULATION OF LAGRANGIAN PARTICLE TRAJECTORIES IN THE ATMOSPHERIC BOUNDARY LAYER}

In this appendix, we outline the calculation of Lagrangian particle trajectories in the Monte Carlo Lagrangian Dispersion Model. This discussion is broken into two sections. The first describes the Langevin model for particle motion, and the second discusses turbulence statistics of the atmospheric boundary layer used within the model.

\section{A.1 THE LANGEVIN MODEL FOR PARTICLE MOTION}

The one-dimensional Langevin equation was presented in Equation 1 in the main text of this report. Extending the discrete Langevin model to two dimensions, the $\mathrm{u}$ and $\mathrm{w}$ velocity equations become:

$$
\mathrm{u}(\mathrm{t}+\Delta t)=\left(1-\frac{\Delta \mathrm{t}}{\mathrm{T}_{\mathrm{Lu}}}\right) \mathrm{u}(\mathrm{t})+\mu_{\mathrm{u}}
$$

and

$$
\mathrm{w}(\mathrm{t}+\Delta t)=\left(1-\frac{\Delta \mathrm{t}}{\mathrm{T}_{\mathrm{Lw}}}\right) \mathrm{w}(\mathrm{t})+\mu_{\mathrm{w}}
$$

where $u$ and $w$ are the horizontal and vertical particle velocities, and $T_{L u}$ and $T_{L w}$ are their respective Lagrangian time scales. Here we have two random forcing functions $\mu_{\mathrm{u}}$ and $\mu_{\mathrm{w}}$, which are related through the velocity covariance $\overrightarrow{\mathrm{uw}}$. From their respective velocities, the particle positions are simply provided by the forward difference equation:

$$
\begin{aligned}
& \mathrm{x}(\mathrm{t}+\Delta t)=\mathrm{x}(\mathrm{t})+\Delta t \mathrm{u}(\mathrm{t}+\Delta \mathrm{t}) \\
& \mathrm{z}(\mathrm{t}+\Delta t)=\mathrm{z}(\mathrm{t})+\Delta t \mathrm{w}(\mathrm{t}+\Delta \mathrm{t})
\end{aligned}
$$

The random forcing function $\mu$ is specified using the moment generating function of Thomson (1984). Considering two-dimensional dispersion in horizontally homogeneous conditions, moments of $\mu$ become

$$
\begin{aligned}
& <\mu_{\mathrm{u}}>=\Delta \mathrm{t} \frac{\partial \overline{\mathrm{uw}}}{\partial \mathrm{z}}, \\
& <\mu_{\mathrm{w}}>=\Delta \mathrm{t} \frac{\partial \overline{w w}}{\partial \mathrm{z}},
\end{aligned}
$$




$$
\begin{gathered}
<\mu_{\mathrm{u}}^{2}>=2 \Delta \mathrm{t} \mathrm{T}_{\mathrm{u}} \overline{\mathrm{uu}}, \\
<\mu_{\mathrm{w}}^{2}>=\Delta \mathrm{t}\left(2 \mathrm{~T}_{\mathrm{w}} \overline{\mathrm{ww}}+\frac{\partial \overline{w w w}}{\partial \mathrm{z}}\right), \\
<\mu_{\mathrm{u}} \mu_{\mathrm{w}}>=\Delta \mathrm{t}\left(\mathrm{T}_{\mathrm{u}}+\mathrm{T}_{\mathrm{w}}\right) \overline{\mathrm{uw}}, \\
<\mu_{\mathrm{u}}^{3}>=-3 \Delta \mathrm{t} \overline{\mathrm{uu}} \frac{\partial \overline{\mathrm{uw}}}{\partial \mathrm{z}},
\end{gathered}
$$

and

$$
<\mu_{\mathrm{w}}^{3}>=\Delta \mathrm{t}\left(3 \overline{\mathrm{www}} \mathrm{T}_{\mathrm{w}}-3 \overline{\mathrm{ww}} \frac{\partial \overline{\mathrm{ww}}}{\partial \mathrm{z}}+\frac{\partial \overline{\mathrm{wwww}}}{\partial \mathrm{z}}\right)
$$

where $T_{u}=1 / T_{L u}$, and $T_{w}=1 / T_{L w}$. Here we have neglected terms containing $\overline{u u u}, \overline{u u w}$, $\overline{u w w}$, and all fourth-order moments except wwww.

For all cases considered in this report, 50,000 particles are used. Initially, each particle is randomly assigned a horizontal and vertical velocity based on the Eulerian statistics at the source. From the source, particles are tracked until they leave the domain (farthest downwind distance of interest). During the simulation, the time scale for each particle is continually adjusted such that it lies between 0.05 and $0.025 \mathrm{~T}_{\mathrm{Lw}}$. Reflection boundary conditions are imposed at the ground and the boundary layer height. However, particles almost never reach the ground, since the vertical velocity variances and Lagrangian time scales $\rightarrow 0$ as $\mathrm{z} \rightarrow 0$. Concentrations are determined directly from the transition probabilities by considering the amount of time particles spend within discrete volume elements. Additional details on the numerical implementation and concentration estimation are contained in Brown (1997).

\section{A.2 ATMOSPHERIC TURBULENCE STATISTICS}

In simulating particle trajectories, the Monte Carlo model uses Eulerian atmospheric statistics to simulate Lagrangian particle trajectories according to the equations in the previous section. Eulerian atmospheric statistics used in the Monte Carlo model include the vertical distributions of (1) the first four moments of the vertical velocity, (2) the first two of the horizontal velocity, and (3) the peak frequencies for horizontal and vertical fluctuations. These required statistics are obtained from relations and data in the literature and are discussed in the following sections.

\section{A.2.1 Lagrangian Time Scale Relationships}

For application of our Monte Carlo model, the Lagrangian time scale is the parameter most difficult to estimate. Indeed, defining general relationships between Lagrangian and Eulerian reference frames is one of the most daunting problems in dispersion research as a whole, since 
dispersion is clearly a Lagrangian process, yet available turbulence data are almost always Eulerian. Fortunately, research into this problem has uncovered strong relationships between Eulerian and Lagrangian time and length scales, allowing the Lagrangian time scale to be estimated from Eulerian properties.

Measurements within the atmospheric boundary layer (ABL), most notably those of Gifford (1955) and Hay and Pasquill (1959), have demonstrated a distinct relationship between the Lagrangian and Eulerian spectra. In short, the Lagrangian spectra were similar in shape to their Eulerian counterparts but were shifted to lower frequencies. This observation is in accordance with Taylor's (1938) well-known "frozen eddy" hypothesis, which states that the spatial turbulence structure remains unchanged, or frozen, as it is advected past a fixed point by the local mean wind. Employing these arguments, Gifford (1955) proposed a simple relationship between the Eulerian and Lagrangian integral time scales,

$$
\mathrm{T}_{\mathrm{L}}=\beta \mathrm{T}_{\mathrm{E}}
$$

where $T_{L}$ and $T_{E}$ are the Lagrangian and Eulerian integral time scales, and $\beta$ is a scaling parameter. Here $\beta$ is inversely proportional to the turbulence intensity, such that

$$
\beta=\gamma \frac{\mathrm{U}}{\sigma_{\mathrm{i}}},
$$

where $\gamma$ is a proportionality constant, generally accepted to be around 0.7 (Hanna 1981).

With this relation, we write the Lagrangian integral time scale as a function of the peak wavelength $\lambda$, such that

$$
\mathrm{T}_{\mathrm{L}}=\beta \mathrm{T}_{\mathrm{E}}=\frac{\beta \lambda_{\mathrm{i}}}{2 \pi \mathrm{U}}=\frac{\gamma \lambda_{\mathrm{i}}}{2 \pi \sigma_{\mathrm{i}}} .
$$

For $T_{L}$ of the horizontal velocity fluctuations, we use $\gamma=0.68$. However, for vertical velocity fluctuations, a value of $\gamma=0.68$ leads to underestimation of the vertical dispersion and, thus, an overestimation of ground-level concentrations from a ground-level source. For the convective boundary layer (CBL), De Baas et al. (1986) and Liljegren (1989) have reported that $\gamma$ for $\mathrm{T}_{\mathrm{Lw}}$ must be set to around 2 to more closely agree with dispersion characteristics reported by Willis and Deardorff (1974) and observed surface-layer concentrations from Project Prairie Grass. Such a value is certainly reasonable, since it provides that the Lagrangian time scale near the middle of the convective mixed layer is roughly the convective time scale $\mathrm{z}_{\mathrm{i}} / \mathrm{w}_{*}$.

In neutral and stable conditions, we also found that setting $\gamma=2$ provides closer agreement of both ground-level concentrations and plume heights between the Monte Carlo model and data from Project Prairie Grass (Barad 1958). 


\section{A.2.2 Vertical Velocity Moments and Length Scales}

\section{A.2.2.1 Velocity Variances}

In the CBL, the vertical velocity variance $\sigma_{\mathrm{w}}$ scales with $\mathrm{u}_{*}$ in the surface layer. Above the surface layer, the scaling velocity becomes the convective velocity scale $\mathrm{w}_{*}$. When $\mathrm{z}_{\mathrm{i}} /|\mathrm{L}|>10$, there exists a matching layer between these regions where neither the surface nor the top of the boundary layer (the inversion) exerts influence. Here both the vertical velocity variance and also the corresponding time scales scale as $z^{1 / 3}$.

Observations of $\sigma_{\mathrm{w}}$ within the surface layer have shown the vertical velocity variance may be conveniently specified by interpolating between the neutral limit of $\sigma_{\mathrm{w}}=1.25 \mathrm{u}_{*}$ and the free convective limit of $\sigma_{\mathrm{w}} \sim \mathrm{z}^{1 / 3}$. In analysis of data from the Minnesota experiments and a variety of low-flying aircraft data, Panofsky et al. (1977) have suggested that

$$
\sigma_{\mathrm{w}}=1.25 \mathrm{u}_{*}\left(1-3 \frac{\mathrm{z}}{\mathrm{L}}\right)^{1 / 3} .
$$

Within the mixed layer, $\sigma_{\mathrm{w}}$ has been parameterized empirically by several workers. Except for slight overprediction of the maximum values, the general expression for the vertical velocity variance as proposed by Lenschow and Stephens (1980), namely,

$$
\sigma_{\mathrm{w}}=1.34 \mathrm{w}_{*}\left(\frac{z}{z_{i}}\right)^{1 / 3}\left(1-0.8 \frac{z}{z_{i}}\right),
$$

fits the available mixed-layer $\sigma_{\mathrm{w}}$ data most closely. In the Monte Carlo model, we must pass smoothly from the surface layer to the convective mixed layer, since a discontinuity in $\sigma_{w}$ is not allowed in light of the random forcing relations. Here we employ a combined equation,

$$
\sigma_{\mathrm{w}}=1.25 \mathrm{u}_{*}\left(1-3 \frac{z}{L}\right)^{1 / 3}\left(1-0.8 \frac{z}{z_{i}}\right)
$$

which is applicable for the entire boundary layer above the canopy. In Figure A.1, this relation is shown in comparison with data from (1) the Minnesota experiments (Caughey et al. 1979), (2) aircraft data of Lenschow and Stephens (1980), (3) water tank data of Adrian et al. (1986), and (4) data from Willis and Deardorff (1974).

The preceding relation is considered valid for conditions where a clearly defined surface layer and mixed layer exist $\left(\mathrm{z}_{\mathrm{i}} /|\mathrm{L}|>10\right)$. When the boundary layer becomes less unstable (i.e., $\mathrm{z}_{\mathrm{i}} / \mathrm{ILL}<10$ ), we consider the boundary layer to be near-neutral. Obviously, significant convection can still exist within the near-neutral ABL. However, the scaling within the boundary layer becomes less well defined, since the surface layer extends into the mixed layer, creating a region where both $\mathrm{u}_{*}$ and $\mathrm{w}_{*}$ are scaling parameters. 


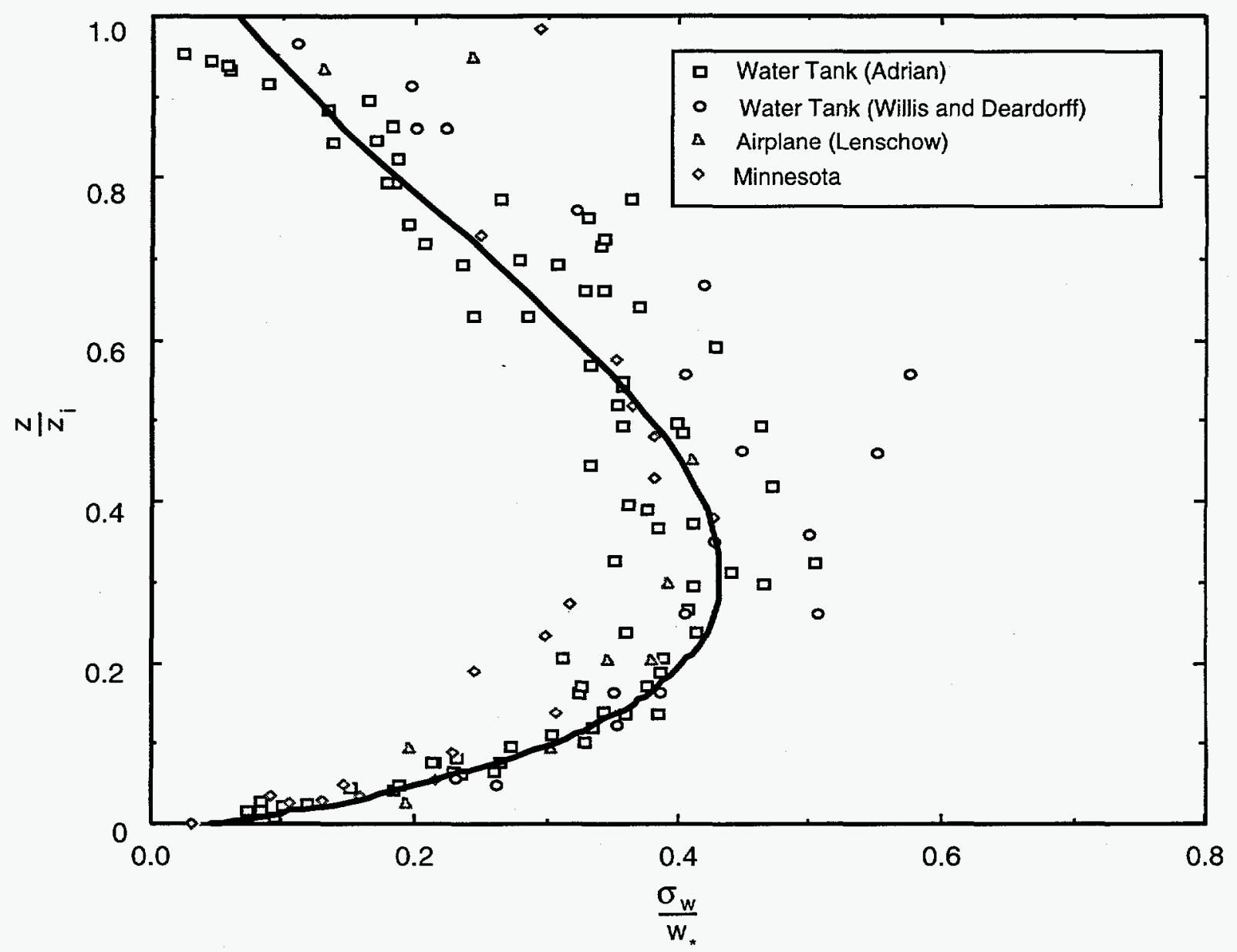

FIGURE A.1 Standard Deviation of the Vertical Velocity Fluctuations as Given by Equation A.18, Shown in Comparison with Data from Water Tank Studies (Adrian et al. 1986; Willis and Deardorff 1974) and ABL Studies (Lenschow and Stephens 1980) 
No general theory exists for scaling the near-neutral ABL. This is undoubtedly linked to the lack of observational data from neutral and near-neutral boundary layers. The available data useful for our concerns include the computational experiments of Wyngaard et al. (1974) and Deardorff (1972) and observational studies of the marine ABL by Nicholls and Readings (1979).

We shall start our discussion by defining $\sigma_{\mathrm{w}}$ for the neutral boundary layer (NBL). Based on results from the second-order model study of the neutral ABL by Wyngaard et al. (1974), Hanna (1984) suggests that

$$
\sigma_{\mathrm{wn}}=1.3 \exp \left(-\frac{2 \mathrm{fz}}{\mathrm{u}_{*}}\right)
$$

Here we have changed the leading constant to 1.25 to conform with the convective boundary-layer relation and other observations within the neutral boundary layer. For the near-neutral ABL, a reasonable scaling choice is an interpolation between surface-layer and convective effects. Thus, for $-10<-\mathrm{z}_{\mathrm{i}} /|\mathrm{L}|<0$, we define $\sigma_{\mathrm{w}}$ using the cubic interpolation formula,

$$
\sigma_{\mathrm{w}}=\left(\sigma_{\mathrm{wn}}^{3}+\sigma_{\mathrm{wc}}^{3}\right)^{1 / 3}
$$

where $\sigma_{\mathrm{wc}}$ is defined according to Equation A.16. A comparison of this relation with $\sigma_{\mathrm{w}}$ data from the second-order turbulence model of Wyngaard et al. (1974), the large-eddy simulation model of Deardorff (1972), and observations of marine boundary layers (Nicholls and Readings 1979) is shown in Figure A.2. The agreement between the interpolation formula and the numerical modeling results is very good. The agreement between the actual observations and the interpolation formula is not quite as good but is still reasonable in light of the uncertainties in both the $\sigma_{\mathrm{w}}$ data and the estimation procedures for $z_{i}$ and $L$ employed by Nicholls and Readings (1979). Part of this discrepancy is undoubtedly due to the comparison of marine-boundary-layer turbulent statistics to those modeled over land. The most obvious artifact of this comparison is the lower value of $\sigma_{\mathrm{w}} / \mathrm{u}_{*}$ at the surface that occurs over water. Additionally, the boundary layers investigated by Nicholls and Readings (1979) were cloud-topped in several cases. In such boundary layers, convection is often driven by radiative cooling of the cloud deck, not heating of the ground, and consequently the governing heat flux parameters are defined at the top of the CBL. Observations from such boundary layers show that the $\sigma_{\mathrm{w}}$ profile shape as suggested by Equation A.17 is inverted in the mixed layer, with the maximum vertical velocity variance occurring around $0.8 \mathrm{z}_{\mathrm{i}}$ (Nicholls 1989). The inclusion of such cases may have affected the data of Nicholls and Readings (1979), in both the maximum $\sigma_{\mathrm{W}}$ and its location within the boundary layer.

Under stable conditions, the behavior of $\sigma_{\mathrm{w}}$ and of other turbulence statistics is less well characterized than in convective conditions. This is largely due to the lack of a solid scaling framework for turbulence in the stable boundary layer (SBL); this lack, in turn, is associated with a rather limited array of experimental data. Two principal problems afflict experimental studies of 
$\circ \quad \overline{\mathrm{z}_{\mathrm{i}} / \mathrm{LL}}=0.9$; stability range $\left.0.5<\mathrm{z}_{\mathrm{i}} / \mathrm{LL}<1.3\right\}$ Marine boundary layer observations

व $\left.\quad \frac{\mathrm{Z}_{\mathrm{i}} / \mathrm{ILI}}{=3.9 ; \text { stability range } 1.6<\mathrm{Z}_{\mathrm{i}} / \mathrm{ILI}<7.3}\right\}$ (Nicholls and Readings, 1979)

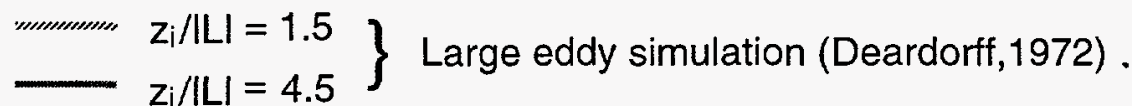

- $\mathrm{z}_{\mathrm{i}} / \mathrm{LLI}=10:$ Second-order closure model (Wyngaard,1974)

Eq. (A.19) forzi $/ L I=0,2,4,6,8$ and 10

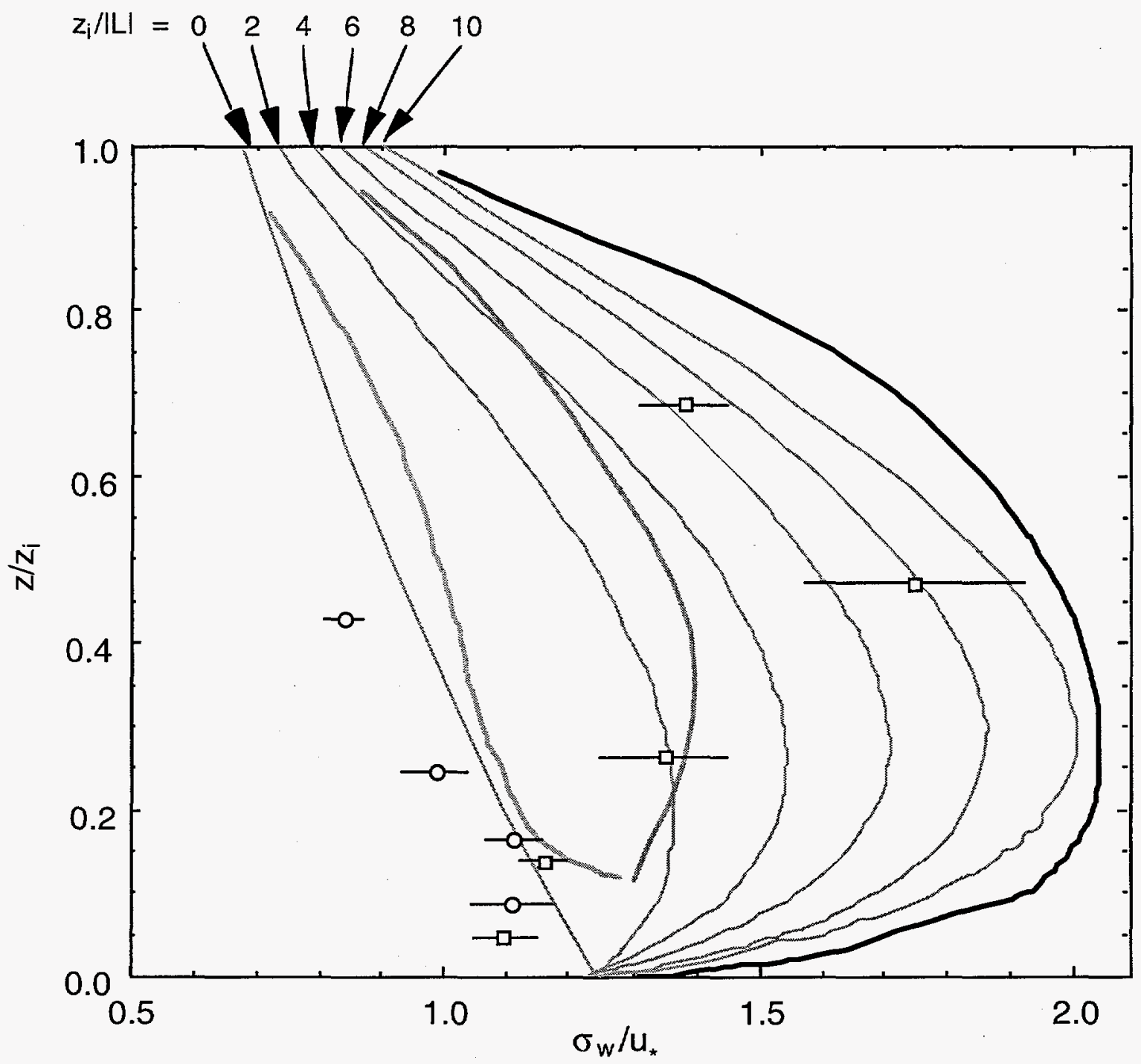

FIGURE A.2 Comparison of the Interpolation Formula (Equation A.19) with Both Numerical and Actual Vertical Velocity Standard Deviation Data from Near-Neutral Boundary Layers. (Data points for the marine boundary layer observations represent averages over the range of stabilities presented in the legend. The error bars corresponding to these points represent standard deviations of averaged data.) 
SBL turbulence. The first is that the turbulence intensities are very low, so that noise in the data becomes a significant source of uncertainty. The second is that the SBL is very sensitive to subtle terrain undulations and inhomogeneous surface characteristics. Thus, experimental data obtained at different sites are often different in character and, therefore, not easily collapsed with universal relationships.

Despite these problems, simple scaling relationships based on the boundary layer height have proven very useful in representing SBL turbulence data, although little theoretical guidance for the appropriate functional forms exists. An example of this boundary-layer-height scaling is shown in Figure A.3 using $\sigma_{\mathrm{w}}$ data from Minnesota (Caughey et al. 1979), Cabauw (Nieuwstadt 1984), and Oklahoma (Lenschow et al. 1988). An empirical relationship that we employ in the Monte Carlo model which adequately represents these data is

$$
\sigma_{\mathrm{w}}=1.25 \mathrm{u}_{*}\left(1-\left(\frac{\mathrm{z}}{\mathrm{h}}\right)^{2}\right)
$$

which is also shown in Figure A.3. We note that this relationship is similar in nature to those proposed by Caughey et al. (1979), Nieuwstadt (1984), and Lenschow et al. (1988) in their respective data analyses.

It is important to highlight the reasons that our empirical expression, Equation A.20, approaches the limit, $\sigma_{\mathrm{W}} \rightarrow 1.25 \mathrm{u}_{*}$ as $\mathrm{z} \rightarrow 0$, whereas the data suggest that $\sigma_{\mathrm{w}} \rightarrow 1.50 \mathrm{u}_{*}$ as $\mathrm{z} \rightarrow 0$. Here, we have chosen to obey Monin-Obukhov similarity scaling rather than merely fitting the observational data for $z \rightarrow 0$. The Monin-Obukhov similarity hypothesis states that

$$
\sigma_{\mathrm{w}}=\mathrm{C}_{1} \mathrm{u}_{*} \phi(\mathrm{z} / \mathrm{L})
$$

where $C_{1}$ is a constant, and $\phi(z / L)$ is a universal function of $z / L$. Clearly, if the Monin-Obukhov theory applies, statistics from the neutral boundary layer should be similar to those in the CBL and SBL for $\mathrm{z} / \mathrm{LL} \ll 1$. Data for the near-neutral boundary layer from various field studies as catalogued by Panofsky and Dutton (1984) indicate that the surface-layer $\sigma_{\mathrm{w}}$ values are proportional to $\mathrm{u}_{*}$ such that

$$
\sigma_{\mathrm{w}}=\mathrm{u}_{*}(1.25 \pm 0.03), \quad \mathrm{z} / \mathrm{L} \rightarrow 0
$$

Observational data from the CBL for $\mathrm{z} \ll \mathrm{L}$ generally agree with this near-neutral boundary layer relationship (e.g., see Equation A.15). In contrast, data from the SBL as shown above imply that $\sigma_{\mathrm{w}} \rightarrow 1.5 \mathrm{u}_{*}$ as $\mathrm{z} / \mathrm{L} \rightarrow 0$.

We believe that these discrepancies are an artifact of uncertainties in $\sigma_{\mathrm{w}}$ and $\mathrm{u}_{*}$ observations rather than a true representation of the turbulent state of the SBL. Observations of $\sigma_{\mathrm{w}} / \mathrm{u}_{*}$ in the SBL represent the ratios of two small numbers, each of which contains rather large uncertainties. 


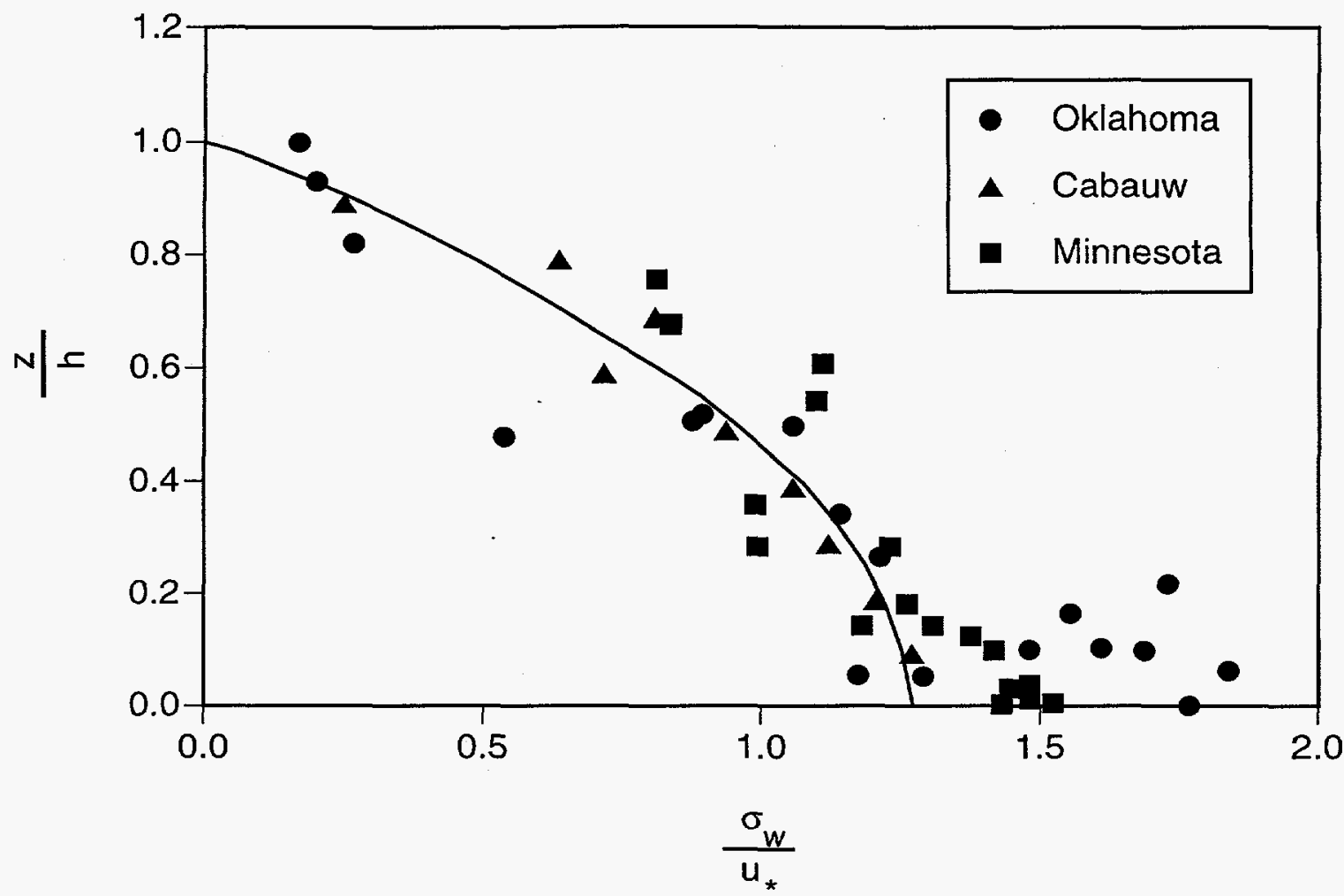

FIGURE A.3 Standard Deviation of Vertical Velocity Fluctuations as Given by Equation A.20, Shown in Comparison with Data from Minnesota (Caughey et al. 1979), Cabauw (Nieuwstadt 1984), and Oklahoma (Lenschow et al. 1988)

Furthermore, uncertainties in $\mathrm{u}_{*}$ generally exceed those of $\sigma_{\mathrm{w}}$, causing a substantial bias toward higher values for the ratio $\sigma_{w} / u_{*}$ (Merry and Panofsky 1976). An example of this bias can be seen in a simple test. Consider 100 hypothetical observations of $\sigma_{\mathrm{W}}$ and $\mathrm{u}_{*}$ with respective means of 0.125 and 0.10 and standard deviations of 0.03 and 0.015 . Clearly, $\left\langle\sigma_{\mathrm{w}}\right\rangle \mid\left\langle u_{*}\right\rangle=1.25$, where $<>$ represents an ensemble average of the observations. However, if we average the ratio, we see that $\left\langle\sigma_{\mathrm{w}} / \mathrm{u}_{*}\right\rangle \approx 1.45$. It is our belief that data from Minnesota, Oklahoma, and, to a lesser extent, Cabauw suffer similar problems. For instance, the Minnesota data represent $75-\mathrm{min}$ averages in evolving stable layers, leading to considerable uncertainty in turbulence properties. The Oklahoma data, which provide the highest estimates of $\sigma_{\mathrm{w}} / \mathrm{u}_{*}$, are the most uncertainty-prone, since the $\sigma_{\mathrm{w}}$ and $\mathrm{u}_{*}$ were obtained from $20-\mathrm{km}$ airplane flights in semitransitional conditions.

It is interesting to point out a particular study where this effect is clearly pronounced. Upon evaluation with near-surface data (i.e., 2-10 m), Merry and Panofsky (1976) suggested that $\sigma_{\mathrm{w}} / \mathrm{u}_{*} \rightarrow 1.3 \mathrm{u}_{*}$ as $\mathrm{z} / \mathrm{L} \rightarrow 0$ and that $\sigma_{\mathrm{w}} / \mathrm{u}_{*}$ actually increases with increasing $\mathrm{z} / \mathrm{L}$, such that

$$
\sigma_{\mathrm{w}}=1.3 \mathrm{u}_{*}\left(\phi_{\mathrm{m}}(\mathrm{z} / \mathrm{L})-2.5 \mathrm{z} / \mathrm{L}\right)^{1 / 3}
$$


Clearly, this is not a physical effect, since $\sigma_{\mathrm{w}}$ profile observations from Minnesota, Cabauw, and Project Prairie Grass clearly show $\sigma_{\mathrm{w}} / \mathrm{u}_{*}$ decreasing with height. We believe the answer to this apparent paradox lies in the bias as discussed above. Note that Merry and Panofsky (1976) only employed near-surface $(<10 \mathrm{~m})$ observations. Therefore, larger $\mathrm{z} / \mathrm{L}$ values are indicative of higher stabilities (i.e., lower values of $L$ ) rather than higher elevations. Since turbulence intensities are generally inversely proportional to stability at night, it is only natural that the ratio $\left\langle\sigma_{\mathrm{w}} / \mathrm{u}_{*}\right\rangle$ increases with stability, since values of $\mathrm{u}_{*}$ and $\sigma_{\mathrm{w}}$ are more uncertain as $\mathrm{L}$ decreases.

\section{A.2.2.2 Higher Order Moments}

Vertical velocity fluctuations in the CBL are markedly non-Gaussian due to the distribution of updrafts and downdrafts within the boundary layer. Generally, updrafts consist of small regions of intense upward vertical motion and are surrounded by larger regions of subsidence or downdrafts. This characteristic imparts a positive skewness in CBL vertical velocity measurements which must be accounted for in the particle motions. Here we use the relation of Bærentsen and Berkowicz (1984):

$$
\overline{\mathrm{www}}=0.8 \mathrm{w}_{*}^{3} \frac{\left(\mathrm{z} / \mathrm{z}_{\mathrm{i}}\right)\left(1-\mathrm{z} / \mathrm{z}_{\mathrm{i}}\right)}{1+0.667 \mathrm{z} / \mathrm{z}_{\mathrm{i}}} .
$$

This relation is compared with applicable laboratory and atmospheric data in Figure A.4. In the stable and neutral boundary layers, the turbulence is more homogeneous, and thus $\overline{w w w}$ is close to zero.

We also require fourth moments of the vertical velocity variations. Here, we follow De Baas et al. (1986) in invoking the Gaussian assumption:

$$
\overline{\mathrm{wwww}}=3 \sigma_{\mathrm{w}}^{4} .
$$

In comparison with the water tank data of Adrian et al. (1986), this relation has proven to be adequate for the CBL. Of course, in stable and neutral conditions, the applicability of Equation A.27 is quite sound due to the more homogeneous nature of the turbulence field.

\section{A.2.2.3 Peak Wavelengths}

From the ground to a height of about twice the surface-roughness elements or plant canopy, the peak wavelength for vertical velocity variations is roughly constant at a value of about $2 z_{\mathfrak{c}}$, where $z_{\mathfrak{c}}$ is the canopy height (Kaimal and Finnigan 1994). Above this level, $\lambda_{w}$ varies with 


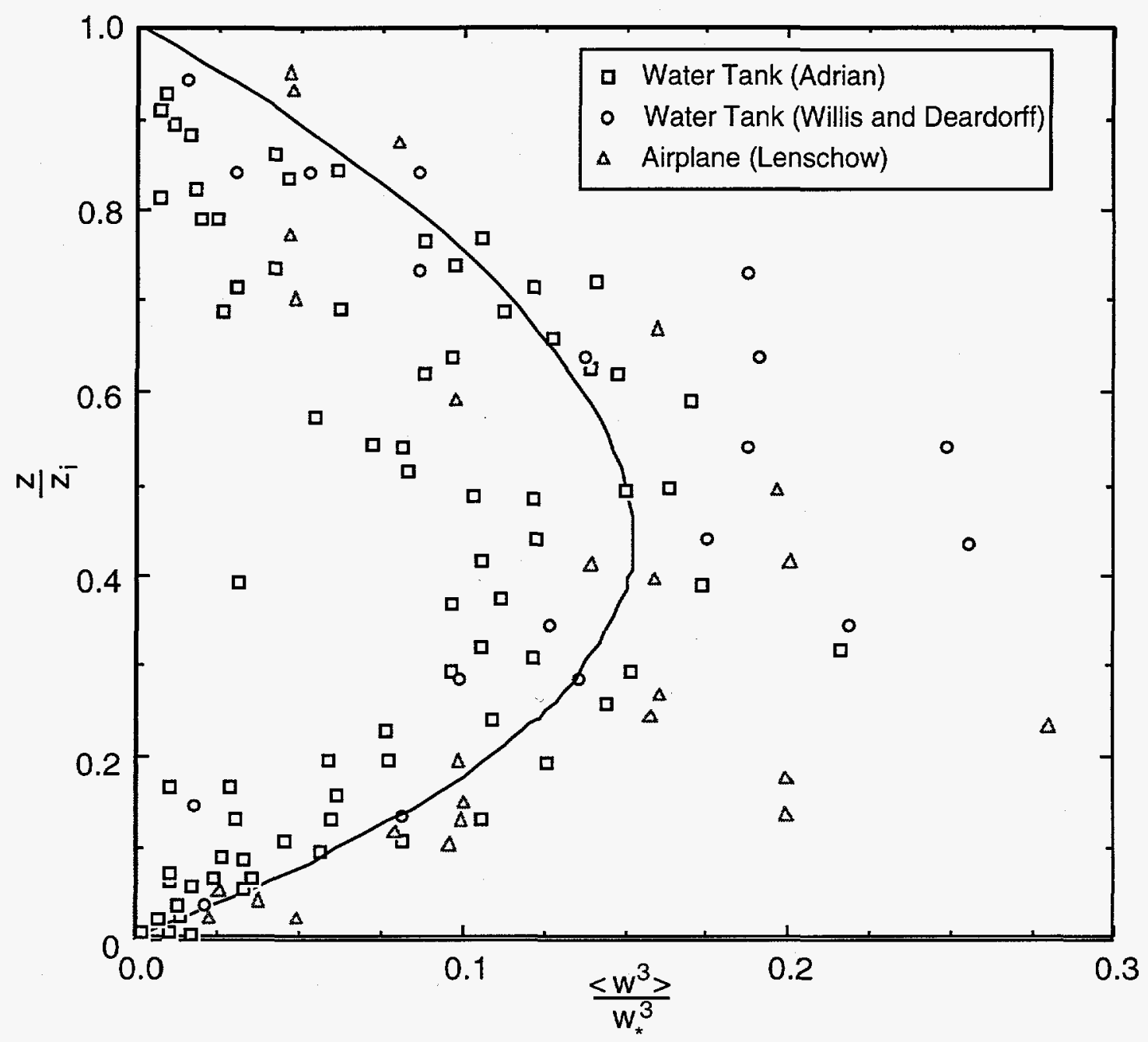

FIGURE A.4 Third-Order Vertical Velocity Moments as Given by Equation A.24, Shown in Comparison with Data from Water Tank Studies (Adrian et al. 1986; Willis and Deardorff 1974) and ABL Studies (Lenschow and Stephens 1980) 
height according to stability. For convective conditions, spectral data from the Minnesota experiments suggest $\lambda_{\mathrm{w}}$ varies (Kaimal et al. 1976; Caughey et al. 1979) as

$$
\lambda_{\mathrm{W}}= \begin{cases}\frac{\mathrm{z}}{0.55+0.38 \mathrm{z} / \mathrm{L}} & 2 \mathrm{zc}<\mathrm{z}<-\mathrm{L} \\ 5.9 \mathrm{z} & -\mathrm{L} \leq \mathrm{z} \leq 0.1 \mathrm{zi} \\ 1.8 \mathrm{z}_{\mathrm{i}}\left(1-\exp \left(-\frac{4 \mathrm{z}}{\mathrm{z}_{\mathrm{i}}}\right)-0.0003 \exp \left(-\frac{8 \mathrm{z}}{\mathrm{z}_{\mathrm{i}}}\right)\right) & 0.1 \mathrm{zi} \leq \mathrm{z} \leq \mathrm{zi}\end{cases}
$$

Here, $\lambda_{\mathrm{w}}$ increases quickly with height, first reaching the free convection limit between $-\mathrm{L}$ and $0.1 \mathrm{z}_{\mathrm{i}}$, and then approaching $1.5 \mathrm{z}_{\mathrm{i}}$ in the middle of the mixed layer. At heights above $0.8 \mathrm{z}_{\mathrm{i}}, \lambda_{\mathrm{w}}$ decreases substantially, since the turbulent energy shifts from the large convective eddies to smaller scales in the dissipative and shear regions of the inversion.

When neutral conditions are approached, considerable evidence suggests that large convective-type structures are present until $\mathrm{z}_{\mathrm{i}} / \mathrm{LL}$ is of order 1 (LeMone 1973; Nicholls and Readings 1979). As $\mathrm{z}_{\mathrm{i}} / \mathrm{LL}$ decreases from around 10 , the chaotic three-dimensional convective thermals give way to more-organized two-dimensional roll vortices which span the depth of the CBL (LeMone 1973). Such behavior indicates the peak wavelengths in the near-neutral boundary layer are similar to those in the fully convective boundary layer, even though the physical mechanisms are somewhat different and the turbulent energy is less intense. For $\mathrm{z}_{\mathrm{i}} / \mathrm{Ll}<10$, Equation A.26 is not fully applicable, however, since a free convective layer is not present. Here the surface shear layer and the convective layer overlap, and the scaling relationships are not clear. In the absence of other data, we apply the following general form based on the convective $\lambda_{w}$ :

$$
\lambda_{w}=\left\{\begin{array}{l}
\frac{z}{0.55+a z / L+b(z / L)^{2}} \\
1.8 z_{i}\left(1-\exp \left(-\frac{4 z}{z_{i}}\right)-0.0003 \exp \left(\frac{8 z}{z_{i}}\right)\right)
\end{array} \quad 2 z_{c} \leq z \leq z_{t}\right.
$$

where $\mathrm{a}$ and $\mathrm{b}$ are selected to match $\lambda_{\mathrm{w}}$ and $\mathrm{d} \lambda_{\mathrm{w}} / \mathrm{dz}$ at $\mathrm{z}_{\mathrm{t}}$, and $\mathrm{z}_{\mathrm{t}}$ is the minimum of $\mid \mathrm{Ll}$ and $0.5 \mathrm{z}_{\mathrm{i}}$. This functional form is consistent with the aforementioned observational evidence while allowing $\lambda_{\mathrm{w}}$ to approach the neutral limit $\left(\lambda_{\mathrm{w}}=\mathrm{z} / 0.55\right)$ as $\mathrm{L}$ becomes large. 
In stable conditions, $\lambda_{\mathrm{w}}$ data from both the Minnesota and Kansas experiments are adequately represented by Kaimal and Finnigan (1994):

$$
\lambda_{\mathrm{W}}= \begin{cases}\frac{\mathrm{z}}{0.55+\mathrm{z} / \mathrm{L}} & 2 \mathrm{z} c<\mathrm{z}<\mathrm{L} \\ \frac{\mathrm{z}}{1.1+0.45 \mathrm{z} / \mathrm{L}} & \mathrm{L} \leq \mathrm{z} \leq 2 \mathrm{~L} \\ \mathrm{~L} & \mathrm{z}>2 \mathrm{~L}\end{cases}
$$

This expression provides that for $\mathrm{z} / \mathrm{L} \ll<1, \lambda_{\mathrm{W}}$ is similar to its neutral values, whereas for heights above $2 \mathrm{~L}, \lambda_{\mathrm{W}}$ is constant, following the z-less stratification concept of Wyngaard et al. (1974). Data from Minnesota support the invariance of $\lambda_{\mathrm{w}}$ in the upper part of the SBL as predicted by Equation A.28, thus demonstrating its applicability for the whole depth of the SBL.

\section{A.2.3 Horizontal Velocity Moments and Length Scales}

\section{A.2.3.1 Wind Profile}

Neglecting Coriolis effects, the mean wind speed throughout the ABL is governed by the geostrophic wind speed, the surface roughness, and the sensible heat flux at the surface. Typically, however, the geostrophic wind speed is unknown. Thus, we estimate the wind profile in the Monte Carlo model using only surface characteristics. This will naturally lead to some errors in the wind profile form near the top of the boundary layer, since surface-based scaling relationships clearly do not apply in this region. However, these errors are assumed to be small and only manifest themselves in the concentration field at large downwind distances after the contaminant is well mixed into the boundary layers.

The horizontal wind profile is given by the similarity relation

$$
\mathrm{U}(\mathrm{z})=\frac{\mathrm{u} *}{\mathrm{k}}\left[\ln \frac{\mathrm{z}^{\prime}}{\mathrm{zo}}-\Psi_{\mathrm{m}}\left(\frac{\mathrm{z}^{\prime}}{\mathrm{L}}\right)+\Psi_{\mathrm{m}}\left(\frac{\mathrm{z}_{\mathrm{o}}}{\mathrm{L}}\right)\right],
$$

where $z^{\prime}=z-d, d$ is the displacement height, $z_{0}$ is the roughness length, $U(z)$ is the mean wind speed at height $\mathrm{z}$, and $\Psi_{\mathrm{m}}$ is the integrated stability function for momentum transfer. The displacement height represents the elevation to which the wind profile is displaced due to the 
presence of the canopy. Typically, $\mathrm{d}$ is $70-80 \%$ of the canopy height but may be substantially lower within sparse canopies. In unstable conditions, we use $\Psi_{\mathrm{m}}$ as provided by Dyer (1974),

$$
\Psi_{\mathrm{m}}(\mathrm{z})=\ln \left[\left(\frac{1+\mathrm{x}}{2}\right)^{2}\left(\frac{1+\mathrm{x}^{2}}{2}\right)\right]-2 \tan ^{-1}(\mathrm{x})+\frac{\pi}{2}
$$

where $x=\left(1-16 \frac{z^{\prime}}{L}\right)^{1 / 4}$.

Although this relation is only strictly valid for $z^{\prime}<-2 L$, we apply it for the full CBL. The profile given by Equation A.32 quickly asymptotes to a near-constant value providing, at least, good qualitative agreement with observational evidence (i.e., constant wind speeds in the mixed layer). Values at the boundary layer top are between $20 \%$ and $40 \%$ of those at $-2 \mathrm{~L}$, depending on stability and roughness length; thus, we expect errors in the profile magnitude to be less than $20 \%$ within the mixed layer.

For stable conditions, we use the wind profile relation of Holtslag and de Bruin (1988):

$$
\Psi_{m}=-0.7 \frac{z^{\prime}}{L}-0.75\left(\frac{z^{\prime}}{L}-14.29\right) \exp \left(-0.35 \frac{z^{\prime}}{L}\right)-10.71
$$

which is valid for $z^{\prime} / L<7$. The extended range of application of this relation deems it preferable to many previously proposed expressions for stable conditions. When $z^{\prime} / L$ is greater than 7 , the wind speed gradient becomes less than that predicted using Equation A.31 (Beljaars and Holtslag 1991). For these cases, we modify the wind speed profile to approach a constant as $z \rightarrow 0$, such that:

$$
\mathrm{U}(\mathrm{z})=\mathrm{U}(6 \mathrm{~L})-(\mathrm{U}(8 \mathrm{~L})-\mathrm{U}(6 \mathrm{~L}))\left[1-\exp \left(-\gamma\left(\mathrm{z}^{\prime}-6 \mathrm{~L}\right)\right)\right]
$$

where $\gamma=\frac{1}{U(8 L)-U(6 L)}\left(\frac{d U}{d z}\right)_{z=6 L}$

and $U(6 \mathrm{~L})$ and $U(8 \mathrm{~L})$ are the wind speeds at heights $6 \mathrm{~L}$ and $8 \mathrm{~L}$ as predicted using Equation A.31. This correction provides the behavior seen in stable wind profile data from Cabauw, as reported by Holtslag and de Bruin (1988) and Beljaars and Holtslag (1991).

\section{A.2.3.2 Velocity Variances and Higher Order Moments}

In unstable conditions, the horizontal velocity variance within the surface layer is well represented by the interpolation equation of Panofsky et al. (1977):

$$
\sigma_{\mathrm{u}}=\mathrm{u}_{*}\left(12-0.5 \frac{\mathrm{z}_{\mathrm{i}}}{\mathrm{L}}\right)^{1 / 3}
$$


which varies between a neutral value of $2.3 \mathrm{u}_{*}$ and a free convective value of $0.6 \mathrm{w}_{*}$. Often, this relation is used to describe the behavior of $\sigma_{\mathbf{u}}$ throughout the boundary layer even though considerable evidence exists that the $\sigma_{\mathrm{u}}$ does indeed vary somewhat with height. In neutral stability, little ABL data exist; however, second-order modeling results of Wyngaard et al. (1974) suggest an exponential behavior (Hanna 1984), such that

$$
\sigma_{\mathrm{u}}=2.28 \mathrm{u}_{*} \exp \left(-\frac{3 \mathrm{fz}}{\mathrm{u}_{*}}\right),
$$

where $\mathrm{f}$ is the Coriolis parameter. Here the leading coefficient has been adjusted from 2 to 2.28 to agree with the relation of Panofsky et al. (1977).

In the Monte Carlo model, we use a hybrid equation that combines both behaviors seen in neutral and free convective regimes. Here we define $\sigma_{\mathbf{u}}$ such that

$$
\sigma_{\mathrm{u}}=\mathrm{u} *\left(12 \exp \left(-\frac{9 \mathrm{fz}}{\mathrm{u}_{*}}\right)-0.5 \frac{\mathrm{z}_{\mathrm{i}}}{\mathrm{L}}\right)^{1 / 3}
$$

This relation provides the correct height-dependent behavior in convective conditions.

For stable conditions, data are less available than for convective conditions. Additionally, fundamental scaling relationships are not nearly as obvious. The principal problem is that the boundary layer height is less well defined. Generally, the boundary layer height $h$ is taken to be a height where turbulent energy drops to a very small fraction of its surface value. Based on this scale height, statistics in the stable boundary layer collapse surprisingly well. Within this scaling regime, $\sigma_{\mathrm{u}}$ is well represented by

$$
\sigma_{\mathrm{u}}=2.3 \mathrm{u}_{*}\left(1-\frac{\mathrm{z}}{\mathrm{h}}\right)
$$

This relation is compared with ABL data of Caughey et al. (1979), Nieuwstadt (1984), and Lenschow et al. (1988) in Figure A.5.

In all regions of the $\mathrm{ABL}$, except the canopy, $\overline{\mathrm{uuu}}$ is zero, since horizontal turbulence is close to Gaussian in nature (canopy turbulence will be discussed in Section A.6). Higher moments of $\mathrm{u}$ are not necessary in the Monte Carlo model. 


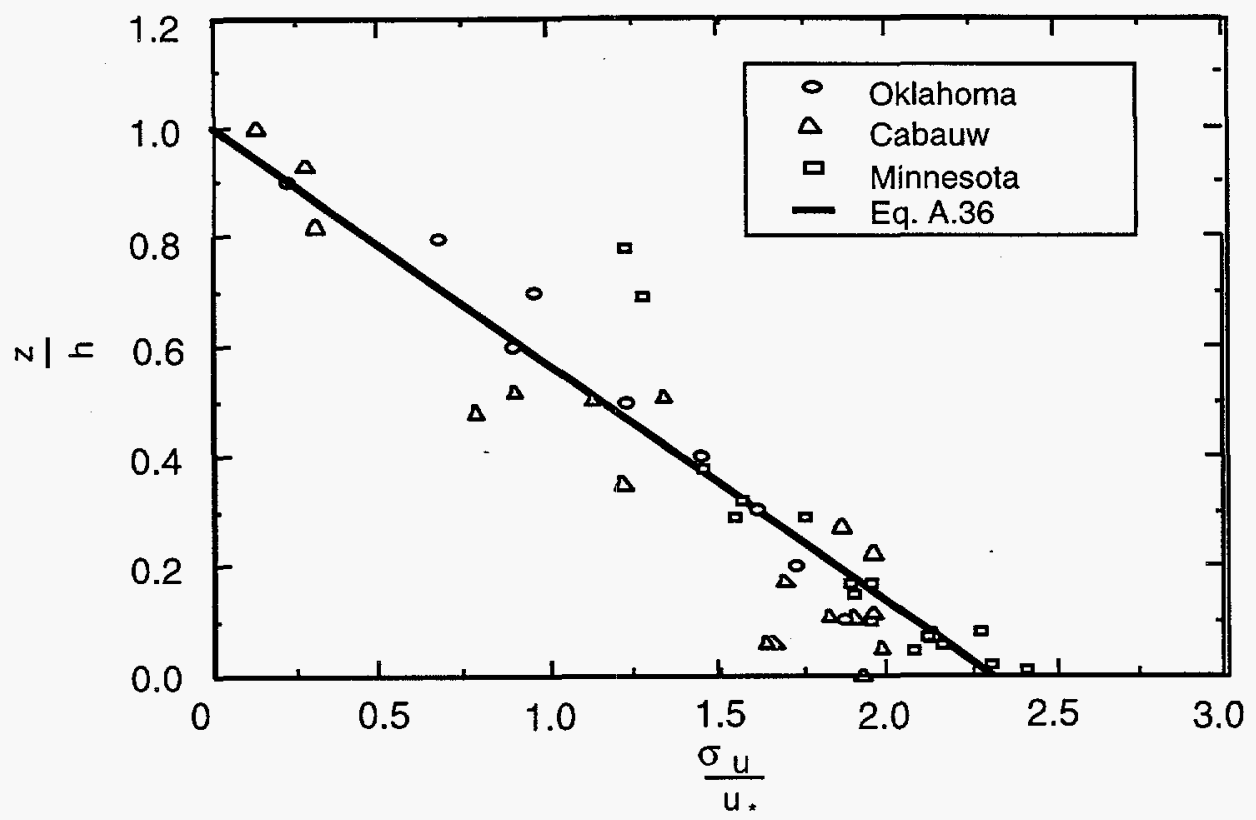

FIGURE A.5 Horizontal Velocity Variances as Given by Equation A.36, Shown in Comparison with Data from Minnesota (Caughey et al. 1979), Cabauw (Nieuwstadt 1984), and Oklahoma (Lenschow et al. 1988) 


\section{A.2.3.3 Peak Wavelengths}

Except for very near the surface, the peak wavelengths for horizontal velocity fluctuations $\lambda_{u}$ in convective conditions are governed by the large-scale convective motions. Data from the Minnesota experiments and the numerical simulations of Deardorff (1974) show that

$$
\lambda_{\mathrm{u}}=1.5 \mathrm{z}
$$

Within and immediately above the canopy, $\lambda_{\mathrm{u}}$ is roughly constant at $6.5 \mathrm{z}_{\mathrm{c}}$. Most likely, a sharp transition in $\lambda_{\mathrm{u}}$ exists between the near surface layer and the rest of the boundary layer. In the Monte Carlo model, this transition is smoothed such that $\lambda_{\mathrm{u}}$ rises linearly from $6.5 \mathrm{z}_{\mathrm{c}}$ to $1.5 \mathrm{z}_{\mathrm{i}}$ between the canopy and $0.01 \mathrm{z}_{\mathrm{i}}$. The details of this transition are not important, however, since substantial variations in $\lambda_{\mathrm{u}}$ have little impact on the resulting concentration fields.

In stable conditions, we use the relation

$$
\lambda_{\mathrm{u}}=4 \lambda_{\mathrm{w}}
$$

This relation reasonably captures the $\lambda_{\mathrm{u}}$ behavior seen in spectral data from the Kansas (Kaimal 1973) and Minnesota (Caughey et al. 1979) experiments.

\section{A.2.4 Covariances and Higher Order Cross Moments}

The $\overline{\mathrm{uw}}$ covariance is employed in the Monte Carlo model to properly correlate the horizontal and vertical particle velocities, although the sensitivity to this parameter is rather weak. In the $\mathrm{CBL}$, the covariance is generally assumed to decrease linearly with height such that

$$
\overline{\mathrm{uw}}=\mathrm{u}_{*}^{2}\left(1-\frac{\mathrm{z}}{\mathrm{z}_{\mathrm{i}}}\right)^{\eta}
$$

where $\eta=1$. This form is supported by the numerical modeling results of Wyngaard et al. (1974) and Deardorff (1972). However, observational evidence is in conflict with this assumption in some cases. In particular, turbulence data from the Minnesota experiments show a maximum in the $\overline{u w}$ profile within the lower to middle CBL. The reasons for this behavior are not fully understood, but Deardorff (1973) has postulated that entrainment of momentum at the inversion may play a role. Fortunately, material concentrations within the CBL are insensitive to the shape of the covariance profile. The maximum differences between predicted concentrations using a linear stress profile and a constant stress profile $(\eta=0)$ are only around $3 \%$.

Observational and numerical evidence shows stress variations with height in the stable and neutral boundary layers are described well using Equation A.39 with $\eta=1.5$ (Deardorff 1974; Caughey et al. 1979; Nieuwstadt 1984). Again, concentration estimates are not particularly 
sensitive to the exponent on Equation A.39 in near-neutral and stable conditions. In the Monte Carlo model, we use Equation A.39 with $\eta$ given by

$$
\eta= \begin{cases}1 & \mathrm{z}_{\mathrm{i}} / \mathrm{L}<-10 \\ 1.5+0.05 \mathrm{z}_{\mathrm{i}} / / \mathrm{Ll} & -10 \leq \mathrm{z}_{\mathrm{i}} / \mathrm{L} \leq 0 \\ 1.5 & \mathrm{z}_{\mathrm{i}} / \mathrm{L}>0\end{cases}
$$

In the Monte Carlo model, we neglect all higher order cross moments. Based on the general insensitivity to the exact formulation of $\overline{u w}$, this is very justifiable. Furthermore, the construction of the random variables governing the particle velocities is significantly more complex if third-order cross correlations are enforced.

\section{A.2.5 Canopy Turbulence Relations}

To estimate material concentrations in the lower surface layer, the lower boundary condition becomes very important. Other Monte Carlo studies of the CBL (De Baas et al. 1986; Liljegren 1989) have fixed velocity statistics constant below $\mathrm{z}<0.0025 \mathrm{z}_{\mathrm{i}}$ and imposed a reflection boundary condition at the ground. Such an approach is not only clearly unphysical but also strongly affects the near-ground concentrations, especially when near-surface releases are considered.

In the current Monte Carlo model, we provide a more physical lower boundary by constructing a canopy layer. In this region, the pertinent velocity statistics $u, \sigma_{u}, \sigma_{w}, \overline{w w w}$, and $\mathrm{T}_{\mathrm{L}}$ go from their above-canopy values to zero at the ground. Relations governing velocity statistics in the canopy layer have been developed from a multitude of wind-tunnel and field studies. Analysis of these studies has shown the remarkable collapse of turbulent statistics for an extremely wide range of canopy types and geometries using $z_{c}$ as the governing length scale and $u_{*}$ as the governing velocity scale (Raupach and Thom 1981; Brutsaert 1982; Kaimal and Finnigan 1994).

The wind profile through a canopy is theoretically derivable if one makes an assumption concerning either the mixing length or the diffusivity within the canopy. For instance, with a constant mixing length, an exponential wind profile is achieved, such that (Cionco 1965)

$$
\mathrm{u}(\mathrm{z})=\mathrm{u}\left(\mathrm{z}_{\mathrm{c}}\right) \exp \left(-\mathrm{a}_{1} \mathrm{z}^{\prime}\right)
$$


where $\mathrm{a}_{1}$ is a constant, and $\mathrm{z}^{\prime}=1-\mathrm{z} / \mathrm{z}_{\mathrm{c}}$. If one assumes that the diffusivity is constant throughout the canopy, the wind profile becomes

$$
u(z)=\frac{u\left(z_{c}\right)}{\left(1-a_{2} z^{\prime}\right)^{2}},
$$

where $a_{2}$ is a constant. In these relations, the constants $a_{1}$ and $a_{2}$ vary from about $1-4$, depending on plant types and density within the canopy.

An immediate observation about Equations A.43 and A.44 is that neither relation has $\mathrm{u}(\mathrm{z}) \rightarrow 0$ as $\mathrm{z} \rightarrow 0$. Indeed, such relations are typically employed only for upper and mid canopy regions. In the Monte Carlo model, we use a different approach. Here we fit the wind profile to the parabolic relation:

$$
u(z)=a_{3} z+a_{4} z^{2}
$$

where $a_{3}$ and $a_{4}$ are chosen to match the wind speed and wind gradient at a reference height $h_{0}$. To encompass a large array of possible canopy and terrain types, the reference height is chosen as the maximum of $1.75 \mathrm{~d}$ or $20 \mathrm{z}_{\mathrm{o}}$. The first limit applies for a regular uniform canopy in fairly flat terrain. The second limit applies in cases where either the terrain is not uniform, such that $z_{0}$ is based not on surface roughness but terrain undulations, or for uniform terrain whose surface is characterized by large, widely spaced roughness elements, such as suburban areas or fields with occasional large trees. The actual value of the limits in both cases represents the minimum heights for which the wind profile becomes logarithmic with height. A comparison of the wind profile fitting equation with canopy wind profile data reviewed by Kaimal and Finnigan (1994) is shown in Figure A.6.

The variances within the canopy are selected to agree qualitatively with the large variety of data reviewed by Kaimal and Finnigan (1994). These data include observations within cornfields (Shaw and Pereira 1974; Wilson et al. 1982) and several forest types (Denmead and Bradley 1987). The data were fit using the functional form:

$$
\sigma_{\mathrm{ij}}^{2}=\sigma_{\mathrm{fs}}^{2}\left(1-\exp \left(-2\left(\frac{\mathrm{z}}{\mathrm{z}_{\mathrm{c}}}\right)^{\mathrm{v}}\right)\right)
$$

where $\sigma$ is the variance in question, $\sigma_{\mathrm{fs}}$ is the free stream value of $\sigma$ (i.e., the value considerably above the canopy), and $u$ is a constant. Here $v=2$ for $\sigma_{w}, v=2.5$ for $\sigma_{u}$, and $v=4$ for $\sqrt{\overline{u w}}$.

The third-order velocity moments (or skewness) within plant canopies are markedly higher than their above-canopy values. This characteristic reflects the highly intermittent nature of canopy turbulence. Here the turbulence is dominated by infrequent but intense incursions, or gusts, of air into the canopy from above. This imparts large negative values of $\mathrm{Sk}_{\mathrm{W}}$ and large positive values of $\mathrm{Sk}_{\mathrm{u}}$ within the canopy. Much scatter exists in the observations reported in the literature (e.g., Maitani 1978; Raupach and Thom 1981; Raupach et al. 1986; and Baldocchi and Meyers 
1988). Generally, $-\mathrm{Sk}_{\mathrm{w}}$ and $\mathrm{Sk}_{\mathrm{u}}$ increase from 0 above the canopy to maximum values within the canopy and then decrease quickly to zero at the ground. The position and magnitude of the maximum skewness is largely dependent on the canopy structure and density. For instance, for fairly uniform canopies representing wheat or corn, skewnesses reach their maximum at $\mathrm{z} / \mathrm{z}_{\mathrm{c}}$ 0.5-0.7 with values of 0.6-0.8 for $\mathrm{Sk}_{\mathrm{W}}$ and 1.0 for $\mathrm{Sk}_{\mathrm{u}}$. The maximum skewnesses for forest canopies, on the other hand, occur near the canopy top (the crown region), with a secondary maximum occurring near the ground.

In the Monte Carlo model, we designate the skewness based upon the simpler uniformcanopy model. A functional form which matches the qualitative description of $\mathrm{Sk}_{\mathrm{W}}$ discussed in Kaimal and Finnigan (1994) is

$$
\mathrm{Sk}_{\mathrm{w}}=-2 \frac{\mathrm{z}}{\mathrm{z}_{\mathrm{c}}} \exp \left(-2\left(\frac{\mathrm{z}}{\mathrm{z}_{\mathrm{c}}}\right)^{2}\right) .
$$

As shown in Figure A.6, although $\mathrm{Sk}_{\mathrm{u}}$ is certainly of importance when discussing concentration fluctuations within the canopy, its importance is minimal for average concentrations outside of the canopy. Thus, for simplicity, we neglect $\mathrm{Sk}_{\mathrm{u}}$ within the canopy. 


\section{A-23}

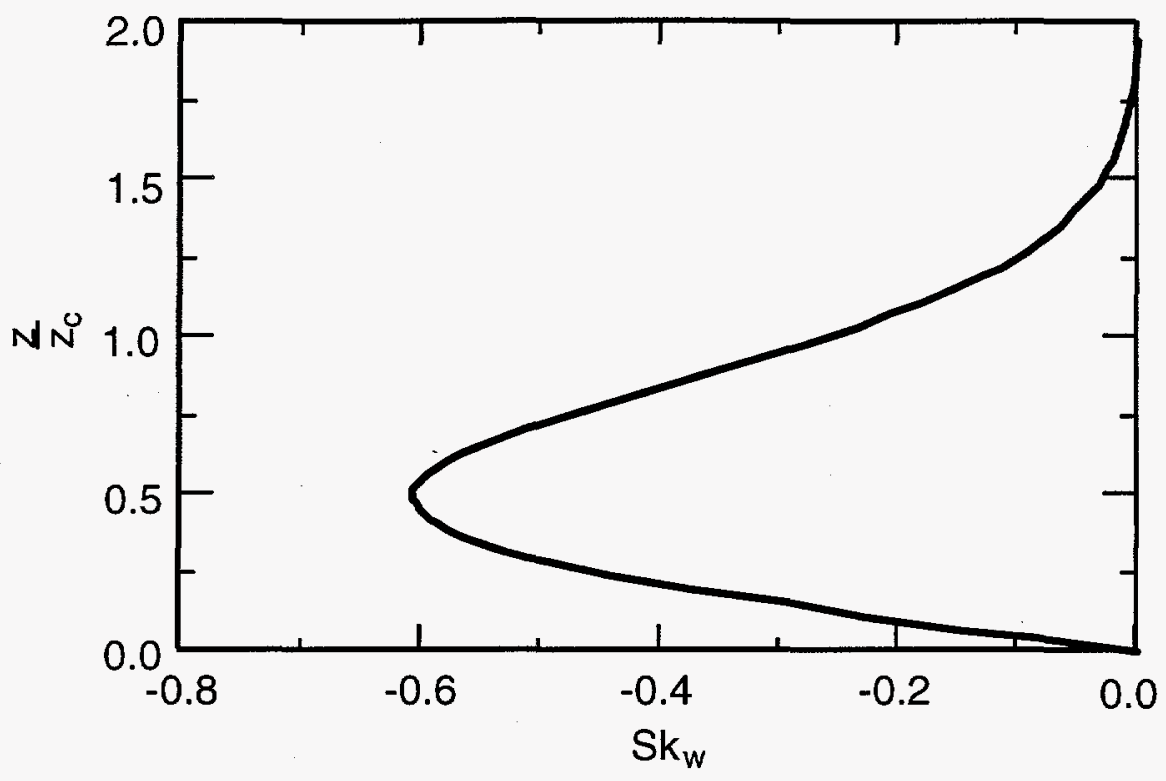

FIGURE A.6 Vertical Velocity Fluctuation Skewness within the Canopy as Provided by Equation A.45 


\section{A.3 REFERENCES}

Adrian, R.J., et al., 1986, "Turbulent Thermal Convection in Wide Horizontal Fluid Layers," Experiments in Fluids 4:121-141.

Bærentsen, J.H., and R. Berkowicz, 1984, "Monte Carlo Simulation of Plume Dispersion in the Convective Boundary Layer," Atmospheric Environment 18:701-712.

Baldocchi, D.D., and T.P. Meyers, 1988, "Turbulence Structure in a Deciduous Forest," Boundary-Layer Meteorology 43:345-364.

Barad, M.L. (editor), 1958, Project Prairie Grass: A Field Program in Diffusion, AD-152572 and AD-152573, vols. 1 and 2, Geophysical Research Papers No. 59, Air Force Cambridge Research Center.

Beljaars, A.C.M., and A.A.M. Holtslag, 1991, "Flux Parameterization over Land Surfaces for Atmospheric Models," Journal of Applied Meteorology 30:327-341.

Brown, D.F., 1997, An Improved Methodology for Characterizing Atmospheric Boundary Layer Turbulence and Dispersion, Ph.D. thesis, University of Illinois, Urbana, Ill.

Brutsaert, W., 1982, Evaporation into the Atmosphere, D. Reidel Publishing Co., Boston, Mass.

Caughey, S.J., et al., 1979, "Turbulence in the Evolving Stable Boundary Layer," Journal of the Atmospheric Sciences 36:1041-1052.

Cionco, R.M., 1965, “A Mathematical Model for Air Flow in a Vegetative Canopy," Journal of Applied Meteorology 4:517-522.

Deardorff, J.W., 1972, "Numerical Investigation of Neutral and Unstable Planetary Boundary Layers," Journal of the Atmospheric Sciences 29:91-115.

Deardorff, J.W., 1973, "An Explanation of Anomalously Large Reynolds Stresses within the Convective Planetary Boundary Layer," Journal of the Atmospheric Sciences 30:1070-1076.

Deardorff, J.W., 1974, "Three-Dimensional Numerical Study of the Height and Mean Structure of a Heated Planetary Boundary Layer," Boundary-Layer Meteorology 7:81-106.

De Baas, A.F., et al., 1986, "An Application of the Langevin Equation for Inhomogeneous Conditions to Dispersion in a Convective Boundary Layer," Quarterly Journal of the Royal Meteorological Society 112:165-180.

Denmead, O.T., and E.F. Bradley, 1987, “On Scalar Transport in Plant Canopies," Irrigation Science 9:131-149. 
Dyer, A.J., 1974, "A Review of Flux-Profile Relationships," Boundary-Layer Meteorology 7:363-372.

Gifford, F.A., 1955, "A Simultaneous Lagrangian-Eulerian Turbulence Experiment," Monthly Weather Review 83:293-301.

Hanna, S.R., 1981, "Lagrangian and Eulerian Time-Scale Relations in the Daytime Boundary Layer," Journal of Applied Meteorology 20:242-249.

Hanna, S.R., 1984, "Applications of Air Pollution Modeling," in Atmospheric Turbulence and Air Pollution Modeling, Nieuwstadt, F.T.M., and H. van Dop (editors), D. Reidel Publishing Co., Boston, Mass., pp. 275-311.

Hay, J.S., and F. Pasquill, 1959, "Diffusion from a Continuous Source in Relation to the Spectrum and Scale of Turbulence," Advances in Geophysics 6:345-365.

Holtslag, A.A.M., and H.A.R. de Bruin, 1988, "Applied Modeling of the Nighttime Surface Energy Balance over Land," Journal of Applied Meteorology 27:689-704.

Kaimal, J.C., 1973, "Turbulence Spectra, Length Scales and Structure Parameters in the Stable Surface Layer," Boundary-Layer Meteorology 4:289-309.

Kaimal, J.C., and J.J. Finnigan, 1994, Atmospheric Boundary Layer Flows, Oxford University Press, New York, N.Y.

Kaimal, J.C., et al., 1976, "Turbulence Structure in the Convective Boundary Layer," Journal of the Atmospheric Sciences 33:2152-2169.

LeMone, M.A., 1973, "The Structure and Dynamics of Horizontal Roll Vortices in the Planetary Boundary Layer," Journal of the Atmospheric Sciences 30:1077-1091.

Lenschow, D.H., and P.L. Stephens, 1980, "The Role of Thermals in the Convective Boundary Layer," Boundary-Layer Meteorology 19:509-532.

Lenschow, D.H., et al., 1988, "The Stably Stratified Boundary Layer over the Great Plains," Boundary-Layer Meteorology 42:95-121.

Liljegren, J.C., 1989, The Atterbury-87 Field Study of Smoke Dispersion and a New Stochastic Dispersion Model, Ph.D. thesis, Department of Mechanical Engineering, University of Illinois, Urbana, Ill.

Maitani, T., 1978, "On the Downward Transport of Turbulent Kinetic Energy in the Surface Layer over Plant Canopies," Boundary-Layer Meteorology 14:571-584.

Merry, M., and H.A. Panofsky, 1976, "Statistics of Vertical Motion over Land and Water," Quarterly Journal of the Royal Meteorological Society 102:255-260. 
Nicholls, S., 1989, "The Structure of Radiatively Driven Convection in Stratocumulus," Quarterly Journal of the Royal Meteorological Society 115:487-511.

Nicholls, S., and C.J. Readings, 1979, "Aircraft Observations of the Structure of the Lower Boundary Layer over the Sea," Quarterly Journal of the Royal Meteorological Society 105:785802 .

Nieuwstadt, F.T.M., 1984, "The Turbulent Structure of the Stable, Nocturnal Boundary Layer," Journal of the Atmospheric Sciences 41:2202-2216.

Panofsky, H.A., and J.A. Dutton, 1984, Atmospheric Turbulence: Models and Methods of Engineering Applications, John Wiley and Sons, New York, N.Y.

Panofsky, H.A., et al., 1977, "The Characteristics of Turbulent Velocity Components in the Surface Layer under Convection Conditions," Boundary-Layer Meteorology 11:355-361.

Raupach, M.R., and A.S. Thom, 1981, "Turbulence in and above Plant Canopies," Annual Review of Fluid Mechanics 13:97-129.

Raupach, M.R., et al., 1986, "Experiments on Scalar Dispersions within a Model Plant Canopy: Part I. The Turbulence Structure," Boundary-Layer Meteorology 35:21-52.

Shaw, R.H., et al., 1974, "Some Observations of Turbulence and Turbulence Transport within and above Plant Canopies," Boundary-Layer Meteorology 5:429-440.

Shaw, R.H., and A.R. Pereira, 1982, "Aerodynamic Roughness of a Plant Canopy: A Numerical Experiment,” Agricultural Meteorology 26:51-65.

Taylor, G.I., 1938, "The Spectrum of Turbulence," Proceedings of the Royal Society 164:476490.

Thomson, D.J., 1984, "Random Walk Modelling of Diffusion in Inhomogeneous Turbulence," Quarterly Journal of the Royal Meteorological Society 110:1107-1120.

Thomson, D.J., 1987, "Criteria for the Selection of Stochastic Models of Particle Trajectories in Turbulent Flows," Journal of Fluid Mechanics 180:529-556.

Willis, G.E., and J.W. Deardorff, 1974, "A Laboratory Model of the Unstable Planetary Boundary Layer," Journal of the Atmospheric Sciences 31:1297-1307.

Wilson, J.D., et al., 1982, "Statistics of Atmospheric Turbulence within and above a Corn Canopy," Boundary-Layer Meteorology 24:495-519.

Wyngaard, J.C., et al., 1974, "Modeling of the Atmospheric Boundary Layer," Advances in Geophysics 18A:193-212. 


\section{$B-1$}

APPENDIX B:

PLUME AND THERMAL RISE RELATIONSHIPS USED IN FIREPLUME 


$$
\text { B-2 }
$$




\section{APPENDIX B:}

\section{PLUME AND THERMAL RISE RELATIONSHIPS USED IN FIREPLUME}

This appendix outlines the plume and thermal rise relationships used within the FIREPLUME model. Section B.1 reviews plume rise relationships, and Section B.2 reviews thermal rise relationships.

\section{B.1 FIRE PLUMES}

\section{B.1.1 Rise Relationships}

The initial momentum of a fire plume is insignificant in comparison with the plume buoyancy. Therefore, we use the Briggs two-thirds law to model fire plume rise. Although the Briggs relationship is primarily used for stack emissions, its extension to fire buoyancy is straightforward. Expressed in terms of the Froude number and the velocity ratio $K$, and including virtual source effects (see Bjorklund et al. [1996] for a discussion of virtual source effects), the Briggs two-thirds law reads

$$
\Delta z=\left[\frac{3 r_{o}}{4 \beta^{2} F^{2} K^{3}} x^{2}+\left(\frac{r_{o}}{\beta}\right)^{3}\right]^{1 / 3}-\frac{r_{o}}{\beta},
$$

where

$$
\begin{aligned}
\Delta z & =\text { plume rise }(\mathrm{m}) \\
x & =\text { downwind distance }(\mathrm{m}), \\
r_{o} & =\text { fire radius }(\mathrm{m}) \\
K & =\text { velocity ratio } \frac{U}{w_{o}} \\
U & =10-\mathrm{m} \text { wind speed }(\mathrm{m} / \mathrm{s}), \\
\beta & =\text { entrainment coefficient }(\beta=0.6),
\end{aligned}
$$


$F=$ Froude number $=w_{o}\left(\frac{\Delta \rho}{\rho_{a}} 2 r_{o} g\right)^{-1 / 2}$,

$w_{o}=$ initial vertical velocity (calculated from $F, \Delta \rho$, and $\left.r_{o}\right)(\mathrm{m} / \mathrm{s})$,

$\Delta \rho=$ initial density difference $=\rho_{a}-\rho_{f}\left(\mathrm{~kg} / \mathrm{m}^{3}\right)$ (note that $\left.\Delta \rho / \rho_{a} \sim \Delta T / T_{f}\right)$,

$\rho_{a}=$ ambient density $\left(\mathrm{kg} / \mathrm{m}^{3}\right)$, and

$T_{f}=$ fire temperature $(\mathrm{K})$

Equation B.1 is used to predict fire plume rise in both stable and unstable conditions; however, in stable conditions, Equation B.1 is not strictly correct. The more correct formulation in stable conditions is

$$
\Delta z=\left\{\frac{3 r_{o} U^{2}}{2 \beta F^{2} K^{3}}\left[1-\cos \left(\frac{N x}{U}\right)\right]+\left(\frac{r_{o}}{\beta}\right)^{3}\right\}^{1 / 3}-\frac{r_{o}}{\beta}, \quad \frac{N x}{U}<\pi,
$$

where $N$, the Brunt Vasaila frequency, is given by

$$
N=\left(\frac{g}{\theta} \frac{\partial \theta}{\partial z}\right)^{1 / 2}
$$

By expansion of the cosine term, Equation B.2 clearly reduces to the Briggs two-thirds law close to the source. For longer travel times, the principal difference between Equation B.2 and the Briggs two-thirds law is the overshoot of plumes past their equilibrium value predicted by Equation B.2. This overshoot is such that the equilibrium plume height is about $84 \%$ of the maximum plume height. For practical applications, however, the plume overshoot is of minor significance in predicting near-surface concentrations as long as the final rise is properly estimated. Therefore, for simplicity and computational convenience, the Briggs two-thirds law is employed for all conditions.

\section{B.1.2 Limiting Plume Rise}

Because of the effects of entrainment into the plume and thermal stratification of the atmosphere, the rise of the fire plume is limited. For stable conditions, the limiting rise is governed 
by thermal stratification. On the basis of a survey of field data, Briggs (1984) suggests that the final rise in stably stratified air is (in terms of $F$ and $K$ )

$$
\Delta z_{f}=2.1\left(\frac{r_{o} U^{2}}{K^{3} F^{2} N^{2}}\right)^{1 / 3}
$$

where $\Delta z_{f}$ is the final rise (m), and $\dot{N}$ is the Brunt Vasaila frequency defined previously in Equation B.3.

For neutral conditions, ambient turbulence, rather than thermal stratification, limits the rise by breaking up the plume. The final rise in this case is the level at which the internal turbulent dissipation rate of the plume matches the ambient turbulent dissipation rate. Equating these quantities, Briggs (1984) specifies the final rise as

$$
\Delta z_{f}=0.76\left(\frac{r_{o} U^{2}}{u_{*}^{2} K^{3} F^{2}}\right),
$$

where $u_{*}$ is the friction velocity $(\mathrm{m} / \mathrm{s})$.

In unstable conditions, plume rise is also limited by turbulence. Here, however, the turbulent dissipation of the downdrafts is equated with the plume dissipation rate because downdrafts are responsible for bringing elevated material to ground level. Under this premise, Briggs (1989) and Weil (1988) suggest that

$$
\Delta z_{f}=4.5\left(\frac{r_{o} U^{2} z_{i}^{2}}{4 F^{2} K^{3} w_{*}^{2}}\right)^{3 / 5},
$$

where $z_{i}$ is the inversion height $(\mathrm{m})$, and $w_{*}$ is the convective velocity scale $(\mathrm{m} / \mathrm{s})$.

Because truly neutral boundary layers are rare, the neutral plume rise serves as a limiting case within our framework. In practice, we use the lesser of the stable or unstable final rise estimate (whichever is applicable) and the neutral estimate. Therefore, in unstable conditions, the final rise is given by

$$
\Delta z_{f}=\min \left[\Delta z _ { f } \left(\text { Eq. B.6), } \Delta z_{f}(\text { Eq. B.5)] ; }\right.\right.
$$


whereas for stable conditions,

$$
\Delta z_{f}=\min \left[\Delta z _ { f } \left(\text { Eq. B.4), } \Delta z_{f}(\text { Eq. B.5)] }\right.\right.
$$

\section{B.2 BUOYANT THERMALS}

\section{B.2.1 Rise Relationships}

On the basis of a variety of laboratory data, Morton et al. (1956) and Scorer (1978) estimate the rise of a buoyant thermal as

$$
\Delta z=2.35 F_{T}^{1 / 4} t^{1 / 2}
$$

where

$$
\begin{aligned}
t & =\text { time }(\mathrm{s}) \\
F_{T} & =\text { initial buoyancy of thermal }=g V_{i} \frac{\Delta \rho}{\rho_{a}}\left(\mathrm{~m}^{4} / \mathrm{s}^{2}\right), \text { and } \\
V_{i} & =\text { initial volume of thermal }\left(\mathrm{m}^{3}\right)
\end{aligned}
$$

Incorporating virtual source effects (Bjorklund et al. 1996), Equation B.9 becomes

$$
\Delta z=\left[30.5 F_{T} t^{2}+\left(\frac{r_{o}}{\beta}\right)^{4}\right]^{1 / 4}-\frac{r_{o}}{\beta},
$$

where $\beta$ is an entrainment coefficient taken as 0.25 .

Note that for cases in which the buoyant thermal has initial momentum such as that provided by an explosive force, the thermal rise can be related to the initial buoyancy of the thermal, such that (Weil 1982)

$$
\Delta z=2.35 F_{T}^{1 / 4}\left(2.8 t+t^{2}\right)^{1 / 4}
$$


In this expression, Weil (1982) sets the ratio of the initial buoyancy flux to the initial momentum flux to be 1.4 on the basis of explosive release data from Pacific Northwest National Laboratory (Horst et al. 1979). Whether Equation B.10 or Equation B.11 is the most appropriate for a particular problem depends on whether source momentum is important. For explosive releases where the initial buoyancy is based on the explosive charge or the energy available, initial momentum is important. On the other hand, for releases where the thermal has an initial size, the initial momentum is usually not a factor. In FIREPLUME, we initialize the thermal with a prescribed size and buoyancy. Thus, we neglect source momentum and use Equation B.10.

\section{B.2.2 Limiting Rise}

Because of the wide variety of atmospheric, numerical, and laboratory data, the limiting rise of thermals is characterized well for stable conditions. In his analysis of the numerical and laboratory data of Morton et al. (1956), Weil (1982) suggested that

$$
\Delta z=2.66{F_{T}}^{1 / 4} N^{-1 / 2}
$$

Limiting rise relationships for convective and neutral conditions are substantially less precise because of the lack of observational data of quality. The expressions used in FIREPLUME are adapted from proportional relationships provided by Weil (1982), where the proportionality constants are chosen to provide physically consistent behavior with the limiting plume rise relationships. For neutral conditions, we specify the limiting rise as

$$
\Delta z_{f}=1.5\left(\frac{F_{T}}{u_{*}^{2}}\right)^{1 / 2},
$$

whereas for unstable conditions, we specify the limiting rise as

$$
\Delta z_{f}=3.5 z_{i}\left(\frac{F_{T}}{w_{*}^{2} z_{i}^{2}}\right)^{3 / 8}
$$

Analogous to the application of the fire plume limiting rise relationships, the minimum of the neutral and unstable or stable rise (whichever is applicable) is used in a particular problem. 


\section{B.3 REFERENCES}

Bjorklund, J.R., et al., 1996, Open Burn/Open Detonation : ispersion Model (OBODM) User's Guide: Volume 2, Technical Description, DPG-TG-96-008b, .S. Army Dugway Proving Ground, West Desert Test Center, Dugway, Utah.

Briggs, G.A., 1984, "Plume Rise and Buoyancy Effects,". in Atmospheric Science and Power Production, D. Randerson (editor), DOE/TIC-27601, U.S. Department of Commerce, National Oceanic and Atmospheric Administration, Weather Service Nuclear Support Office, Las Vegas, Nev., pp. 327-366.

Horst, T.W., et al., 1979, Evaluation of Empirical Atmospheric Diffusion Data, PNL-2955, Batelle Pacific Northwest Laboratory, Richmond, Wash.

Morton, B.R., et al., 1956, "Turbulent Gravitational Convection from Maintained and Instantaneous Sources," Proceedings of the Royal Society of London A234:1-23.

Scorer, R.S., 1978, Environmental Aerodynamics, Halsted Press, New York, N.Y.

Weil, J.C., 1982, "Source Buoyancy Effects in Boundary Layer Diffusion," in Workshop on the Parameterization of Mixed Layer Diffusion, R. Cionco (editor), New Mexico State University, Physical Sciences Laboratory, Las Cruces, N.M.

Weil, J.C., 1988, "Stochastic Modeling of Dispersion of Convective Boundary Layer," in Lectures on Air Pollution Modeling, A. Venkatram and J.C. Wyngaard (editors), American Meteorological Society, Boston, Mass., pp. 167-226. 
C-1

APPENDIX C:

RESULTS FOR ALL OTHER FIREPLUME SCENARIOS 
C-2 


\section{APPENDIX C:}

\section{RESULTS FOR ALL OTHER FIREPLUME SCENARIOS}

TABLE C.1 Downwind Centerline Concentrations for HF for Scenario T2 with D4 Stability

\begin{tabular}{|c|c|c|c|c|}
\hline $\begin{array}{l}\text { Downwind } \\
\text { Distance }(\mathrm{m})\end{array}$ & $\begin{array}{l}\text { Concentration } \\
\left(\mathrm{mg} / \mathrm{m}^{3}\right)\end{array}$ & $\begin{array}{l}\text { Averaging } \\
\text { Time (s) }\end{array}$ & $\begin{array}{l}\text { Exceeds Potential- } \\
\text { Irreversible-Adverse- } \\
\text { Effects Limit }\end{array}$ & $\begin{array}{l}\text { Exceeds Potential- } \\
\text { Adverse-Effects } \\
\text { Limit }\end{array}$ \\
\hline 100 & 0.77 & 3,600 & No & No \\
\hline 150 & 0.57 & 3,600 & No & No \\
\hline 250 & 0.39 & 3,600 & No & No \\
\hline 305 & 0.33 & 3,600 & No & No \\
\hline 350 & 0.29 & 3,600 & No & No \\
\hline 368 & 0.28 & 3,600 & No & No \\
\hline 450 & 0.23 & 3,600 & No & No \\
\hline 550 & 0.18 & 3,600 & No & No \\
\hline 650 & 0.15 & 3,600 & No & No \\
\hline 750 & 0.14 & 3,600 & No & No \\
\hline 805 & 0.13 & 3,600 & No & No \\
\hline 840 & 0.13 & 3,600 & No & No \\
\hline 850 & 0.13 & 3,600 & No & No \\
\hline 920 & 0.13 & 3,600 & No & No \\
\hline 1,210 & 0.28 & 1,800 & No & No \\
\hline 1,350 & 0.38 & 1,500 & No & No \\
\hline 1,450 & 0.41 & 1,500 & No & No \\
\hline 2,414 & 5.51 & 60 & No & No \\
\hline 4,023 & 4.77 & 60 & No & No \\
\hline 5,632 & 2.69 & 60 & No & No \\
\hline 7,241 & 1.43 & 60 & No & No \\
\hline 12,068 & 0.54 & 600 & No & No \\
\hline
\end{tabular}




$$
\text { C-4 }
$$

TABLE C.2 Downwind Centerline Concentrations for $\mathrm{UO}_{2} \mathrm{~F}_{2}$ for Scenario $\mathrm{T} 2$ with D4 Stability

\begin{tabular}{|c|c|c|c|c|}
\hline $\begin{array}{c}\text { Downwind } \\
\text { Distance }(\mathrm{m})\end{array}$ & $\begin{array}{l}\text { Concentration } \\
\left(\mathrm{mg} / \mathrm{m}^{3}\right)\end{array}$ & $\begin{array}{l}\text { Averaging } \\
\text { Time (s) }\end{array}$ & $\begin{array}{l}\text { Exceeds Potential- } \\
\text { Irreversible-Adverse- } \\
\text { Effects Limit }\end{array}$ & $\begin{array}{l}\text { Exceeds Potential- } \\
\text { Adverse-Effects } \\
\text { Limit }\end{array}$ \\
\hline 100 & 2.96 & 3,600 & No & No \\
\hline 150 & 2.19 & 3,600 & No & No \\
\hline 250 & 1.49 & 3,600 & No & No \\
\hline 305 & 1.26 & 3,600 & No & No \\
\hline 350 & 1.11 & 3,600 & No & No \\
\hline 368 & 1.07 & 3,600 & No & No \\
\hline 450 & 0.88 & 3,600 & No & No \\
\hline 550 & 0.70 & 3,600 & No & No \\
\hline 650 & 0.57 & 3,600 & No & No \\
\hline 750 & 0.53 & 3,600 & No & No \\
\hline 805 & 0.51 & 3,600 & No & No \\
\hline 840 & 0.50 & 3,600 & No & No \\
\hline 850 & 0.50 & 3,600 & No & No \\
\hline 920 & 0.50 & 3,600 & No & No \\
\hline 1,210 & 0.74 & 3,600 & No & No \\
\hline 1,350 & 0.89 & 3,600 & No & No \\
\hline 1,450 & 0.95 & 3,600 & No & No \\
\hline 2,414 & 1.63 & 3,600 & No & No \\
\hline 4,023 & 1.41 & 3,600 & No & No \\
\hline 5,632 & 1.03 & 3,600 & No & No \\
\hline 7,241 & 0.72 & 3,600 & No & No \\
\hline 12,068 & 0.53 & 3,600 & No & No \\
\hline
\end{tabular}


TABLE C.3 Downwind Centerline Concentrations for HF for Scenario T2 with F1 Stability

\begin{tabular}{|c|c|c|c|c|}
\hline $\begin{array}{c}\text { Downwind } \\
\text { Distance }(\mathrm{m})\end{array}$ & $\begin{array}{c}\text { Concentration } \\
\left(\mathrm{mg} / \mathrm{m}^{3}\right)\end{array}$ & $\begin{array}{l}\text { Averaging } \\
\text { Time (s) }\end{array}$ & $\begin{array}{l}\text { Exceeds Potential- } \\
\text { Irreversible-Adverse- } \\
\text { Effects Limit }\end{array}$ & $\begin{array}{c}\text { Exceeds Potential- } \\
\text { Adverse-Effects } \\
\text { Limit }\end{array}$ \\
\hline 100 & 0.0279 & 3,600 & No & No \\
\hline 150 & 0.0192 & 3,600 & No & No \\
\hline 250 & 0.0120 & 3,600 & No & No \\
\hline 305 & 0.0103 & 3,600 & No & No \\
\hline 350 & 0.00930 & 3,600 & No & No \\
\hline 368 & 0.00894 & 3,600 & No & No \\
\hline 450 & 0.23 & 60 & No & No \\
\hline 550 & 1.19 & 60 & No & No \\
\hline 650 & 2.31 & 60 & No & No \\
\hline 750 & 3.81 & 60 & No & No \\
\hline 805 & 4.07 & 60 & No & No \\
\hline 840 & 4.23 & 60 & No & No \\
\hline 850 & 4.31 & 60 & No & No \\
\hline 920 & 6.99 & 60 & No & Yes \\
\hline 1,210 & 24.66 & 60 & No & Yes \\
\hline 1,350 & 28.51 & 60 & No & Yes \\
\hline 1,450 & 30.65 & 60 & No & Yes \\
\hline 2,414 & 12.30 & 600 & No & Yes \\
\hline 4,023 & 6.89 & 1,200 & No & Yes \\
\hline 5,632 & 4.60 & 1,500 & No & Yes \\
\hline 7,241 & 2.75 & 2,100 & No & Yes \\
\hline 12,068 & 1.21 & 3,600 & No & No \\
\hline
\end{tabular}


TABLE C.4 Downwind Centerline Concentrations for $\mathrm{UO}_{2} \mathrm{~F}_{2}$ for Scenario $\mathrm{T} 2$ with F1 Stability

\begin{tabular}{|c|c|c|c|c|}
\hline $\begin{array}{c}\text { Downwind } \\
\text { Distance }(\mathrm{m})\end{array}$ & $\begin{array}{c}\text { Concentration } \\
\left(\mathrm{mg} / \mathrm{m}^{3}\right)\end{array}$ & $\begin{array}{l}\text { Averaging } \\
\text { Time (s) }\end{array}$ & $\begin{array}{l}\text { Exceeds Potential- } \\
\text { Irreversible-Adverse- } \\
\text { Effects Limit }\end{array}$ & $\begin{array}{c}\text { Exceeds Potential- } \\
\text { Adverse-Effects } \\
\text { Limit }\end{array}$ \\
\hline 100 & 0.11 & 3,600 & No & No \\
\hline 150 & 0.074 & 3,600 & No & No \\
\hline 250 & 0.0464 & 3,600 & No & No \\
\hline 305 & 0.0398 & 3,600 & No & No \\
\hline 350 & 0.0359 & 3,600 & No & No \\
\hline 368 & 0.0345 & 3,600 & No & No \\
\hline 450 & 0.0456 & 3,600 & No & No \\
\hline 550 & 0.17 & 3,600 & No & No \\
\hline 650 & 0.36 & 3,600 & No & No \\
\hline 750 & 0.64 & 3,600 & No & No \\
\hline 805 & 0.8 & 3,600 & No & No \\
\hline 840 & 0.95 & 3,600 & No & No \\
\hline 850 & 1.00 & 3,600 & No & No \\
\hline 920 & 1.59 & 3,600 & No & No \\
\hline 1,210 & 6.82 & 3,600 & No & No \\
\hline 1,350 & 9.02 & 3,600 & No & Yes \\
\hline 1,450 & 9.94 & 3,600 & No & Yes \\
\hline 2,414 & 10.02 & 3,600 & No & Yes \\
\hline 4,023 & 10.63 & 3,600 & No & Yes \\
\hline 5,632 & 9.4 & 3,600 & No & Yes \\
\hline 7,241 & 7.5 & 3,600 & No & No \\
\hline 12,068 & 4.69 & 3,600 & No & No \\
\hline
\end{tabular}


TABLE C.5 Downwind Centerline Concentrations for HF for Scenario T3 with D4 Stability

\begin{tabular}{|c|c|c|c|c|}
\hline $\begin{array}{c}\text { Downwind } \\
\text { Distance (m) }\end{array}$ & $\begin{array}{l}\text { Concentration } \\
\left(\mathrm{mg} / \mathrm{m}^{3}\right)\end{array}$ & $\begin{array}{l}\text { Averaging } \\
\text { Time (s) }\end{array}$ & $\begin{array}{l}\text { Exceeds Potential- } \\
\text { Irreversible-Adverse- } \\
\text { Effects Limit }\end{array}$ & $\begin{array}{c}\text { Exceeds Potential- } \\
\text { Adverse-Effects } \\
\text { Limit }\end{array}$ \\
\hline 100 & 0.39 & 3,600 & No & No \\
\hline 150 & 0.33 & 2,700 & No & No \\
\hline 250 & 0.22 & 2,700 & No & No \\
\hline 305 & 0.18 & 2,700 & No & No \\
\hline 350 & 0.16 & 2,700 & No & No \\
\hline 368 & 0.16 & 2,700 & No & No \\
\hline 450 & 0.13 & 2,400 & No & No \\
\hline 550 & 0.11 & 2,400 & No & No \\
\hline 650 & 0.0911 & 2,100 & No & No \\
\hline 750 & 0.0835 & 2,100 & No & No \\
\hline 805 & 0.0866 & 1,800 & No & No \\
\hline 840 & 0.0849 & 1,800 & No & No \\
\hline 850 & 0.0846 & 1,800 & No & No \\
\hline 920 & 0.22 & 60 & No & No \\
\hline 1,210 & 0.54 & 60 & No & No \\
\hline 1,350 & 1.17 & 60 & No & No \\
\hline 1,450 & 1.56 & 60 & No & No \\
\hline 2,414 & 2.05 & 60 & No & No \\
\hline 4,023 & 1.20 & 60 & No & No \\
\hline 5,632 & 0.57 & 60 & No & No \\
\hline 7,241 & 0.36 & 60 & No & No \\
\hline 12,068 & 0.14 & 1,500 & No & No \\
\hline
\end{tabular}


TABLE C.6 Downwind Centerline Concentrations for $\mathrm{UO}_{2} \mathrm{~F}_{2}$ for Scenario $\mathrm{T} 3$ with D4 Stability

\begin{tabular}{|c|c|c|c|c|}
\hline $\begin{array}{c}\text { Downwind } \\
\text { Distance }(\mathrm{m})\end{array}$ & $\begin{array}{c}\text { Concentration } \\
\left(\mathrm{mg} / \mathrm{m}^{3}\right)\end{array}$ & $\begin{array}{c}\text { Averaging } \\
\text { Time (s) }\end{array}$ & $\begin{array}{l}\text { Exceeds Potential- } \\
\text { Irreversible-Adverse- } \\
\text { Effects Limit }\end{array}$ & $\begin{array}{c}\text { Exceeds Potential- } \\
\text { Adverse-Effects } \\
\text { Limit }\end{array}$ \\
\hline 100 & 1.49 & 3,600 & No & No \\
\hline 150 & 1.09 & 3,600 & No & No \\
\hline 250 & 0.72 & 3,600 & No & No \\
\hline 305 & 0.61 & 3,600 & No & No \\
\hline 350 & 0.53 & 3,600 & No & No \\
\hline 368 & 0.51 & 3,600 & No & No \\
\hline 450 & 0.41 & 3,600 & No & No \\
\hline 550 & 0.32 & 3,600 & No & No \\
\hline 650 & 0.26 & 3,600 & No & No \\
\hline 750 & 0.23 & 3,600 & No & No \\
\hline 805 & 0.22 & 3,600 & No & No \\
\hline 840 & 0.22 & 3,600 & No & No \\
\hline 850 & 0.22 & 3,600 & No & No \\
\hline 920 & 0.21 & 3,600 & No & No \\
\hline 1,210 & 0.31 & 3,600 & No & No \\
\hline 1,350 & 0.41 & 3,600 & No & No \\
\hline 1,450 & 0.47 & 3,600 & No & No \\
\hline 2,414 & 0.59 & 3,600 & No & No \\
\hline 4,023 & 0.40 & 3,600 & No & No \\
\hline 5,632 & 0.32 & 3,600 & No & No \\
\hline 7,241 & 0.27 & 3,600 & No & No \\
\hline 12,068 & 0.27 & 3,600 & No & No \\
\hline
\end{tabular}


TABLE C.7 Downwind Centerline Concentrations for HF for Scenario T3 with F1 Stability

\begin{tabular}{|c|c|c|c|c|}
\hline $\begin{array}{c}\text { Downwind } \\
\text { Distance }(\mathrm{m})\end{array}$ & $\begin{array}{l}\text { Concentration } \\
\left(\mathrm{mg} / \mathrm{m}^{3}\right)\end{array}$ & $\begin{array}{l}\text { Averaging } \\
\text { Time (s) }\end{array}$ & $\begin{array}{l}\text { Exceeds Potential- } \\
\text { Irreversible-Adverse- } \\
\text { Effects Limit }\end{array}$ & $\begin{array}{l}\text { Exceeds Potential- } \\
\text { Adverse-Effects } \\
\text { Limit }\end{array}$ \\
\hline 100 & 0.0176 & 3,600 & No & No \\
\hline 150 & 0.0121 & 3,600 & No & No \\
\hline 250 & 0.00754 & 3,600 & No & No \\
\hline 305 & 0.17 & 60 & No & No \\
\hline 350 & 0.64 & 60 & No & No \\
\hline 368 & 0.97 & 60 & No & No \\
\hline 450 & 2.39 & 60 & No & No \\
\hline 550 & 4.41 & 60 & No & No \\
\hline 650 & 5.61 & 60 & No & No \\
\hline 750 & 10.19 & 60 & No & Yes \\
\hline 805 & 11.24 & 60 & No & Yes \\
\hline 840 & 11.93 & 60 & No & Yes \\
\hline 850 & 12.28 & 60 & No & Yes \\
\hline 920 & 13.97 & 60 & No & Yes \\
\hline 1,210 & 9.29 & 60 & No & Yes \\
\hline 1,350 & 9.46 & 60 & No & Yes \\
\hline 1,450 & 8.69 & 60 & No & Yes \\
\hline 2,414 & 5.70 & 600 & No & Yes \\
\hline 4,023 & 2.85 & 1,200 & No & Yes \\
\hline 5,632 & 1.53 & 1,800 & No & No \\
\hline 7,241 & 1.08 & 2,100 & No & No \\
\hline 12,068 & 0.44 & 3,600 & No & No \\
\hline
\end{tabular}


TABLE C.8 Downwind Centerline Concentrations for $\mathrm{UO}_{2} \mathrm{~F}_{2}$ for Scenario T3 with F1 Stability

\begin{tabular}{|c|c|c|c|c|}
\hline $\begin{array}{c}\text { Downwind } \\
\text { Distance }(\mathbf{m})\end{array}$ & $\begin{array}{c}\text { Concentration } \\
\left(\mathrm{mg} / \mathrm{m}^{3}\right)\end{array}$ & $\begin{array}{l}\text { Averaging } \\
\text { Time (s) }\end{array}$ & $\begin{array}{l}\text { Exceeds Potential- } \\
\text { Irreversible-Adverse- } \\
\text { Effects Limit }\end{array}$ & $\begin{array}{c}\text { Exceeds Potential- } \\
\text { Adverse-Effects } \\
\text { Limit }\end{array}$ \\
\hline 100 & 0.0680 & 3,600 & No & No \\
\hline 150 & 0.0467 & 3,600 & No & No \\
\hline 250 & 0.0291 & 3,600 & No & No \\
\hline 305 & 0.0309 & 3,600 & No & No \\
\hline 350 & 0.0747 & 3,600 & No & No \\
\hline 368 & 0.10 & 3,600 & No & No \\
\hline 450 & 0.27 & 3,600 & No & No \\
\hline 550 & 0.53 & 3,600 & No & No \\
\hline 650 & 0.86 & 3,600 & No & No \\
\hline 750 & 1.58 & 3,600 & No & No \\
\hline 805 & 2.00 & 3,600 & No & No \\
\hline 840 & 2.22 & 3,600 & No & No \\
\hline 850 & 2.28 & 3,600 & No & No \\
\hline 920 & 2.52 & 3,600 & No & No \\
\hline 1,210 & 2.65 & 3,600 & No & No \\
\hline 1,350 & 2.91 & 3,600 & No & No \\
\hline 1,450 & 3.07 & 3,600 & No & No \\
\hline 2,414 & 4.66 & 3,600 & No & No \\
\hline 4,023 & 4.32 & 3,600 & No & No \\
\hline 5,632 & 3.44 & 3,600 & No & No \\
\hline 7,241 & 2.93 & 3,600 & No & No \\
\hline 12,068 & 1.71 & 3,600 & No & No \\
\hline
\end{tabular}




$$
\text { C-11 }
$$

TABLE C.9 Downwind Centerline Concentrations for HF for Scenario T4 with D4 Stability

\begin{tabular}{|c|c|c|c|c|}
\hline $\begin{array}{c}\text { Downwind } \\
\text { Distance }(\mathrm{m})\end{array}$ & $\begin{array}{c}\text { Concentration } \\
\left(\mathrm{mg} / \mathrm{m}^{3}\right)\end{array}$ & $\begin{array}{l}\text { Averaging } \\
\text { Time (s) }\end{array}$ & $\begin{array}{l}\text { Exceeds Potential- } \\
\text { Irreversible-Adverse- } \\
\text { Effects Limit }\end{array}$ & $\begin{array}{c}\text { Exceeds Potential- } \\
\text { Adverse-Effects } \\
\text { Limit }\end{array}$ \\
\hline 100 & 0.52 & 3,600 & No & No \\
\hline 150 & 0.38 & 3,600 & No & No \\
\hline 250 & 0.26 & 3,600 & No & No \\
\hline 305 & 0.22 & 3,600 & No & No \\
\hline 350 & 0.19 & 3,600 & No & No \\
\hline 368 & 0.19 & 3,600 & No & No \\
\hline 450 & 0.15 & 3,600 & No & No \\
\hline 550 & 0.12 & 3,600 & No & No \\
\hline 650 & 0.0997 & 3,600 & No & No \\
\hline 750 & 0.0922 & 3,600 & No & No \\
\hline 805 & 0.0892 & 3,600 & No & No \\
\hline 840 & 0.0877 & 3,600 & No & No \\
\hline 850 & 0.0874 & 3,600 & No & No \\
\hline 920 & 0.0869 & 3,600 & No & No \\
\hline 1,210 & 0.19 & 1,800 & No & No \\
\hline 1,350 & 0.26 & 1,500 & No & No \\
\hline 1,450 & 0.28 & 1,500 & No & No \\
\hline 2,414 & 1.92 & 60 & No & No \\
\hline 4,023 & 1.64 & 60 & No & No \\
\hline 5,632 & 0.94 & 60 & No & No \\
\hline 7,241 & 0.52 & 60 & No & No \\
\hline 12,068 & 0.21 & 750 & No & No \\
\hline
\end{tabular}


TABLE C.10 Downwind Centerline Concentrations for $\mathrm{UO}_{2} \mathrm{~F}_{2}$ for Scenario $\mathrm{T} 4$ with D4 Stability

\begin{tabular}{|c|c|c|c|c|}
\hline $\begin{array}{c}\text { Downwind } \\
\text { Distance (m) }\end{array}$ & $\begin{array}{c}\text { Concentration } \\
\left(\mathrm{mg} / \mathrm{m}^{3}\right)\end{array}$ & $\begin{array}{c}\text { Averaging } \\
\text { Time (s) }\end{array}$ & $\begin{array}{l}\text { Exceeds Potential- } \\
\text { Irreversible-Adverse- } \\
\text { Effects Limit }\end{array}$ & $\begin{array}{c}\text { Exceeds Potential- } \\
\text { Adverse-Effects } \\
\text { Limit } \\
\end{array}$ \\
\hline 100 & 2.00 & 3,600 & No & No \\
\hline 150 & 1.48 & 3,600 & No & No \\
\hline 250 & 1.00 & 3,600 & No & No \\
\hline 305 & 0.85 & 3,600 & No & No \\
\hline 350 & 0.75 & 3,600 & No & No \\
\hline 368 & 0.72 & 3,600 & No & No \\
\hline 450 & 0.59 & 3,600 & No & No \\
\hline 550 & 0.47 & 3,600 & No & No \\
\hline 650 & 0.38 & 3,600 & No & No \\
\hline 750 & 0.36 & 3,600 & No & No \\
\hline 805 & 0.34 & 3,600 & No & No \\
\hline 840 & 0.34 & 3,600 & No & No \\
\hline 850 & 0.34 & 3,600 & No & No \\
\hline 920 & 0.34 & 3,600 & No & No \\
\hline 1,210 & 0.50 & 3,600 & No & No \\
\hline 1,350 & 0.60 & 3,600 & No & No \\
\hline 1,450 & 0.64 & 3,600 & No & No \\
\hline 2,414 & 0.84 & 3,600 & No & No \\
\hline 4,023 & 0.62 & 3,600 & No & No \\
\hline 5,632 & 0.46 & 3,600 & No & No \\
\hline 7,241 & 0.33 & 3,600 & No & No \\
\hline 12,068 & 0.28 & 3,600 & No & No \\
\hline
\end{tabular}


TABLE C.11 Downwind Centerline Concentrations for HF for Scenario T4 with F1 Stability

\begin{tabular}{|c|c|c|c|c|}
\hline $\begin{array}{c}\text { Downwind } \\
\text { Distance (m) }\end{array}$ & $\begin{array}{c}\text { Concentration } \\
\left(\mathrm{mg} / \mathrm{m}^{3}\right)\end{array}$ & $\begin{array}{l}\text { Averaging } \\
\text { Time (s) }\end{array}$ & $\begin{array}{l}\text { Exceeds Potential- } \\
\text { Irreversible-Adverse- } \\
\text { Effects Limit }\end{array}$ & $\begin{array}{c}\text { Exceeds Potential- } \\
\text { Adverse-Effects } \\
\text { Limit }\end{array}$ \\
\hline 100 & 0.0188 & 3,600 & No & No \\
\hline 150 & 0.0129 & 3,600 & No & No \\
\hline 250 & 0.00811 & 3,600 & No & No \\
\hline 305 & 0.00695 & 3,600 & No & No \\
\hline 350 & 0.00627 & 3,600 & No & No \\
\hline 368 & 0.00603 & 3,600 & No & No \\
\hline 450 & 0.0830 & 60 & No & No \\
\hline 550 & 0.42 & 60 & No & No \\
\hline 650 & 0.80 & 60 & No & No \\
\hline 750 & 1.32 & 60 & No & No \\
\hline 805 & 1.40 & 60 & No & No \\
\hline 840 & 1.45 & 60 & No & No \\
\hline 850 & 1.48 & 60 & No & No \\
\hline 920 & 2.40 & 60 & No & No \\
\hline 1,210 & 8.40 & 60 & No & Yes \\
\hline 1,350 & 9.68 & 60 & No & Yes \\
\hline 1,450 & 10.42 & 60 & No & Yes \\
\hline 2,414 & 4.16 & 600 & No & Yes \\
\hline 4,023 & 2.33 & 1,200 & No & No \\
\hline 5,632 & 1.55 & 1,500 & No & No \\
\hline 7,241 & 0.93 & 2,100 & No & No \\
\hline 12,068 & 0.41 & 3,600 & No & No \\
\hline
\end{tabular}


TABLE C.12 Downwind Centerline Concentrations for $\mathrm{UO}_{2} \mathrm{~F}_{2}$ for Scenario $\mathrm{T} 4$ with F1 Stability

\begin{tabular}{|c|c|c|c|c|}
\hline $\begin{array}{l}\text { Downwind } \\
\text { Distance (m) }\end{array}$ & $\begin{array}{l}\text { Concentration } \\
\left(\mathrm{mg} / \mathrm{m}^{3}\right)\end{array}$ & $\begin{array}{l}\text { Averaging } \\
\text { Time (s) }\end{array}$ & $\begin{array}{l}\text { Exceeds Potential- } \\
\text { Irreversible-Adverse- } \\
\text { Effects Limit }\end{array}$ & $\begin{array}{c}\text { Exceeds Potential- } \\
\text { Adverse-Effects } \\
\text { Limit }\end{array}$ \\
\hline 100 & 0.0725 & 3,600 & No & No \\
\hline 150 & 0.0499 & 3,600 & No & No \\
\hline 250 & 0.0313 & 3,600 & No & No \\
\hline 305 & 0.0268 & 3,600 & No & No \\
\hline 350 & 0.0242 & 3,600 & No & No \\
\hline 368 & 0.0233 & 3,600 & No & No \\
\hline 450 & 0.0234 & 3,600 & No & No \\
\hline 550 & 0.0629 & 3,600 & No & No \\
\hline 650 & 0.13 & 3,600 & No & No \\
\hline 750 & 0.22 & 3,600 & No & No \\
\hline 805 & 0.27 & 3,600 & No & No \\
\hline 840 & 0.32 & 3,600 & No & No \\
\hline 850 & 0.34 & 3,600 & No & No \\
\hline 920 & 0.54 & 3,600 & No & No \\
\hline 1,210 & 2.31 & 3,600 & No & No \\
\hline 1,350 & 3.05 & 3,600 & No & No \\
\hline 1,450 & 3.36 & 3,600 & No & No \\
\hline 2,414 & 3.39 & 3,600 & No & No \\
\hline 4,023 & 3.59 & 3,600 & No & No \\
\hline 5,632 & 3.18 & 3,600 & No & No \\
\hline 7,241 & 2.53 & 3,600 & No & No \\
\hline 12,068 & 1.58 & 3,600 & No & No \\
\hline
\end{tabular}


TABLE C.13 Downwind Centerline Concentrations for HF for Scenario T5 with D4 Stability

\begin{tabular}{|c|c|c|c|c|}
\hline $\begin{array}{c}\text { Downwind } \\
\text { Distance }(\mathrm{m})\end{array}$ & $\begin{array}{c}\text { Concentration } \\
\left(\mathrm{mg} / \mathrm{m}^{3}\right)\end{array}$ & $\begin{array}{l}\text { Averaging } \\
\text { Time (s) }\end{array}$ & $\begin{array}{l}\text { Exceeds Potential- } \\
\text { Irreversible-Adverse- } \\
\text { Effects Limit }\end{array}$ & $\begin{array}{c}\text { Exceeds Potential- } \\
\text { Adverse-Effects } \\
\text { Limit }\end{array}$ \\
\hline 100 & 0 & 0 & No & No \\
\hline 150 & 0 & 0 & No & No \\
\hline 250 & 0 & 0 & No & No \\
\hline 305 & 0 & 0 & No & No \\
\hline 350 & 0 & 0 & No & No \\
\hline 368 & 0 & 0 & No & No \\
\hline 450 & 0 & 0 & No & No \\
\hline 550 & 0 & 0 & No & No \\
\hline 650 & 0 & 0 & No & No \\
\hline 750 & 0 & 0 & No & No \\
\hline 805 & 0 & 0 & No & No \\
\hline 840 & 0 & 0 & No & No \\
\hline 850 & 0 & 0 & No & No \\
\hline 920 & 0 & 0 & No & No \\
\hline 1,210 & 0 & 0 & No & No \\
\hline 1,350 & 0 & 0 & No & No \\
\hline 1,450 & 0 & 0 & No & No \\
\hline 2,414 & $7.06 \times 10^{-8}$ & 1,800 & No & No \\
\hline 4,023 & $3.68 \times 10^{-5}$ & 1,800 & No & No \\
\hline 5,632 & $2.42 \times 10^{-4}$ & 1,800 & No & No \\
\hline 7,241 & $2.87 \times 10^{-4}$ & 1,800 & No & No \\
\hline 12,068 & $4.58 \times 10^{-4}$ & 1,800 & No & No \\
\hline
\end{tabular}


TABLE C.14 Downwind Centerline Concentrations for $\mathrm{UO}_{2} \mathrm{~F}_{2}$ for Scenario $\mathrm{T} 5$ with D4 Stability

\begin{tabular}{|c|c|c|c|c|}
\hline $\begin{array}{c}\text { Downwind } \\
\text { Distance (m) }\end{array}$ & $\begin{array}{c}\text { Concentration } \\
\left(\mathrm{mg} / \mathrm{m}^{3}\right)\end{array}$ & $\begin{array}{l}\text { Averaging } \\
\text { Time (s) }\end{array}$ & $\begin{array}{l}\text { Exceeds Potential- } \\
\text { Irreversible-Adverse- } \\
\text { Effects Limit }\end{array}$ & $\begin{array}{c}\text { Exceeds Potential- } \\
\text { Adverse-Effects } \\
\text { Limit }\end{array}$ \\
\hline 100 & 0 & 0 & No & No \\
\hline 150 & 0 & 0 & No & No \\
\hline 250 & 0 & 0 & No & No \\
\hline 305 & 0 & 0 & No & No \\
\hline 350 & 0 & 0 & No & No \\
\hline 368 & 0 & 0 & No & No \\
\hline 450 & 0 & 0 & No & No \\
\hline 550 & 0 & 0 & No & No \\
\hline 650 & 0 & 0 & No & No \\
\hline 750 & 0 & 0 & No & No \\
\hline 805 & 0 & 0 & No & No \\
\hline 840 & 0 & 0 & No & No \\
\hline 850 & 0 & 0 & No & No \\
\hline 920 & 0 & 0 & No & No \\
\hline 1,210 & 0 & 0 & No & No \\
\hline 1,350 & 0 & 0 & No & No \\
\hline 1,450 & 0 & 0 & No & No \\
\hline 2,414 & $2.07 \times 10^{-7}$ & 2,400 & No & No \\
\hline 4,023 & $1.10 \times 10^{-4}$ & 2,400 & No & No \\
\hline 5,632 & $6.55 \times 10^{-4}$ & 2,700 & No & No \\
\hline 7,241 & $5.90 \times 10^{-4}$ & 3,600 & No & No \\
\hline 12,068 & $9.71 \times 10^{-4}$ & 3,600 & No & No \\
\hline
\end{tabular}


TABLE C.15 Downwind Centerline Concentrations for HF for Scenario T5 with F1 Stability

\begin{tabular}{|c|c|c|c|c|}
\hline $\begin{array}{c}\text { Downwind } \\
\text { Distance }(\mathrm{m})\end{array}$ & $\begin{array}{l}\text { Concentration } \\
\left(\mathrm{mg} / \mathrm{m}^{3}\right)\end{array}$ & $\begin{array}{c}\text { Averaging } \\
\text { Time (s) }\end{array}$ & $\begin{array}{l}\text { Exceeds Potential- } \\
\text { Irreversible-Adverse- } \\
\text { Effects Limit }\end{array}$ & $\begin{array}{c}\text { Exceeds Potential- } \\
\text { Adverse-Effects } \\
\text { Limit }\end{array}$ \\
\hline 100 & 0 & 0 & No & No \\
\hline 150 & 0 & 0 & No & No \\
\hline 250 & 0 & 0 & No & No \\
\hline 305 & 0 & 0 & No & No \\
\hline 350 & 0 & 0 & No & No \\
\hline 368 & 0 & 0 & No & No \\
\hline 450 & 0 & 0 & No & No \\
\hline 550 & 0 & 0 & No & No \\
\hline 650 & 0 & 0 & No & No \\
\hline 750 & 0 & 0 & No & No \\
\hline 805 & 0 & 0 & No & No \\
\hline 840 & 0 & 0 & No & No \\
\hline 850 & 0 & 0 & No & No \\
\hline 920 & 0 & 0 & No & No \\
\hline 1,210 & 0 & 0 & No & No \\
\hline 1,350 & 0 & 0 & No & No \\
\hline 1,450 & 0 & 0 & No & No \\
\hline 2,414 & 0 & 0 & No & No \\
\hline 4,023 & 0 & 0 & No & No \\
\hline 5,632 & 0 & 0 & No & No \\
\hline 7,241 & 0 & 0 & No & No \\
\hline 12,068 & 0 & 0 & No & No \\
\hline
\end{tabular}


TABLE C.16 Downwind Centerline Concentrations for $\mathrm{UO}_{2} \mathrm{~F}_{2}$ for Scenario $\mathrm{T} 5$ with F1 Stability

Exceeds Potential- Exceeds PotentialDownwind Concentration Averaging Irreversible-Adverse Adverse-Effects

$\begin{array}{llll}\text { Distance }(\mathrm{m}) & \left(\mathrm{mg} / \mathrm{m}^{3}\right) & \text { Time }(\mathrm{s}) & \text { Effects Limit Limit }\end{array}$

\begin{tabular}{|c|c|c|c|c|}
\hline 100 & 0 & 0 & No & No \\
\hline 150 & 0 & 0 & No & No \\
\hline 250 & 0 & 0 & No & No \\
\hline 305 & 0 & 0 & No & No \\
\hline 350 & 0 & 0 & No & No \\
\hline 368 & 0 & 0 & No & No \\
\hline 450 & 0 & 0 & No & No \\
\hline 550 & 0 & 0 & No & No \\
\hline 650 & 0 & 0 & No & No \\
\hline 750 & 0 & 0 & No & No \\
\hline 805 & 0 & 0 & No & No \\
\hline 840 & 0 & 0 & No & No \\
\hline 850 & 0 & 0 & No & No \\
\hline 920 & 0 & 0 & No & No \\
\hline 1,210 & 0 & 0 & No & No \\
\hline 1,350 & 0 & 0 & No & No \\
\hline 1,450 & 0 & 0 & No & No \\
\hline 2,414 & 0 & 0 & No & No \\
\hline 4,023 & 0 & 0 & No & No \\
\hline 5,632 & 0 & 0 & No & No \\
\hline 7,241 & 0 & 0 & No & No \\
\hline 12,068 & 0 & 0 & No & No \\
\hline
\end{tabular}


D-1

APPENDIX D:

ANALYSIS OF INITIAL URANIUM HEXAFLUORIDE RELEASE TO INITIALIZE FIREPLUME 
D-2 


\section{APPENDIX D:}

\section{ANALYSIS OF INITIAL URANIUM HEXAFLUORIDE RELEASE TO INITIALIZE FIREPLUME}

Below are the relationships used to estimate the initial properties of the uranium hexafluoride $\left(\mathrm{UF}_{6}\right)$-air mixture after the initial hydraulic rupture. This set of equations was solved in EES (Engineering Equation Solver). The listing provides the equations and comments (i.e., the text within braces) as they appear in the program, followed by the solutions. The analysis shown is for a single $48 \mathrm{G}$ cylinder.

\section{D.1 EQUATION LISTING (Comments in Braces)}

\{all masses are in $\mathrm{Kg}$, all temperatures are in $\mathrm{K}$, all volumes are in cubic meters

\{set atmospheric pressure $\}$

patm $=101300$

\{set initial mass of UF6 and initial vapor fraction of UF6 \}

massUF6 $=1744$

fracvapor $=0.082$

\{calculate initial temperature and volume of UF6

TiUF6 $=(1-$ fracvapor $) * 330+$ fracvapor*628

viUF6 $=(\mathrm{kmolesUF6} * 8314 *$ TiUF6/patm $)$

\{entrain air into UF6 at the rate of $75 / 1$ by volume

vair $=75^{*}$ viUF6

\{set temperatures of hot (combustion) and cold (ambient air) \}

Thair $=1075$

Tcair $=300$

\{calculate volumes and masses of hot and cold air entrained

vhair $=\min (400$, vair $)$

vcair $=\max (0$, vair - vhair $)$

masshair = vhair*patm $/((8314 /$ nair $) *$ Thair $)$

masscair = vcair*patm $/((8314 /$ nair $) *$ Tcair $)$

\{calculate heat added due to hydrolysis reaction\}

fract $=1.0$

hhydro $=$ fract $* 101500 *$ kmolesUF6

\{calculate cooling due to solid UF6 sublimation

fractsolid $=0.245$

hsubl $=$ fractsolid $* 47600 *$ kmolesUF6

\{calculate enthalpy changes of constituents 


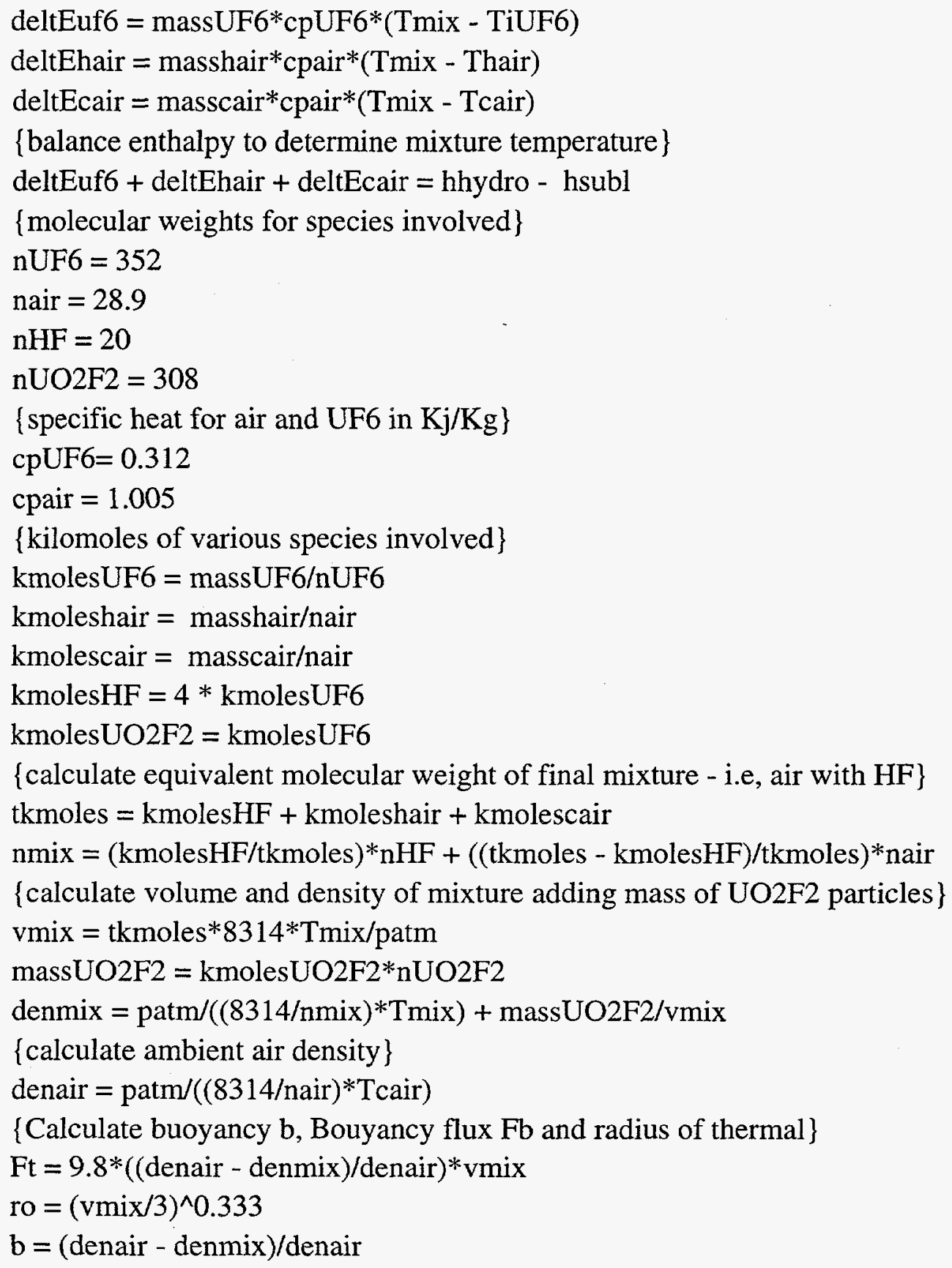

\section{D.2 RESULTS}

$b=0.030$

deltEcair $=546689.441$

deltEhair $=-96188.294$

deltEuf6 = -5394.692

denair $=1.174$ 


$$
\begin{aligned}
& \text { denmix }=1.138 \\
& \mathrm{Ft}=3651.706 \\
& \text { hhydro }=502886.364 \\
& \text { hsubl }=57779.909 \\
& \text { kmolescair }=422.772 \\
& \text { kmoleshair }=4.534 \\
& \text { kmolesHF }=19.82 \\
& \text { kmolesUF6 }=4.955 \\
& \text { kmolesUO2F2 }=4.955 \\
& \text { masscair }=12218.100 \\
& \text { masshair }=131.023 \\
& \text { massUF6 }=1744.000 \\
& \text { massUO2F } 2=1526.000 \\
& \text { ro }=15.988 \\
& \text { Tcair }=300.000 \\
& \text { Thair }=1075.000 \\
& \text { TiUF6 }=354.436 \\
& \text { tkmoles }=447.123 \\
& \text { Tmix }=344.522 \\
& \text { vair }=10809.447 \\
& \text { vcair }=10409.447 \\
& \text { vhair }=400.000 \\
& \text { viUF6 }=144.126 \\
& \text { vmix }=12362.649
\end{aligned}
$$


